\title{
AGAPEROS: Searching for variable stars in the LMC Bar with the Pixel Method ${ }^{\star}$
}

\section{Detection, astrometry and cross-identification ${ }^{\star \star}$}

\author{
A.-L. Melchior ${ }^{1,2}$, S.M.G. Hughes ${ }^{3}$, and J. Guibert ${ }^{4}$ \\ 1 Astronomy Unit, Queen Mary and Westfield College, Mile End Road, London E1 4NS, UK \\ 2 DEMIRM (UMR 8540), Observatoire de Paris, 61 avenue de l'Observatoire, 75014 Paris Cedex, France \\ 3 Institute of Astronomy, University of Cambridge, Madingley Road, Cambridge CB3 0EZ, UK \\ ${ }^{4}$ Centre d'Analyse des Images de l'INSU (UMR 8633), Observatoire de Paris, 61 avenue de l'Observatoire, 75014 Paris, France
}

Received December 5, 1999; accepted April 11, 2000

\begin{abstract}
We extend the work developed in previous papers on microlensing with a selection of variable stars. We use the Pixel Method to select variable stars on a set of $2.510^{6}$ pixel light curves in the LMC Bar presented elsewhere. The previous treatment was done in order to optimise the detection of long timescale variations (larger than a few days) and we further optimise our analysis for the selection of Long Timescale and Long Period Variables (LT\&LPV). We choose to perform a selection of variable objects as comprehensive as possible, independent of periodicity and of their position on the colour magnitude diagram. We detail the different thresholds successively applied to the light curves, which allow to produce a catalogue of 632 variable objects. We present a table with the coordinate of each variable, its EROS magnitudes at one epoch and an indicator of blending in both colours, together with a finding chart.

A cross-correlation with various catalogues shows that $90 \%$ of those variable objects were undetected before, thus enlarging the sample of LT\&LPV previously known in this area by a factor of 10 . Due to the limitations of both the Pixel Method and the data set, additional data - namely a longer baseline and near infrared photometry - are required to further characterise these variable stars, as will be addressed in subsequent papers.
\end{abstract}

Key words: stars: variables: general - methods: data analysis - AGB and post-AGB - techniques:

Send offprint requests to: A.-L. Melchior

* This work is based on data collected by the EROS collaboration.

$\star \star$ Table 2 is also available in electronic form at the CDS via anonymous ftp to cdsarc.u-strasbg.fr (130.79.128.5) or via http://cdsweb.u-strasbg.fr/Abstract.html Correspondence to: A.L.Melchior@obspm.fr photometric - galaxies: Magellanic clouds — stars: evolution

\section{Introduction}

The microlensing searches, motivated by the study of dark matter in galaxies and its possible fraction of compact objects (hereafter Machos), have collected some unprecedented databases of images of neighbouring galaxies, and in particular of the Large Magellanic Cloud (LMC). The microlensing candidates are compatible with large Macho masses, and exhibit long timescale variations, typically 10-200 days (Alcock et al. 1997a,b,c; Renault et al. 1997; Palanque-Delabrouille et al. 1998; Alard et al. 1997; Udalski et al. 1994; Ansari et al. 1999). Possible contamination by variable stars is often suggested (e.g. della Valle \& Livio 1996), but no systematic searches for variable objects have been undertaken so far on the microlensing databases. Whereas particular variables, such as RR Lyrae and cepheids are relatively well understood, little statistical information is known about the Long Timescale and Long Period Variable stars (hereafter LT\&LPV), with timescales/periods in the range of $\sim 100$ to $\sim 800$ days, which are an important stage of stellar evolution. They are easily rejected for these microlensing searches either with a cut on marginal stellar populations identified on the colour magnitude diagram (hereafter CMD) or by their periodicity. Aperiodic signals which do not satisfy these simple criteria are however more difficult to discriminate and to select.

In this paper, we perform a selection of variable objects on pixel light curves covering a $0.25 \mathrm{deg}^{2}$ field of the LMC Bar. We used the pixel light curves produced in Melchior 
et al. (1999, hereafter Paper I) adopting looser thresholds than those used for the selection of microlensing events in Melchior et al. (1998, hereafter Paper II). In Sect. 2, we summarise the characteristics of the data set. In Sect. 3, we discuss the automatic selection procedure used to keep all significant genuine variable stars. In Sect. 4, we introduce a magnitude estimate for each variable and display its position in the colour-magnitude diagram. In Sect. 5, we describe the procedure used to obtain the equatorial coordinates. In Sect. 6, we cross-identify the selected variable stars with existing databases. Finally, we provide the catalogue in Sect. 7.

\section{EROS CCD data and AGAPEROS pixel light curves}

\subsection{EROS CCD data}

We use the EROS-1 CCD dataset, taken at ESO over the period 1991 December 18 to 1992 April 11, using a $40 \mathrm{~cm}$ telescope with a wide field camera composed of 16 CCD chips, each with $400 \times 579$ pixels of 1.21 arcsec (Arnaud et al. 1994b; Queinnec 1994; Aubourg et al. 1995 and Grison et al. 1995). Images of one field in the LMC Bar were taken in two wide non-standard blue $(\bar{\lambda}=490 \mathrm{~nm})$ and red $(\bar{\lambda}=670 \mathrm{~nm})$ filters, with a mean seeing of 2. arcsec.

The EROS-1 experiment (Arnaud et al. 1994a,b) was motivated by the study of dark compact objects in the dark halo of our Galaxy and contributed to show that the so-called brown dwarves could not be a significant component of the dark matter (Renault et al. 1997).

This dataset, treated in Paper I, is composed of some 1000 images per CCD and per colour spread over 120 days. Only 10 CCD fields were available in $91-92$, so we restrict our analysis to this field of $0.25 \mathrm{deg}^{2}$.

\subsection{AGAPEROS pixel light curves}

For this selection, we use the pixel light curves produced in Paper I, as a first application to the EROS data of the Pixel Method (Baillon et al. 1993). In Paper I, we described in detail the data treatment we applied to the EROS-1 data set described in the previous paragraph. The frames were first geometrically and photometrically aligned with respect to a reference image. In order to decrease the level of noise on these $8-12$ min exposures, we averaged the $10-20$ frames available each night. Whereas this increases our sensitivity to possibly dim LT\&LPV, this is not optimised for the detection of short period variable stars, already studied elsewhere on the same data set (Grison et al. 1995; Beaulieu et al. 1995; Hill \& Beaulieu 1997).

The data are then arranged in super-pixel light curves, and an empiric seeing correction is then applied to each light curve. The limitations of this technique reside in the
Table 1. Selection procedure. Column (A) gives the parameters used for thresholding, (B) gives the value of the threshold. (C) provides the number of light curves kept at each step. Numbers surrounded by boxes provide the actual threshold used and the actual number of curves selected. Other numbers show how the weakening or strengthening of these thresholds affect the number of selected light curves. This procedure is further illustrated in Fig. 1

\begin{tabular}{|c|c|c|}
\hline $\begin{array}{cc}\text { Step } & \text { Parameters } \\
(\mathrm{A})\end{array}$ & $\begin{array}{l}\text { Threshold } \\
\text { (B) }\end{array}$ & $\begin{array}{l}\text { Number } \\
\text { (C) }\end{array}$ \\
\hline (0) Starting point after & excision & $2093584(100 \%)$ \\
\hline \multirow{3}{*}{ (1) $\operatorname{Min}\left(\left.\left(\frac{\sigma_{1}}{\sigma_{2}}\right)\right|_{B},\left.\left(\frac{\sigma_{1}}{\sigma_{2}}\right)\right|_{R}\right)$} & $<0.7$ & $133394(6.37 \%)$ \\
\hline & $<0.6$ & $32067(1.53 \%)$ \\
\hline & $<0.5$ & $11369(0.54 \%)$ \\
\hline \multirow{3}{*}{ (2) $\operatorname{Max}\left(L_{B}, L_{R}\right)$} & $>300$ & $24892(1.19 \%)$ \\
\hline & $>400$ & $20942(1.00 \%)$ \\
\hline & $>500$ & $17857(0.85 \%)$ \\
\hline (3) Clusters identification & & $3782(0.18 \%)$ \\
\hline (4) $\operatorname{Max}\left(L_{B}, L_{R}\right)$ & $>400$ & $3637(0.17 \%)$ \\
\hline $\operatorname{Min}\left(\left.\left(\frac{\sigma_{1}}{\sigma_{2}}\right)\right|_{B},\left.\left(\frac{\sigma_{1}}{\sigma_{2}}\right)\right|_{R}\right)$ & $<0.6$ & $3381(0.16 \%)$ \\
\hline \multirow{3}{*}{ (5) $N_{\text {clus }}$} & $>4$ & $999(0.05 \%)$ \\
\hline & $>6$ & $747(0.04 \%)$ \\
\hline & $>10$ & $544(0.03 \%)$ \\
\hline
\end{tabular}

conversion of pixel fluxes in magnitudes, which can be done efficiently with kernel convolution techniques developed by Tomaney \& Crotts (1996) and Alard (1998). Due the large filters of the EROS database and the short baseline (120 days) available with this data set, we choose to postpone this step to the next paper, which will produce periods with 3 -years light curves together with a crossidentification with the DENIS photometry. In this paper, we provide a magnitude estimate for one epoch, together with an indication of blending, and put the emphasis on the selection procedure and the cross-identification with other catalogues.

The light curves we use in the following to select variable stars correspond to the super-pixel flux $\phi_{n}(t)$ measured at different epochs $n$ :

$\phi_{n}(t)=\phi_{\text {star }}(t)+\phi_{\text {sky }}$

where $\phi_{\text {sky }}$ includes the sky and stellar background, and $\phi_{\text {star }}(t)$ is the flux of the variable star.

\section{Selection of genuine variable stars}

We apply an automatic selection of genuine luminosity variations to the 91-92 dataset. Firstly, we introduce the definition of a variation. Secondly, we adjust the thresholds in order to keep genuine variations but reject most artifacts due to noise. Last, we carefully inspect selected light curves close to bad pixels. 

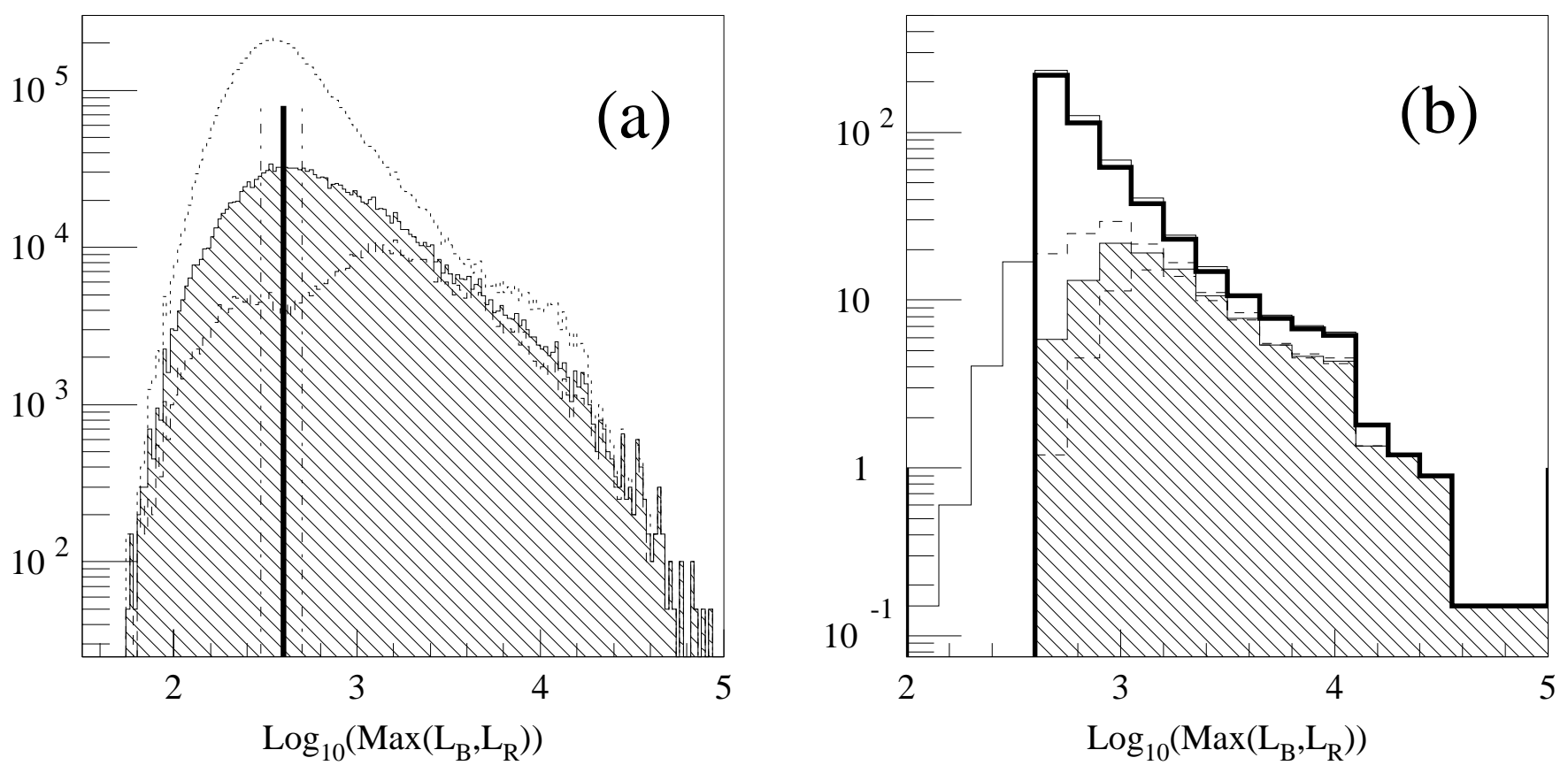

Fig. 1. Effect of the selection procedure on the $\operatorname{Max}\left(L_{B}, L_{R}\right)$ distribution. Panel a) illustrates the effect of the steps (1) and (2) of the selection procedure indicated in Table 1. The hatched area corresponds to the pixels kept at step (1). The dashed and dotted histograms each show how this distribution is affected if this threshold is changed as indicated in Table 1 . The thick line displays the effect of step (2). The dot-dashed lines correspond to the weakening/strengthening of this cut. Panel b) illustrates the effects of steps (4) and (5). The large amplitude histogram shows the distribution after step (3), the thick-line histogram shows the result of step (4), and the hatched area corresponds to pixels kept at the end of step (5). The dashed histograms show the sensitivity of this last threshold

\subsection{Definition of a variation}

A baseline flux $\left(\phi_{\mathrm{bl}}\right)$ is calculated for each super-pixel light curve by sorting all points in order of increasing flux, with $\phi_{\mathrm{bl}}$ being the $10^{\text {th }}$ sorted point. $\sigma_{\mathrm{bl}}$ is the error associated with the baseline flux determination. For a sample taken from a Gaussian distribution with a standard deviation $\sigma$ this estimate lies $1.3 \sigma$ below the mean value of the distribution.

Deviations from this baseline are recorded when measurements lie $3 \sigma_{n}$ above the baseline:

$\sigma_{n}=\sqrt{{\sigma_{n}^{\prime}}^{2}+\sigma_{\mathrm{bl}}^{2}}$

where $\sigma_{n}^{\prime}$ is the error associated with each super-pixel flux computed in Paper I for night $n$. These deviations are quantified in each colour with a likelihood function $(L)$ :

$L=-\ln \left(\prod_{n \in \text { bump }} P\left(\phi \geq \phi_{n}\right)\right.$ given $\left\{\begin{array}{c}\phi_{\mathrm{bl}} \\ \sigma_{n}\end{array}\right)$

where $\phi_{n}$ is the super-pixel flux for the measurement $n$. All the measurements above $\phi_{\mathrm{bl}}$ are accounted for.

\subsection{Minimal threshold}

With the definition introduced above, we apply the selection procedure summarised in Table 1 .
First of all we excise the pixels, covering $3.4 \%$ of the CCD fields, which exhibit obvious spurious variations (such as bad columns). In addition, in order to remove automatically artifacts due to bad pixels, we remove from the light curves the epochs for which there is at least one pixel which datum is at zero within a $11 \times 11$ window centred on the super-pixel. (1) We require a regularity condition to remove the noise: the ratio $\sigma_{1} / \sigma_{2}$ has to be smaller than 0.6 in at least one colour, with:

$$
\begin{aligned}
& \sigma_{1}^{2}=\frac{2}{3(N-2)} \sum_{n=2}^{N-1}\left[\frac{\phi_{n+1}-\phi_{n-1}}{2}-\phi_{n}\right]^{2} \\
& \sigma_{2}{ }^{2}=\frac{1}{(N-1)} \sum_{n=1}^{N}\left[\phi_{n}-\phi_{\text {mean }}\right]^{2}
\end{aligned}
$$

where $\phi_{\text {mean }}$ is the mean super-pixel flux and $N$ is the total number of measurements on each light curve. (2) We then select the light curves which vary such that $L>400$ in at least one colour. As there are as many super-pixels as pixels, a genuine variable is expected to affect all the super-pixels within the seeing spot. (3) We search for clusters of super-pixels (using a Friend of Friends algorithm), and keep the central pixel of the clusters if (4) the previous requirements are also satisfied for these pixels and, if (5) the number $N_{\text {clus }}$ of super-pixels that compose each cluster is larger than 6 . These requirements eliminate most 


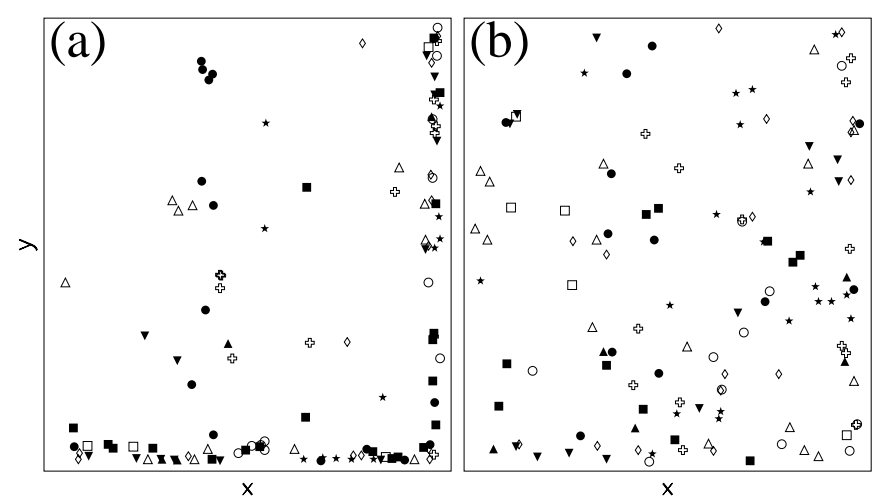

Fig. 2. Artifact removals. Panel a) displays the positions of the 116 rejected light curves on the CCD chips. Panel b) shows a similar distribution but for those among the 237 light curves close to CCD defects that have been kept. Each symbol corresponds to a different chip. Each panel corresponds to the size of the chips $x \in[0,400], y \in[0,579]$

artifacts due to bright stars $^{1}$ and CCD defects that do not exhibit a clear spatial PSF-like pattern. We finally keep 747 super-pixel light curves. The sensitivity of these thresholds is illustrated in Fig. 1. Among the 747 selected variations, two have been counted twice ${ }^{2}$, leaving 745 independent light curves.

\subsection{Artifact removals}

We select 237 light curves for which there is at least one bad pixel (saturated or set at zero) within a $21 \times 21$ window centred on the selected pixel for at least one epoch and at least one colour. A careful visual inspection of these light curves shows 121 genuine variable stars against 116 artifacts, subsequently removed. Figure 2 shows that the removed light curves are mainly concentrated close to the edges, whereas the distribution of the kept light curves (among the 237) is more uniform. We finally end with a catalogue of 631 variable stars.

\section{Magnitude estimation}

Whereas the pixel method of analysis is able to detect variable stars beyond the crowding limit, it does not measure photometry - total flux - of these objects, that can be blended or even unresolved on part of the light curves. Obtaining their photometry would give a first indication of the type of the variable stars. Hence in this section, we associate a magnitude and colour to each flux measurement.

\footnotetext{
1 Super-pixels around a few bright stars exhibit artifacts such that the spatial correlation of the position of these super-pixels looks like a partial ring or an arc.

2 For computing reasons, each chip has been cut into two pieces with an overlapping region through the analysis.
}
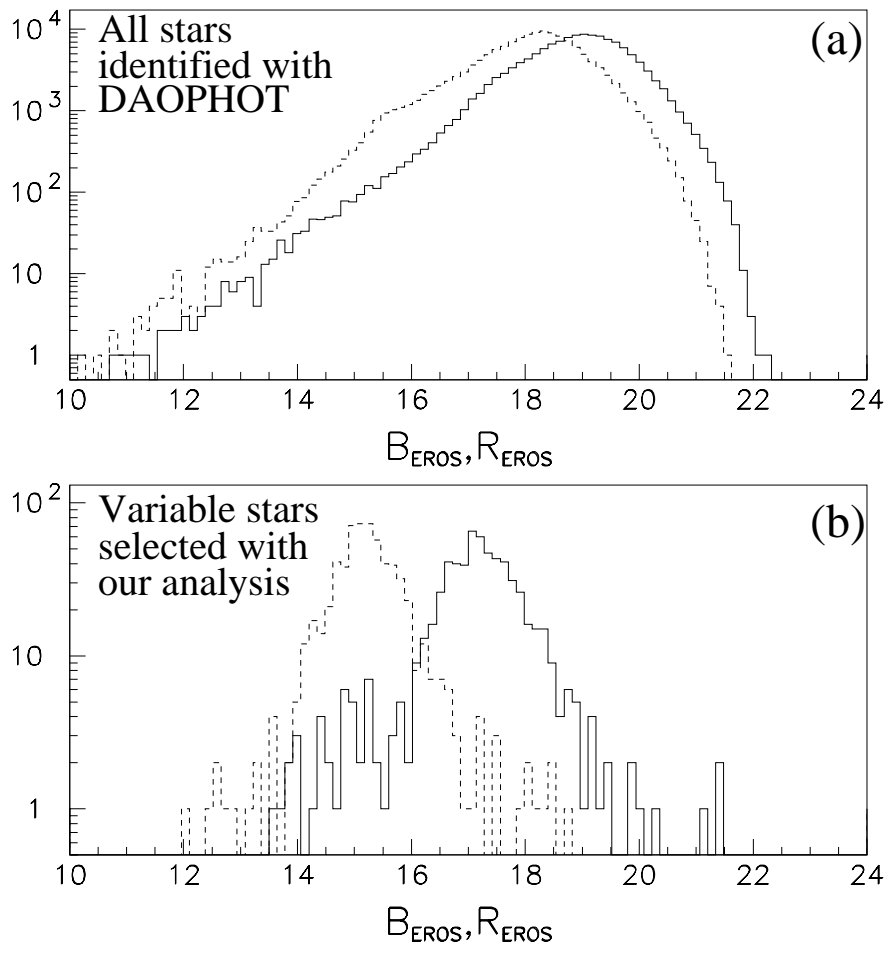

Fig. 3. Luminosity functions in blue (full line) and in red (dashed line) at the epoch JD $=2448678.3$. The upper histograms a) correspond to the magnitudes estimated for all the stars with DAOPHOT. The lower histograms b) correspond to the magnitudes estimated as described in Sect. 4.1 for the selected variable stars

\subsection{Pseudo-aperture photometry}

As discussed in Paper II, the flux of the super-pixel is composed of the fraction of the flux of the star plus the local background (from sky and undetected stars). For our sample of variable stars, we can presume that there is a star within the corresponding super-pixel and that its flux significantly contributes to this super-pixel, at least at the maximum of the variation. Because of the crowding conditions, standard background estimates (circular annulus for example, see Stetson 1987) fail and cannot be used in an automatic way. Hence, we choose to perform a pseudoaperture photometry as follows. For an image taken in the middle of the period of observation (JD 2448678.3) and with an average seeing, we use the PSF fitting procedure of DAOPHOT (Stetson 1987) to measure the fluxes of the resolved stars, and the background below them. This thus gives a local estimate of the background that is the less affected by the crowding of the field. Then for each selected super-pixel we look for the detected star that is closest. The background estimate associated with this star is supposed to be the same as the one present below the variable star (and is even identical if the variable stars are resolved on this reference frame). This background is subtracted from the super-pixel flux. This flux is then corrected for 
the seeing fraction and converted into a magnitude, corresponding to an isolated star.

Whereas this definition of the sky-background is rather robust to the crowding conditions, the magnitude estimation is not necessary so, as some additional flux (stellar background) could contribute to the super-pixel due to neighbours. We thus quantify the blending with the ratio $\phi_{\mathrm{c}} / \phi_{0}$ computed as follows: the flux $\phi_{\mathrm{c}}$ is the averaged value computed along the light curve of the central pixel of the super-pixel, and the flux $\phi_{0}$ is a similar average of the 8 surrounding pixels within the super-pixel. The behaviour of this parameter is described in the Appendix.

Optimised star detection with DAOPHOT allows to detect 135098 stars in blue and 142870 stars in red. The corresponding luminosity function computed with DAOPHOT for all the stars present on the studied field, exhibited in Fig. 3a, shows that the star detection is in first approximation complete down to magnitude 18 in red and 19 in blue. Figure 3b shows that the magnitude distributions at the same epoch for the selected variable stars peak at the bright end, whereas the stars are redder than average with $B_{\mathrm{EROS}}-R_{\mathrm{EROS}} \simeq 2$. Whereas it is difficult to compute our detection efficiencies as no reliable theoretical distribution of variable stars is available, it is clear that we do not detect a population of variable stars unresolved at minimum, even though we do detect a tail of this distribution with very dim stars in at least one colour.

\subsection{Colour-magnitude diagram}

Figure 4 displays the position of the 631 variable stars in the CMD. This CMD has been obtained with the resolved stars detected with DAOPHOT in both colours. The conversion of the EROS magnitudes into a standard system has been studied by Grison et al. (1995), but introduces significant systematic errors especially for stars with $B_{\text {EROS }}-R_{\text {EROS }}>1$. We hence choose to work in the EROS system. The crowding limit prevents the detection of stars with $R_{\text {EROS }}>19$. The main sequence and red clump are clearly identified. Very little variations of the CMD are observed from one chip to another suggesting a uniform stellar population across this field. The vast majority of the detected variable stars lies in the red part. A visual inspection of the corresponding light curves shows that they are compatible with LT\&LPV. This catalogue offers the perspective to systematically study the later stages of stellar evolution within the LMC Bar. However, the isochrones superimposed in Fig. 4 illustrate the difficulty to classify variable stars with the sole CMD, as it is impossible to disentangle their age and mass for a given metalicity. The photometric system made it also inappropriate for further interpretation with this sole data. Due to their complexity and the difficulties to model them, the LT\&LPV are better characterised in the IR, as addressed in a subsequent paper. Some "bluer" objects have also been detected and they will be classify when we study their periodicity.

As shown in Fig. 4, variable stars not significantly affected by crowding $\left(\phi_{\mathrm{c}} / \phi_{0}>3\right)$ lie in areas of the colourmagnitude diagram corresponding to stars expected variable. Those affected by blending and crowding will have to be treated with caution. In the CMD areas where the larger number of LT\&LPV have been detected, in the magnitude $\left(R_{\mathrm{EROS}}=14.6-15.8\right)$ and colour $\left(B_{\mathrm{EROS}}-\right.$ $\left.R_{\text {EROS }}=1.7-2.3\right)$ ranges, about $17 \%$ of the stars exhibit a variation detected with our analysis.

It is also clear that the vast majority of the detected variable stars are above the crowding limit. The few outliers that can be noticed correspond to stars unresolved in at least one colour, but their number does not exceed $5 \%$ of the total. In terms of microlensing, this means that events due to unresolved stars in the LMC will not be significantly contaminated by the bulk of variable stars. In further galaxies, like M31, variable stars will be a more troublesome affair, and will have to be carefully studied (e.g. Crotts \& Tomaney 1996). However, high amplification microlensing events are far less likely to be mimicked by an intrinsic variation (Ansari et al. 1999), and will allow to probe possible biases introduced by variable stars.

\section{Astrometric reduction}

The rectangular sky area covered by the EROS-1 chips is enclosed in a circle of radius $\sim 30^{\prime}$ centred on the position $\alpha=05^{\mathrm{h}} 21^{\mathrm{m}} 52.1^{\mathrm{s}} ; \delta=-69^{\circ} 34^{\prime} 16^{\prime \prime}(2000.0)$. In this region, the density of PMM astrometric standards ${ }^{3}$ is highly irregular, e.g. four $\sim 20^{\prime} \times 15^{\prime}$ areas are completely empty. This is mainly due to the crowding of the survey plates used at USNO. We therefore chose to use a U plate taken at the ESO $1 \mathrm{~m}$ Schmidt telescope to define the secondary astrometric standards. This plate was scanned with the MAMA microdensitometer ${ }^{4}$, and reduced to the International Celestial Reference System (ICRS) ${ }^{5}$ with the ACT catalogue ${ }^{6}$. Thanks to the modest sensitivity of the $\mathrm{U}$ emulsion/filter combination, the effects of crowding are reduced. A remarkably regular distribution of stars is detected with the SExtractor software (Bertin \& Arnouts 1996), with on average 2700 stars per chip.

The secondary standards $(\sim 1500 /$ chip $)$ are identified to EROS stars using a first linear transformation based on some 15 visually cross-identified stars per chip. The astrometric reduction software (Robichon et al. 1995) is then run using this set of references. After iteration, the final

\footnotetext{
3 http://ftp.nofs.navy.mil/projects/pmm/

4 MAMA (http://dsmama.obspm.fr) is operated by INSU (Institut National des Sciences de l'Univers) and Observatoire de Paris.

5 http://hpiers.obspm.fr/webiers/general/syframes/SY.html

${ }^{6}$ http://vizier.u-strasbg.fr/cgi-bin/VizieR?-source=I/246
} 


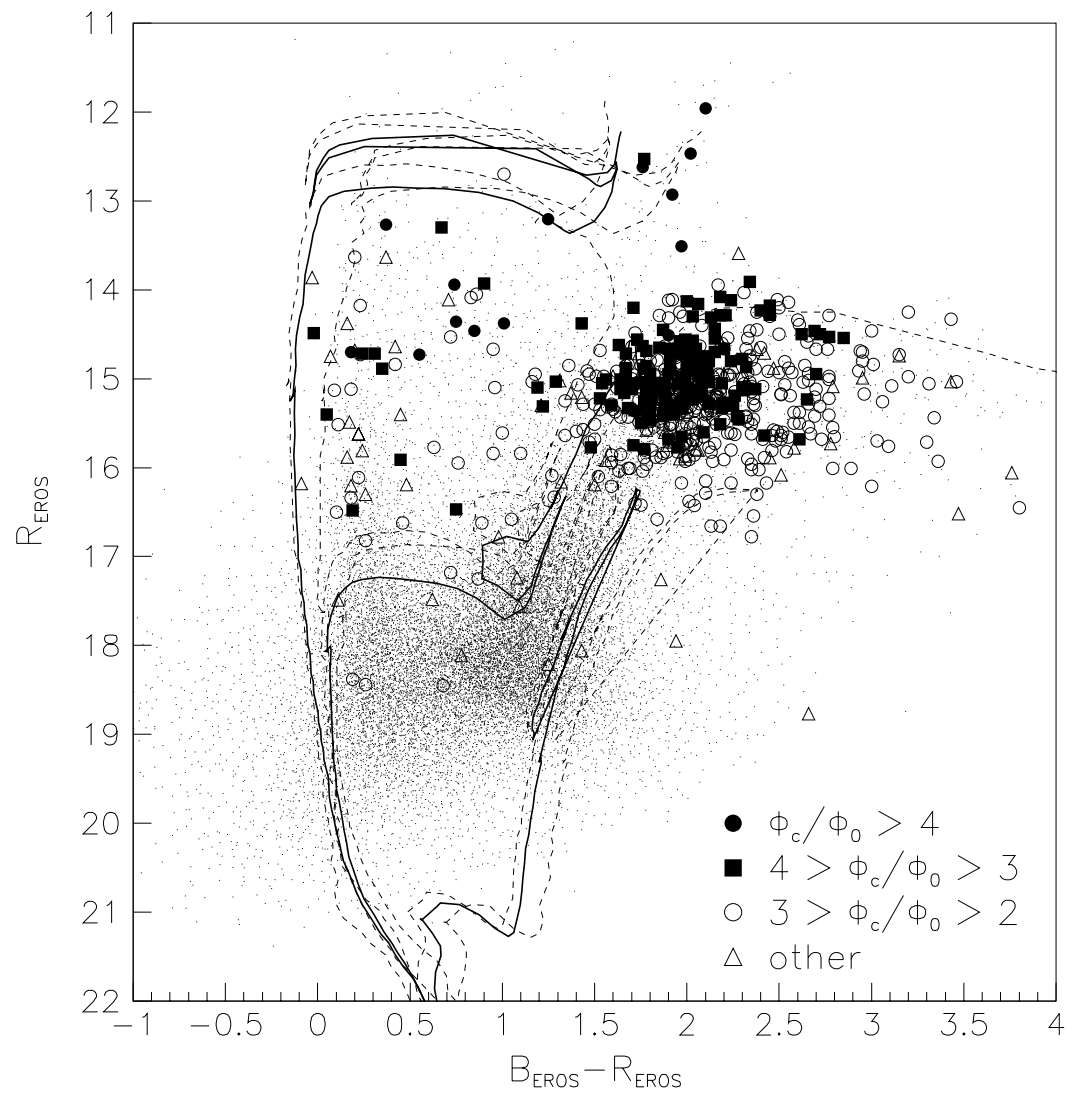

Fig. 4. CMD at JD $=2448678.3$ : small dots correspond to the stars detected with DAOPHOT, symbols to the 631 selected variations. The different symbols correspond to different ranges of the $\phi_{\mathrm{c}} / \phi_{0}$ ratio: filled symbols correspond to stars with a high $\mathrm{S} / \mathrm{N}$ ratio and not affected by crowding. The superimposed isochrones (full lines) are adapted from Bertelli et al. (1994) to the EROS system (Grison et al. 1995) with a foreground extinction $A_{B_{\mathrm{EROS}}}=0.54$ and $A_{R_{\mathrm{EROS}}}=0.37$, deduced from reddening $E(B-V)=0.15$ measured by Schwering \& Israel (1991) with the extinction law from Cardelli et al. (1989). They correspond to LMC metalicity $(Z=0.008)$, helium abundance $(Y=0.25)$ with ages of $\log ($ age $)=7.4,8.4$ and 9.4 . The dashed lines show the uncertainties introduced on each isochrone by the photometric transformation

$2^{\text {nd }}$ order reduction keeps 1000 stars per chip with final rms deviation of the order of $0.2^{\prime \prime}$.

According to the galactic model ${ }^{7}$ from Besançon, more than $95 \%$ of the secondary references belong to LMC. Furthermore, we check that the global proper motion of the LMC (Kroupa \& Bastian 1997), together with upper limits on its internal velocity dispersion cannot affect the positions of our standards by more than 30 mas, over the 848-days separating the ESO plate from the EROS reference.

\section{Cross-identifications}

The detected variable stars are uniformly distributed along the CCD chips, and no obvious bias (due e.g. to internal extinction) are suspected. In order to appreciate the sensitivity of our analysis, we cross-identified this catalogue with previous works. Among the 631 variable stars presented here, 72 have already been studied elsewhere. We considered the main catalogues which covered

\footnotetext{
7 http://WWW.obs-besancon.fr/www/modele/s_tab.html
}

this area, namely the catalogues of LT\&LPV by Hughes (1989), eclipsing binaries and cepheids by EROS (Grison et al. 1994 and Beaulieu et al. 1996), radio sources (Marx et al. 1999), X-ray sources (Haberl \& Pietsch 1999), as well as the General Catalogue of Variable Stars $^{8}$ (Artiukhina et al. 1995) and the $\mathrm{NED}^{9}$ data-base. We define a genuine cross-identification any object whose offsets with respect to the variable objects detected here are smaller than $\Delta \alpha_{\max }=5^{\prime \prime}$ and $\Delta \delta_{\max }=5^{\prime \prime}$.

Among the 58 LT\&LPV found by Hughes (1989) in this field, 41 have been detected here, 12 are missed due to CCD defects (one of those is rejected with the visual inspection described in Sect. 3.3). This gives the order of magnitude of the completeness of our sample over a 120-day window: we typically miss up to $20 \%$ of genuine

\footnotetext{
8 We used the electronic version of the GCVS (http://www.sai.msu.su/groups/cluster/gcvs/gcvs/), supported by the Russian Foundation for Basic Research.

9 The NASA/IPAC Extragalactic Database (NED) is operated by the Jet Propulsion Laboratory, California Institute of Technology, under contract with the National Aeronautics and Space Administration.
} 


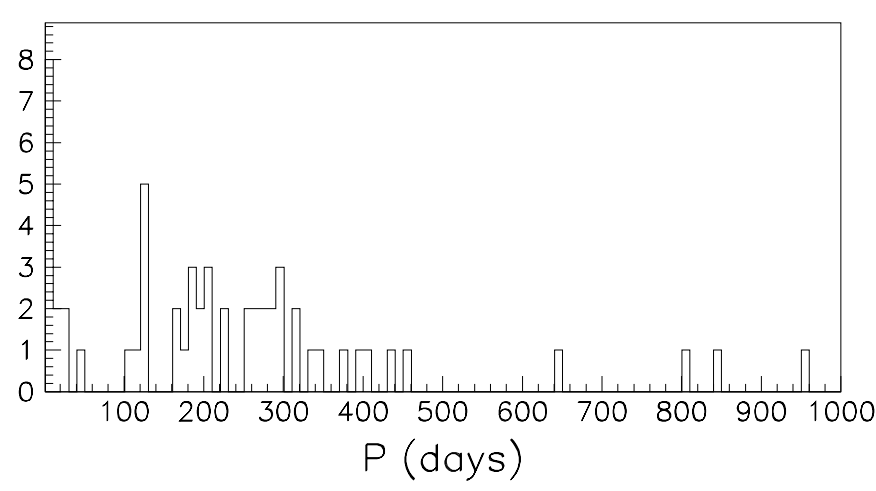

Fig. 5. Histogram of the periods. We present here the periods measured elsewhere which correspond to 57 of the 631 variable stars detected here

variable stars due to CCD defects. More interestingly, the last 5 missing LT\&LPV escape our selection for no obvious reason. One of them (SHV0527122-695006) has been subsequently observed in the near-infrared (Hughes \& Wood 1990): it did not follow the $(\mathrm{K}, \log P)$ relation, and was interpreted as a supergiant or a foreground Mira. According to the DAOPHOT magnitudes measured at epoch JD $=2448678.3 B_{\mathrm{EROS}}=15.7$ and $R_{\mathrm{EROS}}=13.7$, it is consistent with a supergiant. The 4 remaining, namely SHV0516251-693241, SHV0519415-693441, SHV0522220694441, SHV0522251-692902 - not observed subsequently by Hughes \& Wood (1990) - were reported by Hughes (1989) with a low amplitude $(\Delta I \simeq 0.5 \mathrm{mag})$ and 3 of them were only marginally periodic. Moreover, our nondetection can be explained for some of them by changes in mass-loss rates as suggested by Whitelock (1997). The extension of this work with a longer baseline together with DENIS photometry is expected to provide further arguments about this kind of behaviour (in preparation).

The short periodic variable stars from the EROS catalogue (Grison et al. 1994; Beaulieu et al. 1996) are missed here for most of them: short timescale variations are broken by the averaging procedure as explained in Sect. 2 . Only 22 out of the 181 variable stars previously detected by EROS are present in this catalogue. In addition, 5 of the 7 pre-main-sequence candidates published by Beaulieu et al. (1996) have been detected. None of the radio-sources, detected by Marx et al. (1997), are lying in the studied field. 2 X-ray sources detected with ROSAT (Haberl \& Pietsch 1999) are present in the field, but none of our variable stars lies in the 90\% CL error box of those sources. 29 extragalactic sources (but not necessarily variable) from NED are present in the field, none is among the variable stars detected here. Last, whereas 129 sources from the GCVS are lying in the field, 52 are selected here. Most of them were also in the catalogues mentioned above. According to the GCVS classification, among these 52 variables, 17 are Miras, 26 semi-regulars, 2 irregulars, and 7 cepheids.
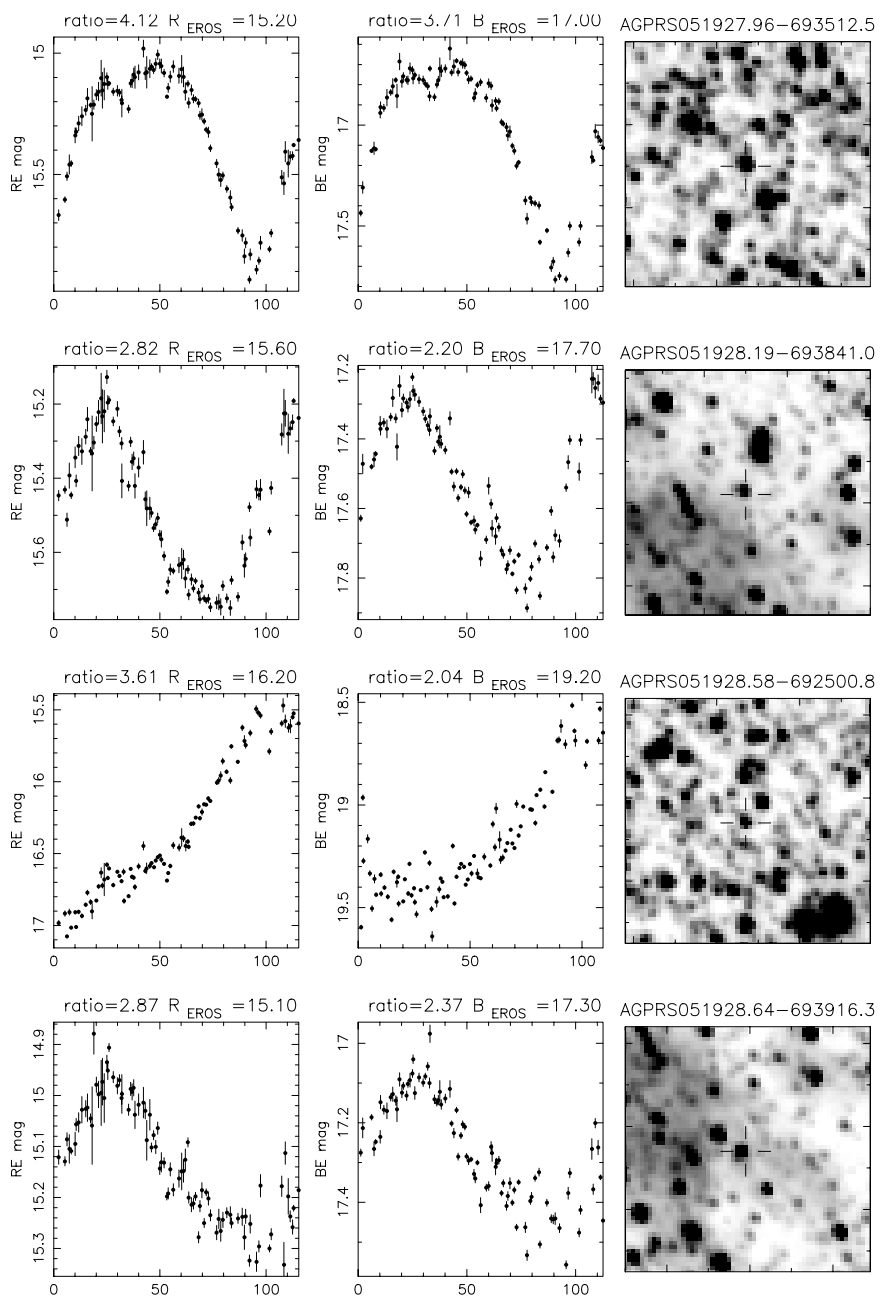

Fig. 6. Examples of red variables. The light curves in red and blue together with the corresponding finding chart in red are displayed for 4 red variable stars from the catalogue. The $\phi_{\mathrm{c}} / \phi_{0}$ ratio is provided for each light curve, as well as the magnitude at $\mathrm{JD}=2448678.3$. Note the fact that the large dispersion with respect to the errors observed for some blue light curves is due to blending and those light curves have a low $\phi_{\mathrm{c}} / \phi_{0}$ ratio

A total of 72 sources out of 631 were previously reported, 57 of which have a published period. Those are presented in Fig. 5: they are clearly of the order of $100-$ 300 days. A visual inspection confirms that besides a few short periods, these timescales are quite representative of the bulk of a distribution dominated by LT\&LPV.

\section{Catalogue}

LT\&LPV ("Red" variable stars) represent the bulk of the stars presented in this catalogue. Figures 6 and 7 show typical light curves detected with the corresponding finding charts. Amplitudes measured over 120 days can be as low as 0.1 mag up to several magnitudes, depending on the timescale, and brightness range. The limitations (in the photometry) due to the crowding are also illustrated. 

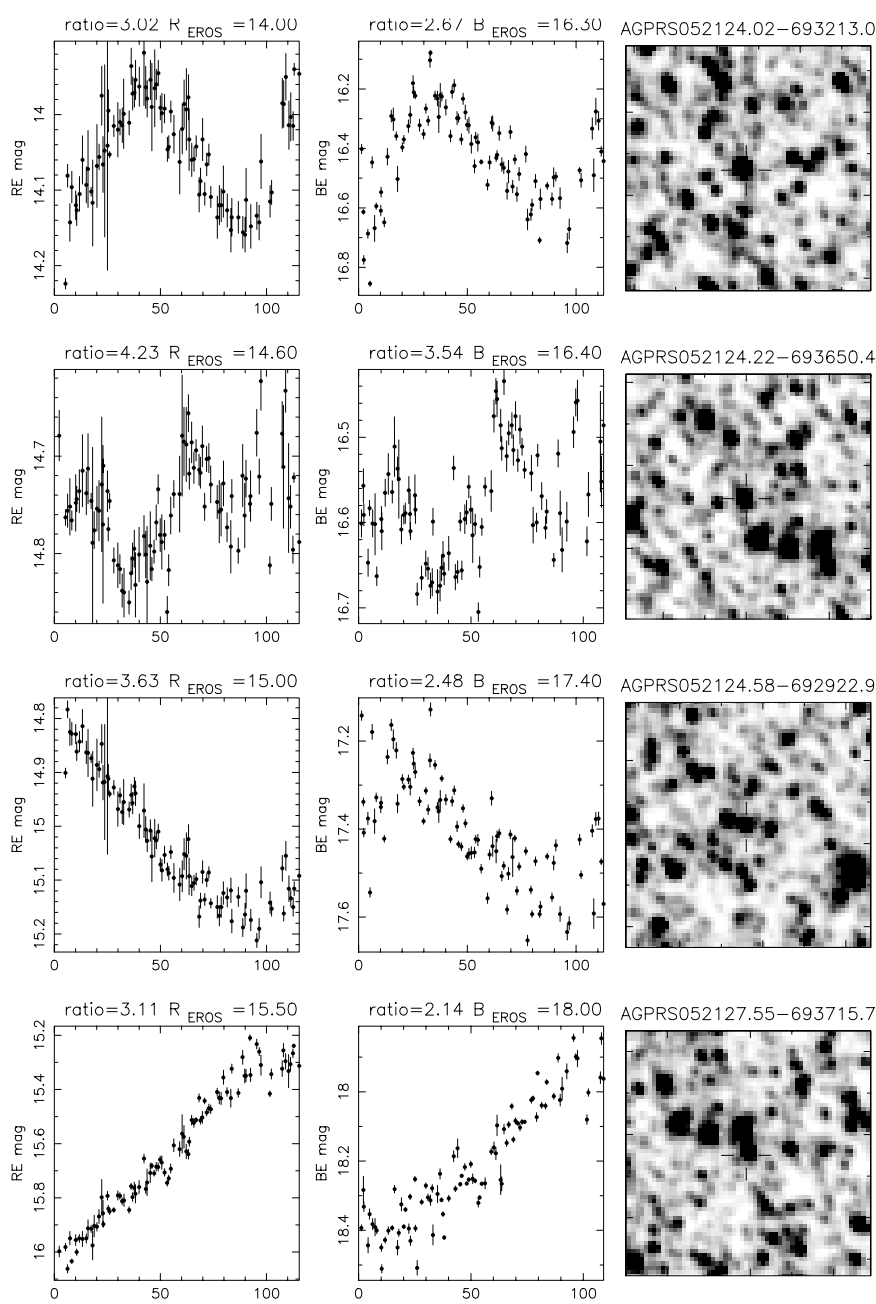

Fig. 7. Examples of red variables. Same as Fig. 6

The error bars (estimated in Paper I) account for the level of photon noise and other residual errors, but they do not account for the effect of crowding on the star flux. For light curves with $\phi_{\mathrm{c}} / \phi_{0} \leq 3$, error bars are underestimated with respect to the scatter along the variation. This explains why the amplitude of variations in blue can be smaller (or comparable) than in red for a few LT\&LPV: the crowding is more important in blue and larger amplitudes of variation are expected on dimmer stars. Hence, we do not attempt to extract information about the amplitude, but provide magnitude estimates at one epoch with the $\phi_{\mathrm{c}} / \phi_{0}$ ratio. For most of them, the timescale of the variation is much longer than the period of observation, and the periodicity will not be studied here.

Table 2 contains the following informations. Column 1: The position, at J2000.0 epoch, is incorporated into the name of each variable, in accordance with IAU convention (Dickel et al. 1987); Column 2: $N / X / Y$ : chip number $N$ and position $(X, Y)$ on the chip. There were 10 chips on the EROS-1 CCD camera. Column 3: the $\phi_{\mathrm{c}} / \phi_{0}$ ratio in blue and red; Column 4: the $B_{\mathrm{EROS}}$ and $R_{\mathrm{EROS}}$ magnitude estimate at epoch JD $=2448678.3 ;$ Column 5: the num- ber of stars detected by DAO in the super-pixel at epoch $\mathrm{JD}=2448678.3$ in $B / R$; Columns 6 and 7: the $B_{\mathrm{EROS}}$ and $R_{\text {EROS }}$ magnitudes (at the same epoch) of the closest stars as estimated by DAOPHOT. Figures in bracket (on a second line) provide the magnitude of another star detected in the super-pixel. Column 8: identification with the other databases, discussed in the text. The Harvard variable numbers are given, as well as variables (WBP) detected by Wood et al. (1985).

The finding charts in red are presented for each variable in Fig. 2. They correspond to the epoch for which the stellar magnitude and blending has been studied $(\mathrm{JD}=2448678.3)$. Each chart is labelled with the name of the variable. A cross indicates the position at which the variable star has been detected.

\section{Conclusion}

Besides being a by-product of the microlensing searches, the variable stars constitute their background and their understanding and discrimination are important (e.g. della Valle \& Livio 1996). They need to be catalogued for any on-line microlensing searches (cf. MACHO and EROSII). In this paper, we have produced a comprehensive catalogue of 631 variable stars selected over a 0.25 $\mathrm{deg}^{2}$ field in the LMC Bar with the Pixel Method applied to a 120-day window, with a sampling of about one measurement per day. For each variable star, we provide an astrometric position accurate within $1^{\prime \prime}$, together with a finding chart. The study of their position in the CMD shows that this catalogue is dominated by a population of LT\&LPV, while a few "bluer" variables have also been detected. Cross-identification with existing catalogues shows that $11 \%$ of them have already been studied elsewhere. We hence enlarge by a factor of 10 the number of LT\&LPV detected in this area of the LMC Bar.

The pixel analysis presented here allows a selection of variable objects independently of a photometry. It hence uses all the information present in the frames but does not provide a photometry for these objects. It is complementary to the image subtraction techniques. We have shown that not surprisingly the pixel light curves are significantly polluted by blending, especially in blue and that their conversion in magnitude can only be rough. Hence, for each variable star, we provide an indicator of blending in both colours. The preliminary study of these variable stars together with their cross-identification with previous works show that our photometry does not introduce significant bias on the overall distribution. Recent improvements of the image subtraction techniques developed for microlensing searches (Alard 1999; Alcock et al. 1999a,b) will have to be considered for the future to improve the photometry of the variable stars detected in such crowded fields (e.g. Olech et al. 1999). However, most of these objects are Long Period Variables better characterized with IR photometry than optical non-standard photometry anyway. 
The limitation of this dataset is hence reached and it needs to be complemented by other data. In a companion paper, we will extend these selected light curves to the whole EROS I baseline (850 days window), with the 199294 data taken with a different set of filters. This will enable us to study the periodicity of these variable stars. In a forthcoming paper, we will cross-identify these variable stars with the IJK photometry of the DENIS catalogue.

Acknowledgements. We thank the EROS collaboration (http://www.lal.in2p3.fr/recherche/eros/erosa.html) for giving us their 91-92 data, and Marc Moniez for a careful reading of this manuscript. The $U$ plate used for the astrometry was taken at the ESO Schmidt telescope at La Silla. We thank the MAMA team for scanning and reducing this plate. We acknowledge Dave Monet for the informations he kindly provided on the PMM/USNO catalogue. We are particularly grateful to C. Lamy for her useful help on data handling during this work, done in part on the computers of PCC-Collège de France. A.-L. Melchior has been supported by a European contract ERBFMBICT972375 at QMW. This research has made use of the NASA/IPAC Extragalactic Database (NED) which is operated by the Jet Propulsion Laboratory, California Institute of Technology, under contract with the National Aeronautics and Space Administration. The Vizier service (Ochsenbein 1997) at CDS has been used throughout this work.

\section{References}

Alard C., 1999, astro-ph/9903111

Alard C., Guibert J., 1997, A\&A 326, 1

Alard C., Lupton R.H., 1998, ApJ 503, 325

Alcock C., et al., 1997a, ApJ 486, 697

Alcock C., et al., 1997b, ApJ 491, L11

Alcock C., et al., 1997c, ApJ 479, 119

Alcock C., et al., 1999a, ApJ 521, 602

Alcock C., et al., 1999b, ApJS 124, 171

Ansari R., et al., 1997, A\&A 324, 843

Ansari R., et al., 1999, A\&A 344, L49
Arnaud M., et al., 1994, Exp. Astron. 4, 265

Arnaud M., et al., 1994, Exp. Astron. 4, 279

Artiukhina N., et al., 1995, General Catalogue of Variable Stars, 4rd ed., Vol. V. Extragalactic Variable Stars. Kosmosinform, Moscow

Aubourg E., et al., 1995, A\&A 301, 1

Baillon P., et al., 1993, A\&A 277, 1

Beaulieu J.-Ph., et al., 1995, A\&A 303, 137

Beaulieu J.-Ph., et al., 1996, Sci 272, 995

Bertelli G., et al., 1994, A\&AS 106, 275

Bertin E., Arnouts S., 1996, A\&A 117, 393

Cardelli C., et al., 1989, ApJ 345, 245

Crotts A., Tomaney A., 1996, ApJ 473, L87

della Valle M., Livio M., 1996, ApJ 457, L77

Dickel H., et al., 1987, A\&AS 68, 75

Grison Ph., 1994, Ph.D. Thesis, Université de Paris VII, Paris

Grison Ph., et al., 1995, A\&AS 109, 447

Haberl F., Pietsch W., 1999, A\&A 344, 521

Hill V., Beaulieu J.-Ph., 1997, Variables Stars and the Astrophysical Returns of the Microlensing Surveys, Ferlet R., Maillard J.-P. and Raban B. (eds.), p. 267

Hughes S., 1989, AJ 97, 1634

Hughes S., Wood P., 1990, AJ 99, 784

Kroupa P., Bastian U., 1997, in ESA Symposium 402 "Hipparcos - Venice '97", Battrick B., Perryman M.A.C. and Bernacca P.L. (eds.), p. 615

Marx M., et al., 1997, A\&AS 126, 325

Melchior A.-L., et al., 1998, A\&A 339, 658

Melchior A.-L., et al., 1999, A\&AS 134, 377

Ochsenbein F., 1997, Baltic Astron. 6, 221

Olech A., et al., 1999, MNRAS 310, 759

Palanque-Delabrouille N., et al., 1998, A\&A 332, 1

Queinnec F., 1994, Ph.D. Thesis, Université de Paris VII, Paris Renault C., 1996, Ph.D. Thesis, Université de Paris VII, Paris Renault C., et al., 1997, A\&A 324, L69

Robichon N., et al., 1995, A\&A 304, 132

Schwering P., Israel F., 1991, A\&A 246, 231

Stetson P.B., 1987, PASP 99, 191

Tomaney A.B., Crotts A., 1996, AJ 112, 2872

Udalski A., et al., 1994, Acta Astron. 44, 165

Wood P., et al., 1985, ApJ 290, 477 


\section{Appendix A: Limitations of the Pixel Method}

Figure A1 displays the behaviour of the ratio $\phi_{\mathrm{c}} / \phi_{0}$ computed for the variable stars of the catalogue. Figure A2 compares our magnitude estimate with the DAOPHOT one for the selected light curves.
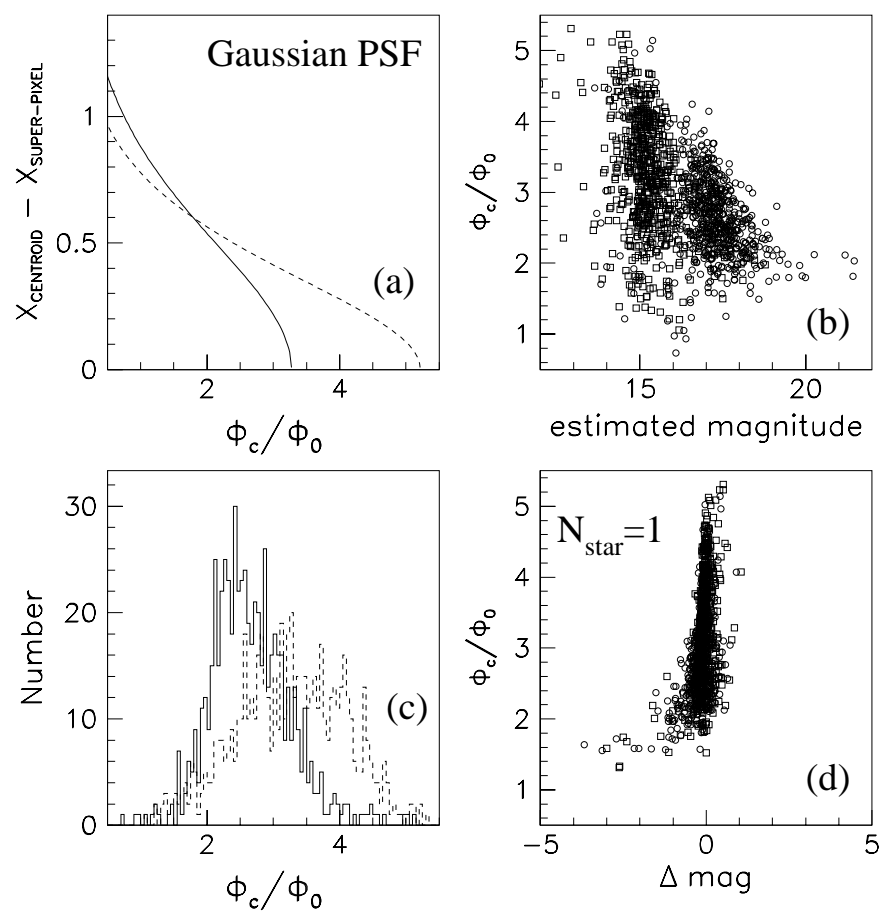

Fig. A1. Quantification of blending. Square symbols correspond to red measurements and circle to blue. a) The position of the star's centroid as a function of the $\phi_{\mathrm{c}} / \phi_{0}$ ratio is displayed for a single Gaussian PSF (seeing $=2.0-1.6 \operatorname{arcsec}$ ), without any crowding. In addition, cylindrical symmetry is assumed. b) The measured ratio $\phi_{\mathrm{c}} / \phi_{0}$, which also includes a measure of the $S / N$ ratio, shows a strong correlation with the magnitude of the stars at JD $=2448678.3$. c) Histograms of the measured $\phi_{\mathrm{c}} / \phi_{0}$ ratio in blue (full line) and in red (dashed line) of all the selected light curves: blending is stronger in blue d) Dependence of the ratio $\phi_{\mathrm{c}} / \phi_{0}$ as a function of the difference between the estimated magnitude and the magnitude of the closest star detected by DAOPHOT at the epoch JD = 2448678.3 for $N_{\text {star }}=1$, discussed above and in Fig. A2b

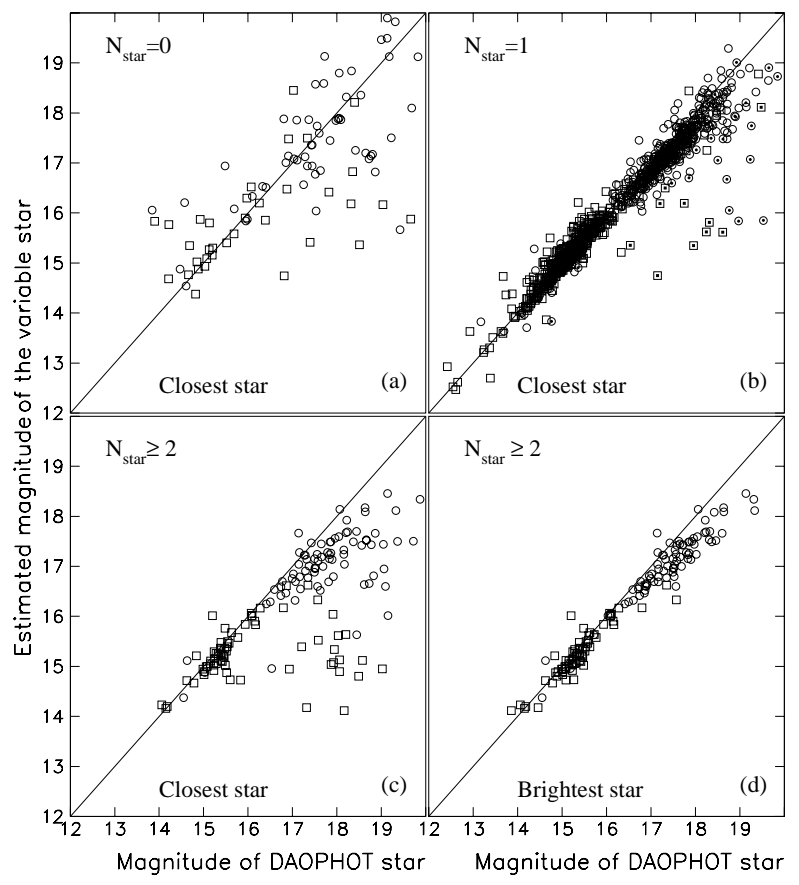

Fig. A2. Study of the crowding conditions of each variable star of the catalogue with magnitude estimates at the epoch JD = 2448678.3. The squares correspond to the red measurements and the circles to the blue ones. Each panel corresponds to a given value of $N_{\text {star }}$, the number of stars in the super-pixel, as detected by DAOPHOT. a) These points gather stars unresolved at the epoch studied (the majority in blue), stars missed by DAOPHOT (bad PSF or other defect), mis-alignment of the super-pixel with respect to the variable star, and few apparently spurious variations. No correlation is observed with the closest star. b) There is a good correlation between the magnitude of the star detected by DAOPHOT and the estimated magnitude, except for a few ones. Filled symbols are measurements for which there is a brighter star within 3 pixels of the centre of the super-pixel, and are clearly affected by blending. The observed dispersion, and in particular the points for which the DAOPHOT magnitude is brighter, is mainly due to the fact that the precision on the position of the centre of the super-pixel is 1 pixel, whereas the position of the centroid of the star defined by DAOPHOT is much more accurate. Panel c) displays the correspondence between the estimated magnitude and the magnitude of the closest star detected by DAOPHOT. A significant component of blending can be observed. Panel d) shows a better correlation as the brightest star detected by DAOPHOT in the super-pixel has been used. At the dim end, the crowding limit produces unavoidable blending 
Table 2. Catalogue of the variable objects detected in this paper. They are sorted in order of increasing right ascension

\begin{tabular}{|c|c|c|c|c|c|c|c|}
\hline $\begin{array}{l}\text { Name } \\
(1)\end{array}$ & $\begin{array}{c}\operatorname{chip} / X / Y \\
(2)\end{array}$ & $\begin{array}{c}\left.\frac{\phi_{\mathrm{c}}}{\phi_{0}}\right|_{B} /\left.\frac{\phi_{\mathrm{c}}}{\phi_{0}}\right|_{R} \\
(3)\end{array}$ & $\begin{array}{c}B_{\text {EROS }} / R_{\text {EROS }} \\
\text { (4) }\end{array}$ & $\begin{array}{c}N_{\mathrm{star}}^{B / R} \\
(5)\end{array}$ & $\begin{array}{c}B_{\mathrm{EROS}}^{\mathrm{DAO}} \\
(6)\end{array}$ & $\begin{array}{c}R_{\mathrm{EROS}}^{\mathrm{DAO}} \\
\quad(7)\end{array}$ & $\begin{array}{c}\text { Cross-identifications } \\
(8)\end{array}$ \\
\hline AGPRS051521.44-693622.6 & $00 / 028 / 061$ & $2.33 / 2.77$ & $17.71 / 15.88$ & $1 / 1$ & 17.56 & 15.50 & \\
\hline AGPRS051526.84-693527.1 & $00 / 039 / 112$ & $3.13 / 4.48$ & $17.88 / 15.23$ & $1 / 1$ & 17.53 & 14.66 & \\
\hline AGPRS051532.74-693154.9 & $00 / 018 / 290$ & $3.14 / 3.22$ & $16.29 / 14.56$ & $1 / 1$ & 16.45 & 14.53 & \\
\hline AGPRS051533.81-693555.6 & $00 / 075 / 097$ & $1.84 / 1.68$ & $17.86 / 15.80$ & $0 / 0$ & 17.37 & 15.13 & \\
\hline AGPRS051535.68-693641.7 & $00 / 093 / 062$ & $3.02 / 3.27$ & $16.50 / 14.65$ & $1 / 1$ & 16.75 & 14.71 & \\
\hline AGPRS051536.17-693228.3 & $00 / 040 / 267$ & $3.01 / 3.99$ & $17.74 / 15.46$ & $1 / 1$ & 17.96 & 15.45 & \\
\hline AGPRS051536.28-693434.9 & $00 / 068 / 165$ & $4.14 / 4.66$ & $17.08 / 15.36$ & $1 / 0$ & 16.89 & 18.51 & \\
\hline AGPRS051537.22-692954.9 & $00 / 011 / 392$ & $2.27 / 2.19$ & $15.63 / 15.52$ & $2 / 2$ & $\begin{array}{c}18.45 \\
(15.72)\end{array}$ & $\begin{array}{l}17.58 \\
(15.59)\end{array}$ & \\
\hline AGPRS051538.31-693227.6 & $00 / 049 / 270$ & $2.99 / 4.04$ & $18.41 / 16.02$ & $1 / 1$ & 18.16 & 15.61 & \\
\hline AGPRS051539.28-693707.8 & $00 / 114 / 045$ & $3.10 / 4.17$ & $17.69 / 15.51$ & $1 / 1$ & 17.72 & 15.32 & \\
\hline AGPRS051539.47-693536.4 & $00 / 095 / 119$ & $2.54 / 3.16$ & $18.36 / 15.82$ & $1 / 1$ & 18.29 & 15.60 & \\
\hline AGPRS051540.60-693437.3 & $00 / 087 / 168$ & $1.96 / 2.10$ & $17.36 / 15.58$ & $0 / 0$ & 17.44 & 15.68 & \\
\hline AGPRS051546.85-692902.8 & $00 / 041 / 445$ & $2.29 / 2.23$ & $16.94 / 15.34$ & $2 / 2$ & $\begin{array}{c}19.06 \\
(17.17)\end{array}$ & $\begin{array}{c}17.94 \\
(15.28)\end{array}$ & \\
\hline AGPRS051550.18-693156.1 & 00/093/309 & $1.91 / 2.25$ & $17.26 / 14.96$ & $1 / 1$ & 17.40 & 14.59 & \\
\hline AGPRS051550.49-692737.5 & $00 / 038 / 518$ & $2.30 / 2.29$ & $16.71 / 15.95$ & $1 / 1$ & 16.77 & 15.92 & \\
\hline AGPRS051552.32-693513.7 & $00 / 145 / 152$ & $3.34 / 3.94$ & $17.20 / 15.22$ & $1 / 1$ & 17.26 & 15.09 & \\
\hline AGPRS051555.16-693050.0 & $00 / 100 / 368$ & $2.12 / 2.60$ & $17.05 / 15.35$ & $1 / 1$ & 18.51 & 16.53 & \\
\hline AGPRS051555.82-692946.5 & $00 / 089 / 420$ & $1.98 / 2.45$ & $17.05 / 14.67$ & $1 / 1$ & 17.57 & 14.54 & \\
\hline AGPRS051558.69-692922.0 & $00 / 096 / 443$ & $2.65 / 3.37$ & $18.31 / 15.89$ & $1 / 1$ & 18.09 & 15.67 & \\
\hline AGPRS051600.29-693217.8 & $00 / 141 / 303$ & $4.67 / 4.48$ & $14.68 / 13.94$ & $1 / 1$ & 14.77 & 13.91 & $\begin{array}{c}\text { EROS } 2091 \\
\text { HV2414 }\end{array}$ \\
\hline AGPRS051600.80-693559.2 & $00 / 191 / 125$ & $3.33 / 3.83$ & $17.33 / 15.40$ & $1 / 1$ & 17.52 & 15.36 & \\
\hline AGPRS051601.25-693135.8 & $00 / 136 / 338$ & $3.06 / 4.06$ & $18.29 / 15.68$ & $1 / 1$ & 18.12 & 15.46 & \\
\hline AGPRS051602.35-693009.3 & $00 / 122 / 409$ & $2.08 / 3.04$ & $17.74 / 14.97$ & $1 / 1$ & 18.13 & 14.77 & \\
\hline AGPRS051602.80-692919.1 & $00 / 113 / 450$ & $1.92 / 1.77$ & $17.22 / 15.27$ & $1 / 0$ & 17.31 & 15.12 & \\
\hline AGPRS051605.13-692819.2 & $00 / 110 / 501$ & $3.53 / 3.96$ & $16.32 / 15.03$ & $2 / 1$ & $\begin{array}{c}17.06 \\
(16.60)\end{array}$ & 14.59 & \\
\hline AGPRS051605.16-692809.3 & $00 / 108 / 509$ & $2.62 / 3.28$ & $17.80 / 16.21$ & $1 / 1$ & 17.65 & 15.36 & \\
\hline AGPRS051605.45-693049.7 & $00 / 144 / 380$ & $2.38 / 2.62$ & $17.12 / 14.95$ & $1 / 1$ & 17.07 & 14.76 & \\
\hline AGPRS051606.18-692006.6 & $08 / 011 / 310$ & $2.62 / 3.79$ & $18.23 / 15.90$ & $1 / 1$ & 18.56 & 15.78 & \\
\hline AGPRS051606.47-692213.2 & $08 / 040 / 208$ & $3.38 / 4.08$ & $16.56 / 14.66$ & $1 / 1$ & 16.68 & 14.71 & \\
\hline AGPRS051606.76-692054.4 & $08 / 024 / 272$ & $2.12 / 3.22$ & $20.25 / 16.45$ & $1 / 1$ & 20.07 & 16.53 & \\
\hline AGPRS051607.08-692522.3 & $08 / 084 / 056$ & $1.97 / 3.54$ & $19.82 / 16.06$ & $0 / 2$ & 19.31 & $\begin{array}{c}16.07 \\
(19.27)\end{array}$ & \\
\hline AGPRS051607.31-693705.4 & $00 / 233 / 079$ & $2.33 / 2.94$ & $17.19 / 14.96$ & $2 / 1$ & $\begin{array}{c}17.66 \\
(17.66)\end{array}$ & 15.14 & \\
\hline AGPRS051607.95-692026.4 & $08 / 023 / 296$ & $2.43 / 3.16$ & $17.03 / 15.13$ & $1 / 1$ & 17.43 & 15.21 & \\
\hline AGPRS051608.33-692739.0 & $00 / 115 / 537$ & $2.25 / 3.18$ & $16.21 / 14.25$ & $0 / 1$ & 14.57 & 14.40 & \\
\hline AGPRS051609.45-692200.0 & $08 / 050 / 222$ & $2.05 / 2.08$ & $16.66 / 14.87$ & $1 / 1$ & 17.08 & 14.98 & \\
\hline AGPRS051609.66-693518.4 & $00 / 220 / 168$ & $2.25 / 2.85$ & $17.67 / 16.04$ & $1 / 2$ & 18.83 & $\begin{array}{c}17.91 \\
(16.11)\end{array}$ & \\
\hline AGPRS051609.70-693239.8 & $00 / 186 / 296$ & $4.32 / 4.42$ & $15.11 / 14.36$ & $2 / 1$ & $\begin{array}{c}14.63 \\
(17.99)\end{array}$ & 13.73 & $\begin{array}{c}\text { LMC V1826 } \\
\text { HV923 } \\
\text { EROS } 2092\end{array}$ \\
\hline AGPRS051611.60-691842.6 & $08 / 016 / 384$ & $2.21 / 3.35$ & $18.13 / 15.17$ & $1 / 1$ & 18.49 & 15.23 & \\
\hline AGPRS051612.72-691901.5 & $08 / 025 / 370$ & $3.32 / 4.39$ & $17.25 / 15.50$ & $1 / 1$ & 17.46 & 15.45 & \\
\hline AGPRS051613.73-692320.3 & $08 / 086 / 162$ & $2.70 / 3.05$ & $17.07 / 15.43$ & $1 / 1$ & 17.13 & 15.32 & \\
\hline AGPRS051615.01-691816.5 & $08 / 025 / 409$ & $2.16 / 2.36$ & $16.98 / 15.37$ & $1 / 1$ & 17.30 & 15.50 & \\
\hline AGPRS051616.20-692826.1 & $00 / 159 / 508$ & $3.20 / 4.00$ & $16.53 / 15.31$ & $0 / 1$ & 16.33 & 15.30 & \\
\hline AGPRS051616.71-693513.4 & $00 / 249 / 180$ & $3.60 / 4.07$ & $17.17 / 15.38$ & $1 / 1$ & 17.19 & 15.29 & \\
\hline AGPRS051616.83-692422.8 & 08/113/115 & $2.65 / 3.34$ & $17.01 / 15.51$ & $1 / 1$ & 17.45 & 15.66 & \\
\hline
\end{tabular}




\begin{tabular}{|c|c|c|c|c|c|c|c|}
\hline $\begin{array}{l}\text { Name } \\
(1)\end{array}$ & $\begin{array}{c}\operatorname{chip} / X / Y \\
(2)\end{array}$ & $\begin{array}{c}\left.\frac{\phi_{\mathrm{c}}}{\phi_{0}}\right|_{B} /\left.\frac{\phi_{\mathrm{c}}}{\phi_{0}}\right|_{R} \\
\text { (3) }\end{array}$ & $\begin{array}{c}B_{\text {EROS }} / R_{\text {EROS }} \\
(4)\end{array}$ & $\begin{array}{c}N_{\text {star }}^{B / R} \\
\quad(5)\end{array}$ & $\begin{array}{c}B_{\mathrm{EROS}}^{\mathrm{DAO}} \\
(6)\end{array}$ & $\begin{array}{c}R_{\mathrm{EROS}}^{\mathrm{DAO}} \\
\quad(7)\end{array}$ & $\begin{array}{c}\text { Cross-identifications } \\
\text { (8) }\end{array}$ \\
\hline AGPRS051617.06-692115.0 & $08 / 073 / 267$ & $2.77 / 3.60$ & $17.20 / 15.30$ & $1 / 1$ & 17.46 & 15.47 & \\
\hline AGPRS051618.56-691558.0 & $08 / 010 / 525$ & $1.59 / 2.74$ & $17.07 / 15.35$ & $1 / 0$ & 19.24 & 14.68 & \\
\hline AGPRS051619.65-691820.5 & $08 / 046 / 411$ & $5.02 / 5.08$ & $15.31 / 14.46$ & $1 / 1$ & 15.34 & 14.35 & EROS 2088 \\
\hline AGPRS051620.35-691951.7 & $08 / 069 / 338$ & $1.72 / 1.74$ & $16.05 / 15.81$ & $1 / 1$ & 18.76 & 18.31 & \\
\hline AGPRS051621.48-691726.1 & $08 / 042 / 457$ & $1.23 / 1.45$ & $16.56 / 16.30$ & $0 / 0$ & 17.25 & 15.97 & \\
\hline AGPRS051622.42-692019.3 & $08 / 084 / 318$ & $3.46 / 3.08$ & $15.45 / 15.40$ & $1 / 1$ & 15.47 & 15.39 & \\
\hline AGPRS051623.59-693009.4 & $00 / 213 / 433$ & $2.39 / 2.93$ & $18.39 / 16.29$ & $1 / 1$ & 18.53 & 16.31 & \\
\hline AGPRS051623.69-692306.9 & $08 / 126 / 184$ & $2.70 / 3.64$ & $16.95 / 15.15$ & $1 / 1$ & 17.28 & 15.25 & \\
\hline AGPRS051623.70-691642.3 & $08 / 042 / 495$ & $2.80 / 3.76$ & $17.08 / 15.09$ & $0 / 1$ & 18.73 & 15.12 & \\
\hline AGPRS051623.90-692753.5 & $00 / 185 / 543$ & $2.10 / 2.35$ & $17.66 / 15.89$ & $2 / 1$ & $\begin{array}{c}18.87 \\
(18.60)\end{array}$ & 16.04 & \\
\hline AGPRS051624.27-693603.7 & $00 / 292 / 148$ & $3.78 / 4.42$ & $16.63 / 14.64$ & $1 / 1$ & 16.81 & 14.61 & \\
\hline AGPRS051625.27-691756.1 & $08 / 065 / 437$ & $3.63 / 4.37$ & $16.59 / 14.44$ & $2 / 1$ & $\begin{array}{c}16.74 \\
(19.37)\end{array}$ & 14.44 & \\
\hline AGPRS051625.47-693708.6 & $00 / 311 / 097$ & $2.36 / 2.49$ & $16.73 / 15.29$ & $1 / 2$ & 17.02 & $\begin{array}{c}15.24 \\
(15.24)\end{array}$ & \\
\hline AGPRS051625.56-692157.7 & $08 / 119 / 242$ & $1.80 / 1.99$ & $19.49 / 18.06$ & $0 / 1$ & 19.13 & 18.58 & \\
\hline AGPRS051626.05-692111.4 & $08 / 111 / 280$ & $2.27 / 2.87$ & $17.13 / 15.29$ & $1 / 1$ & 17.63 & 15.35 & \\
\hline AGPRS051627.88-692338.8 & $08 / 151 / 163$ & $2.68 / 3.39$ & $16.19 / 15.03$ & $1 / 1$ & 16.49 & 15.15 & \\
\hline AGPRS051628.30-691931.8 & 08/099/363 & $3.34 / 3.36$ & $14.30 / 12.53$ & $1 / 1$ & 14.47 & 12.55 & \\
\hline AGPRS051628.94-693444.7 & $00 / 295 / 217$ & $2.82 / 3.00$ & $16.81 / 14.97$ & $1 / 1$ & 16.54 & 14.69 & $\begin{array}{c}\text { LMC V1852 } \\
\text { SHV0516509-693752 }\end{array}$ \\
\hline AGPRS051629.24-692835.6 & $00 / 217 / 515$ & $2.53 / 2.57$ & $14.96 / 14.73$ & $2 / 2$ & $\begin{array}{c}16.53 \\
(15.19)\end{array}$ & $\begin{array}{l}15.60 \\
(15.27)\end{array}$ & \\
\hline AGPRS051629.56-691541.2 & $08 / 054 / 551$ & $2.32 / 3.20$ & $18.31 / 15.96$ & $1 / 1$ & 18.61 & 15.84 & \\
\hline AGPRS051629.75-691717.8 & $08 / 076 / 473$ & $1.97 / 1.93$ & $15.66 / 15.49$ & $0 / 1$ & 19.42 & 15.50 & EROS ELHC3 \\
\hline AGPRS051631.09-692058.6 & $08 / 130 / 296$ & $1.98 / 2.76$ & $17.94 / 14.99$ & $1 / 1$ & 18.89 & 15.21 & \\
\hline AGPRS051631.26-693220.5 & $00 / 274 / 336$ & $4.15 / 3.54$ & $14.47 / 14.49$ & $1 / 1$ & 14.68 & 14.61 & \\
\hline AGPRS051631.68-691653.3 & 08/079/495 & $1.80 / 2.25$ & $16.46 / 14.72$ & $2 / 1$ & $\begin{array}{c}16.85 \\
(19.62)\end{array}$ & 14.71 & \\
\hline AGPRS051631.76-692321.9 & $08 / 164 / 181$ & $2.21 / 2.71$ & $17.24 / 15.41$ & $2 / 0$ & $\begin{array}{l}18.16 \\
(18.02)\end{array}$ & 17.40 & \\
\hline AGPRS051632.51-692130.3 & $08 / 143 / 272$ & $2.35 / 2.19$ & $18.70 / 18.44$ & $1 / 1$ & 18.28 & 17.86 & \\
\hline AGPRS051633.24-692606.2 & $08 / 206 / 050$ & $2.22 / 3.73$ & $17.59 / 15.50$ & $1 / 1$ & 18.21 & 15.49 & \\
\hline AGPRS051633.72-692802.2 & $00 / 229 / 547$ & $3.75 / 3.44$ & $14.96 / 14.72$ & $1 / 2$ & 14.99 & $\begin{array}{c}14.62 \\
(18.47)\end{array}$ & \\
\hline AGPRS051634.59-693430.3 & $00 / 316 / 235$ & $2.99 / 3.45$ & $17.24 / 15.12$ & $1 / 2$ & 17.41 & $\begin{array}{l}18.58 \\
(15.09)\end{array}$ & \\
\hline AGPRS051634.85-693352.3 & $00 / 309 / 266$ & $3.11 / 3.76$ & $16.69 / 15.04$ & $1 / 1$ & 16.94 & 15.04 & \\
\hline AGPRS051635.48-692517.3 & $08 / 205 / 092$ & $3.13 / 3.95$ & $16.93 / 15.15$ & $1 / 1$ & 17.20 & 15.20 & \\
\hline AGPRS051636.03-692048.1 & $08 / 149 / 310$ & $3.52 / 4.55$ & $16.90 / 14.90$ & $1 / 1$ & 17.06 & 14.89 & \\
\hline AGPRS051637.38-693710.4 & $00 / 362 / 109$ & $2.58 / 3.45$ & $17.94 / 15.28$ & $1 / 1$ & 17.98 & 15.20 & \\
\hline AGPRS051637.62-691559.8 & $08 / 093 / 545$ & $2.70 / 3.60$ & $17.08 / 14.74$ & $1 / 1$ & 17.34 & 14.82 & SHV0516570-691909 \\
\hline AGPRS051638.26-691908.6 & $08 / 137 / 393$ & $3.08 / 3.89$ & $16.64 / 14.86$ & $1 / 1$ & 16.98 & 14.94 & \\
\hline AGPRS051638.43-693351.1 & $00 / 324 / 271$ & $2.51 / 3.21$ & $17.51 / 15.36$ & $1 / 1$ & 17.73 & 15.26 & \\
\hline AGPRS051639.23-692048.9 & $08 / 163 / 313$ & $2.93 / 2.71$ & $17.08 / 16.82$ & $1 / 0$ & 17.06 & 18.35 & EROS ELHC7 \\
\hline AGPRS051639.77-692633.9 & $08 / 240 / 035$ & $2.25 / 2.68$ & $16.37 / 14.91$ & $1 / 1$ & 17.14 & 15.13 & \\
\hline AGPRS051640.23-691938.5 & $08 / 152 / 371$ & $2.63 / 2.91$ & $17.35 / 15.28$ & $1 / 1$ & 17.62 & 15.36 & \\
\hline AGPRS051640.55-693400.2 & $00 / 335 / 266$ & $2.40 / 3.22$ & $16.06 / 15.10$ & $0 / 1$ & 13.85 & 15.48 & \\
\hline AGPRS051641.58-692430.0 & $08 / 221 / 137$ & $2.06 / 2.47$ & $18.32 / 15.26$ & $0 / 1$ & 18.22 & 15.04 & \\
\hline AGPRS051641.97-691609.5 & $08 / 114 / 542$ & $2.03 / 2.79$ & $21.46 / 17.04$ & $0 / 0$ & 19.90 & 20.39 & \\
\hline AGPRS051642.42-692403.9 & $08 / 219 / 159$ & $3.73 / 4.29$ & $16.26 / 14.08$ & $1 / 1$ & 16.15 & 13.86 & \\
\hline AGPRS051642.78-692557.2 & $08 / 245 / 068$ & $2.80 / 3.32$ & $17.42 / 15.30$ & $2 / 1$ & $\begin{array}{c}18.56 \\
(17.58) \\
\end{array}$ & 15.24 & \\
\hline
\end{tabular}




\begin{tabular}{|c|c|c|c|c|c|c|c|}
\hline $\begin{array}{l}\text { Name } \\
(1)\end{array}$ & $\begin{array}{c}\operatorname{chip} / X / Y \\
(2)\end{array}$ & $\begin{array}{c}\left.\frac{\phi_{\mathrm{c}}}{\phi_{0}}\right|_{B} /\left.\frac{\phi_{\mathrm{c}}}{\phi_{0}}\right|_{R} \\
(3)\end{array}$ & $\begin{array}{c}B_{\text {EROS }} / R_{\text {EROS }} \\
(4)\end{array}$ & $\begin{array}{c}N_{\mathrm{star}}^{B / R} \\
(5)\end{array}$ & $\begin{array}{c}B_{\mathrm{EROS}}^{\mathrm{DAO}} \\
(6)\end{array}$ & $\begin{array}{c}R_{\mathrm{EROS}}^{\mathrm{DAO}} \\
\quad(7)\end{array}$ & $\begin{array}{c}\text { Cross-identifications } \\
\text { (8) }\end{array}$ \\
\hline AGPRS051645.41-692925.5 & $00 / 297 / 493$ & $1.92 / 2.23$ & $17.13 / 14.71$ & $1 / 1$ & 17.40 & 14.52 & \\
\hline AGPRS051645.51-691953.2 & $08 / 178 / 365$ & $1.87 / 1.67$ & $17.88 / 15.09$ & $0 / 0$ & 18.02 & 15.07 & \\
\hline AGPRS051645.53-691558.4 & $08 / 127 / 555$ & $2.22 / 2.66$ & $17.89 / 15.63$ & $1 / 1$ & 18.11 & 15.72 & \\
\hline AGPRS051646.22-692754.8 & $00 / 281 / 567$ & $2.23 / 2.65$ & $16.79 / 14.78$ & $1 / 1$ & 17.06 & 14.71 & \\
\hline AGPRS051649.12-693454.3 & $00 / 383 / 232$ & $2.21 / 2.59$ & $17.72 / 15.83$ & $1 / 1$ & 17.58 & 15.38 & \\
\hline AGPRS051649.41-691817.2 & $08 / 174 / 447$ & $2.91 / 3.73$ & $17.17 / 15.35$ & $0 / 2$ & 18.80 & $\begin{array}{c}15.38 \\
(18.00)\end{array}$ & \\
\hline AGPRS051649.67-692952.5 & $00 / 321 / 476$ & $1.70 / 1.78$ & $13.83 / 13.86$ & $1 / 1$ & 14.76 & 14.64 & \\
\hline AGPRS051650.24-692534.0 & $08 / 272 / 095$ & $2.69 / 3.26$ & $17.52 / 15.30$ & $1 / 1$ & 17.68 & 15.34 & \\
\hline AGPRS051651.60-692630.5 & $08 / 290 / 051$ & $2.44 / 3.23$ & $17.02 / 15.07$ & $1 / 1$ & 17.65 & 15.20 & \\
\hline AGPRS051652.56-692352.0 & $08 / 260 / 180$ & $4.57 / 4.90$ & $14.38 / 12.62$ & $2 / 1$ & $\begin{array}{c}14.55 \\
(17.73)\end{array}$ & 12.65 & \\
\hline AGPRS051652.73-692837.4 & $00 / 318 / 540$ & $2.43 / 2.56$ & $17.06 / 15.27$ & $1 / 1$ & 16.95 & 14.98 & \\
\hline AGPRS051652.91-692403.6 & $08 / 264 / 171$ & $2.57 / 3.46$ & $16.68 / 14.96$ & $1 / 1$ & 17.22 & 15.12 & \\
\hline AGPRS051653.74-692908.6 & $00 / 329 / 516$ & $2.11 / 2.58$ & $19.01 / 15.71$ & $1 / 1$ & 18.93 & 15.25 & \\
\hline AGPRS051653.96-691855.6 & $08 / 202 / 421$ & $0.97 / 1.22$ & $16.04 / 15.88$ & $0 / 0$ & 17.53 & 19.67 & \\
\hline AGPRS051655.33-693807.1 & $01 / 034 / 083$ & $3.82 / 4.71$ & $16.84 / 14.75$ & $1 / 1$ & 16.91 & 14.74 & \\
\hline AGPRS051656.12-692159.2 & $08 / 251 / 275$ & $1.98 / 2.08$ & $19.46 / 18.21$ & $0 / 0$ & 19.00 & 18.40 & \\
\hline AGPRS051657.27-692840.0 & $00 / 338 / 543$ & $3.97 / 4.21$ & $15.91 / 14.20$ & $1 / 2$ & 16.06 & $\begin{array}{c}14.18 \\
(17.08)\end{array}$ & \\
\hline AGPRS051657.48-692428.5 & $08 / 289 / 156$ & $2.50 / 2.90$ & $17.45 / 15.58$ & $1 / 2$ & 17.75 & $\begin{array}{c}15.77 \\
(18.18)\end{array}$ & \\
\hline AGPRS051658.44-692633.7 & $08 / 320 / 056$ & $2.59 / 3.01$ & $17.42 / 15.51$ & $1 / 1$ & 17.67 & 15.61 & \\
\hline AGPRS051659.08-691855.3 & $08 / 224 / 427$ & $3.02 / 3.08$ & $13.97 / 13.30$ & $1 / 1$ & 14.15 & 13.36 & \\
\hline AGPRS051659.22-692048.0 & $08 / 249 / 336$ & $3.09 / 3.75$ & $17.16 / 15.04$ & $1 / 1$ & 17.35 & 15.08 & \\
\hline AGPRS051659.57-693821.7 & $01 / 055 / 076$ & $1.82 / 1.98$ & $21.43 / 18.77$ & $0 / 1$ & 19.93 & 19.42 & \\
\hline AGPRS051659.81-692711.6 & $08 / 334 / 027$ & $2.13 / 2.56$ & $17.23 / 15.24$ & $1 / 1$ & 17.63 & 15.34 & \\
\hline AGPRS051700.21-693706.9 & $01 / 042 / 137$ & $2.13 / 2.63$ & $18.29 / 15.62$ & $1 / 1$ & 18.29 & 15.59 & \\
\hline AGPRS051700.43-693523.1 & $01 / 021 / 221$ & $2.44 / 2.19$ & $18.57 / 18.38$ & $0 / 1$ & 17.52 & 20.00 & \\
\hline AGPRS051700.51-693656.2 & $01 / 041 / 146$ & $3.04 / 3.67$ & $17.44 / 15.13$ & $1 / 1$ & 17.70 & 15.30 & \\
\hline AGPRS051701.65-691813.1 & $08 / 226 / 464$ & $2.54 / 2.82$ & $17.61 / 15.62$ & $1 / 1$ & 17.81 & 15.70 & \\
\hline AGPRS051701.92-692601.3 & $08 / 328 / 086$ & $2.74 / 3.31$ & $17.38 / 15.51$ & $1 / 1$ & 17.65 & 15.59 & \\
\hline AGPRS051702.41-692725.1 & $08 / 348 / 019$ & $2.98 / 2.59$ & $16.33 / 16.11$ & $1 / 1$ & 16.20 & 15.74 & EROS 1031 \\
\hline AGPRS051702.48-693050.0 & $00 / 388 / 444$ & $2.80 / 2.04$ & $19.13 / 18.45$ & $0 / 0$ & 17.72 & 17.02 & \\
\hline AGPRS051703.30-692222.8 & $08 / 287 / 264$ & $2.50 / 3.29$ & $17.66 / 15.59$ & $1 / 1$ & 17.90 & 15.55 & \\
\hline AGPRS051704.01-691826.2 & $08 / 239 / 456$ & $2.02 / 1.53$ & $16.64 / 15.21$ & $1 / 1$ & 17.37 & 16.33 & \\
\hline AGPRS051704.48-692021.9 & $08 / 266 / 363$ & $2.47 / 3.49$ & $17.67 / 15.51$ & $1 / 1$ & 18.00 & 15.58 & \\
\hline AGPRS051705.00-693530.6 & $01 / 042 / 220$ & $2.89 / 3.94$ & $16.52 / 14.85$ & $2 / 1$ & $\begin{array}{c}17.63 \\
(16.86)\end{array}$ & 14.90 & \\
\hline AGPRS051705.62-691945.1 & $08 / 263 / 394$ & $2.94 / 3.77$ & $17.44 / 15.09$ & $2 / 1$ & $\begin{array}{c}19.05 \\
(17.98)\end{array}$ & 15.20 & \\
\hline AGPRS051706.16-693822.1 & $01 / 083 / 083$ & $3.34 / 4.84$ & $16.85 / 14.70$ & $2 / 1$ & $\begin{array}{c}17.02 \\
(18.53)\end{array}$ & 14.49 & \\
\hline AGPRS051709.34-692553.0 & 08/358/101 & $2.10 / 2.26$ & $18.04 / 15.80$ & $1 / 1$ & 18.71 & 15.81 & \\
\hline AGPRS051710.44-693520.8 & $01 / 063 / 234$ & $3.08 / 3.86$ & $17.24 / 15.05$ & $1 / 1$ & 17.44 & 15.14 & \\
\hline AGPRS051711.48-692552.2 & $08 / 367 / 104$ & $1.19 / 1.31$ & $15.84 / 15.62$ & $0 / 1$ & 15.96 & 18.24 & \\
\hline AGPRS051712.54-693201.5 & $01 / 030 / 397$ & $2.90 / 3.16$ & $16.48 / 14.97$ & $1 / 1$ & 16.88 & 15.22 & \\
\hline AGPRS051712.84-691706.8 & $08 / 260 / 530$ & $2.15 / 2.84$ & $18.11 / 15.42$ & $1 / 1$ & 18.38 & 15.39 & \\
\hline AGPRS051714.61-692243.3 & $08 / 340 / 260$ & $2.50 / 3.72$ & $17.36 / 14.92$ & $1 / 1$ & 17.77 & 15.02 & \\
\hline AGPRS051714.88-692104.6 & $08 / 320 / 340$ & $3.02 / 4.02$ & $17.44 / 15.11$ & $1 / 2$ & 17.81 & $\begin{array}{c}15.15 \\
(15.15)\end{array}$ & \\
\hline AGPRS051714.93-692044.9 & $08 / 316 / 356$ & $2.26 / 2.93$ & $16.48 / 15.07$ & $1 / 1$ & 16.80 & 15.18 & \\
\hline AGPRS051715.42-693349.7 & $01 / 065 / 313$ & $3.25 / 4.15$ & $17.02 / 15.21$ & $1 / 1$ & 17.29 & 15.26 & \\
\hline AGPRS051715.61-692544.3 & $08 / 383 / 115$ & $3.00 / 4.11$ & $17.56 / 15.79$ & $1 / 1$ & 17.96 & 15.73 & \\
\hline
\end{tabular}




\begin{tabular}{|c|c|c|c|c|c|c|c|}
\hline $\begin{array}{c}\text { Name } \\
(1)\end{array}$ & $\begin{array}{c}\operatorname{chip} / X / Y \\
(2)\end{array}$ & $\begin{array}{c}\left.\frac{\phi_{\mathrm{c}}}{\phi_{0}}\right|_{B} /\left.\frac{\phi_{\mathrm{c}}}{\phi_{0}}\right|_{R} \\
(3)\end{array}$ & $\begin{array}{c}B_{\text {EROS }} / R_{\text {EROS }} \\
(4)\end{array}$ & $\begin{array}{c}N_{\text {star }}^{B / R} \\
\quad(5)\end{array}$ & $\begin{array}{c}B_{\mathrm{EROS}}^{\mathrm{DAO}} \\
(6)\end{array}$ & $\begin{array}{c}R_{\text {EROS }}^{\mathrm{DAO}} \\
\quad(7)\end{array}$ & $\begin{array}{c}\text { Cross-identifications } \\
\text { (8) }\end{array}$ \\
\hline AGPRS051715.88-691743.1 & $08 / 281 / 504$ & $1.81 / 1.82$ & $15.06 / 14.64$ & $1 / 1$ & 15.21 & 14.70 & \\
\hline AGPRS051716.21-693741.4 & $01 / 117 / 127$ & $2.91 / 4.08$ & $17.82 / 15.46$ & $1 / 1$ & 17.76 & 15.25 & \\
\hline AGPRS051716.28-691835.6 & $08 / 294 / 462$ & $2.50 / 2.91$ & $16.90 / 15.10$ & $1 / 1$ & 17.18 & 15.29 & \\
\hline AGPRS051717.41-692055.7 & $08 / 329 / 350$ & $2.11 / 2.32$ & $17.51 / 16.62$ & $2 / 2$ & $\begin{array}{c}18.66 \\
(18.46)\end{array}$ & $\begin{array}{l}17.35 \\
(17.45)\end{array}$ & \\
\hline AGPRS051717.68-692136.9 & $08 / 339 / 317$ & $3.41 / 3.32$ & $15.03 / 14.72$ & $1 / 1$ & 14.93 & 14.65 & EROS ELHC4 \\
\hline AGPRS051717.69-693152.5 & $01 / 050 / 410$ & $3.87 / 4.52$ & $16.93 / 15.05$ & $1 / 1$ & 16.98 & 15.06 & \\
\hline AGPRS051718.14-691639.5 & $08 / 277 / 558$ & $3.16 / 3.05$ & $17.22 / 16.47$ & $2 / 1$ & $\begin{array}{c}17.26 \\
(19.92)\end{array}$ & 16.41 & \\
\hline AGPRS051719.63-692043.9 & $08 / 336 / 362$ & $1.57 / 1.68$ & $14.82 / 14.75$ & $1 / 1$ & 15.01 & 17.15 & \\
\hline AGPRS051720.37-692052.3 & $08 / 341 / 356$ & $2.20 / 3.08$ & $17.08 / 15.36$ & $1 / 1$ & 17.37 & 15.22 & \\
\hline AGPRS051720.78-692905.5 & $01 / 028 / 548$ & $2.33 / 4.43$ & $18.78 / 15.44$ & $1 / 1$ & 19.01 & 15.31 & \\
\hline AGPRS051721.76-693739.0 & $01 / 140 / 135$ & $2.88 / 3.31$ & $17.45 / 15.86$ & $0 / 0$ & 17.85 & 16.39 & \\
\hline AGPRS051721.79-691909.1 & $08 / 325 / 441$ & $2.29 / 2.39$ & $18.18 / 15.70$ & $1 / 1$ & 18.40 & 15.61 & \\
\hline AGPRS051721.85-692008.6 & $08 / 338 / 393$ & $2.70 / 2.36$ & $13.71 / 12.70$ & $1 / 1$ & 14.20 & 13.39 & \\
\hline AGPRS051723.52-692035.6 & $08 / 351 / 373$ & $2.57 / 2.55$ & $13.83 / 13.63$ & $1 / 1$ & 13.17 & 12.93 & \\
\hline AGPRS051723.55-693420.6 & $01 / 106 / 297$ & $1.22 / 1.38$ & $14.54 / 14.38$ & $0 / 0$ & 14.61 & 14.82 & \\
\hline AGPRS051724.50-692058.0 & $08 / 360 / 356$ & $4.07 / 4.07$ & $15.28 / 14.73$ & $1 / 1$ & 14.38 & 13.68 & $\begin{array}{l}\text { LMC V1910 } \\
\text { EROS } 2090\end{array}$ \\
\hline AGPRS051725.20-692020.6 & $08 / 355 / 387$ & $1.92 / 1.94$ & $14.82 / 14.11$ & $1 / 1$ & 15.28 & 14.23 & \\
\hline AGPRS051725.83-691729.6 & $08 / 321 / 526$ & $2.80 / 3.22$ & $16.68 / 14.91$ & $1 / 1$ & 16.92 & 15.02 & \\
\hline AGPRS051725.85-693708.7 & $01 / 151 / 164$ & $3.11 / 3.72$ & $16.90 / 15.08$ & $1 / 1$ & 17.36 & 15.34 & \\
\hline AGPRS051726.08-691757.1 & $08 / 328 / 504$ & $2.20 / 2.14$ & $16.60 / 16.50$ & $1 / 1$ & 17.47 & 17.32 & \\
\hline AGPRS051726.09-693251.1 & $01 / 098 / 372$ & $2.59 / 2.76$ & $17.38 / 15.33$ & $1 / 1$ & 17.45 & 15.43 & $\begin{array}{c}\text { LMC V1913 } \\
\text { SHV0517478-693554 }\end{array}$ \\
\hline AGPRS051726.16-69319.5 & $01 / 077 / 454$ & $2.14 / 2.27$ & $17.16 / 15.39$ & $2 / 2$ & $\begin{array}{c}17.50 \\
(19.58)\end{array}$ & $\begin{array}{c}17.21 \\
(15.63)\end{array}$ & \\
\hline AGPRS051726.51-693855.0 & $01 / 176 / 079$ & $2.67 / 2.87$ & $16.70 / 15.00$ & $1 / 2$ & 16.92 & $\begin{array}{l}15.08 \\
(15.08)\end{array}$ & \\
\hline AGPRS051726.76-691825.2 & $08 / 337 / 482$ & $1.95 / 1.96$ & $14.00 / 13.63$ & $1 / 1$ & 14.09 & 13.63 & \\
\hline AGPRS051729.32-693905.0 & 01/190/074 & $2.87 / 4.29$ & $17.78 / 15.01$ & $1 / 1$ & 17.39 & 14.56 & \\
\hline AGPRS051731.00-691910.6 & $08 / 365 / 450$ & $3.02 / 3.28$ & $16.25 / 13.91$ & $2 / 1$ & $\begin{array}{c}16.41 \\
(16.41)\end{array}$ & 13.94 & \\
\hline AGPRS051731.14-693949.6 & $01 / 207 / 040$ & $1.87 / 1.80$ & $18.10 / 17.48$ & $1 / 0$ & 18.98 & 16.92 & \\
\hline AGPRS051731.23-693145.0 & $01 / 106 / 431$ & $3.37 / 4.00$ & $17.01 / 14.95$ & $1 / 1$ & 17.21 & 15.08 & \\
\hline AGPRS051731.57-691721.3 & $08 / 344 / 539$ & $3.33 / 3.72$ & $16.76 / 15.12$ & $1 / 1$ & 16.73 & 14.97 & \\
\hline AGPRS051733.23-693420.2 & $01 / 147 / 308$ & $1.58 / 1.81$ & $18.32 / 17.24$ & $1 / 1$ & 19.97 & 17.79 & \\
\hline AGPRS051734.11-691932.2 & $08 / 383 / 436$ & $2.94 / 2.82$ & $17.02 / 14.99$ & $1 / 2$ & 16.54 & $\begin{array}{l}15.06 \\
(16.09)\end{array}$ & \\
\hline AGPRS051734.11-693348.0 & $01 / 144 / 335$ & $1.05 / 3.00$ & $16.33 / 15.02$ & $0 / 2$ & 16.10 & $\begin{array}{l}15.49 \\
(15.49)\end{array}$ & \\
\hline AGPRS051734.95-693554.3 & $01 / 174 / 234$ & $3.33 / 4.21$ & $16.82 / 15.12$ & $0 / 2$ & 18.86 & $\begin{array}{c}15.39 \\
(17.25)\end{array}$ & \\
\hline AGPRS051736.70-693830.5 & $01 / 214 / 110$ & $2.15 / 2.35$ & $17.34 / 15.19$ & $1 / 1$ & 17.32 & 15.06 & \\
\hline AGPRS051736.78-692952.3 & $01 / 106 / 528$ & $0.93 / 1.20$ & $16.38 / 16.20$ & $0 / 0$ & 20.48 & 16.25 & \\
\hline AGPRS051740.61-693623.1 & $01 / 204 / 217$ & $3.01 / 3.55$ & $16.81 / 14.90$ & $1 / 2$ & 17.07 & $\begin{array}{c}15.01 \\
(17.77)\end{array}$ & \\
\hline AGPRS051741.44-693406.6 & $01 / 179 / 328$ & $2.10 / 2.13$ & $14.41 / 14.18$ & $1 / 2$ & 14.77 & $\begin{array}{c}17.32 \\
(14.46)\end{array}$ & \\
\hline AGPRS051741.44-692938.8 & $01 / 123 / 544$ & $2.45 / 3.31$ & $17.78 / 15.83$ & $1 / 2$ & 18.29 & $\begin{array}{c}16.17 \\
(17.93)\end{array}$ & \\
\hline AGPRS051744.54-693400.9 & $01 / 191 / 336$ & $2.37 / 2.60$ & $14.91 / 14.05$ & $1 / 1$ & 15.36 & 14.22 & \\
\hline AGPRS051745.63-693300.4 & $01 / 183 / 386$ & $2.89 / 3.88$ & $17.56 / 15.33$ & $2 / 1$ & $\begin{array}{c}17.95 \\
(19.06) \\
\end{array}$ & 15.42 & \\
\hline
\end{tabular}




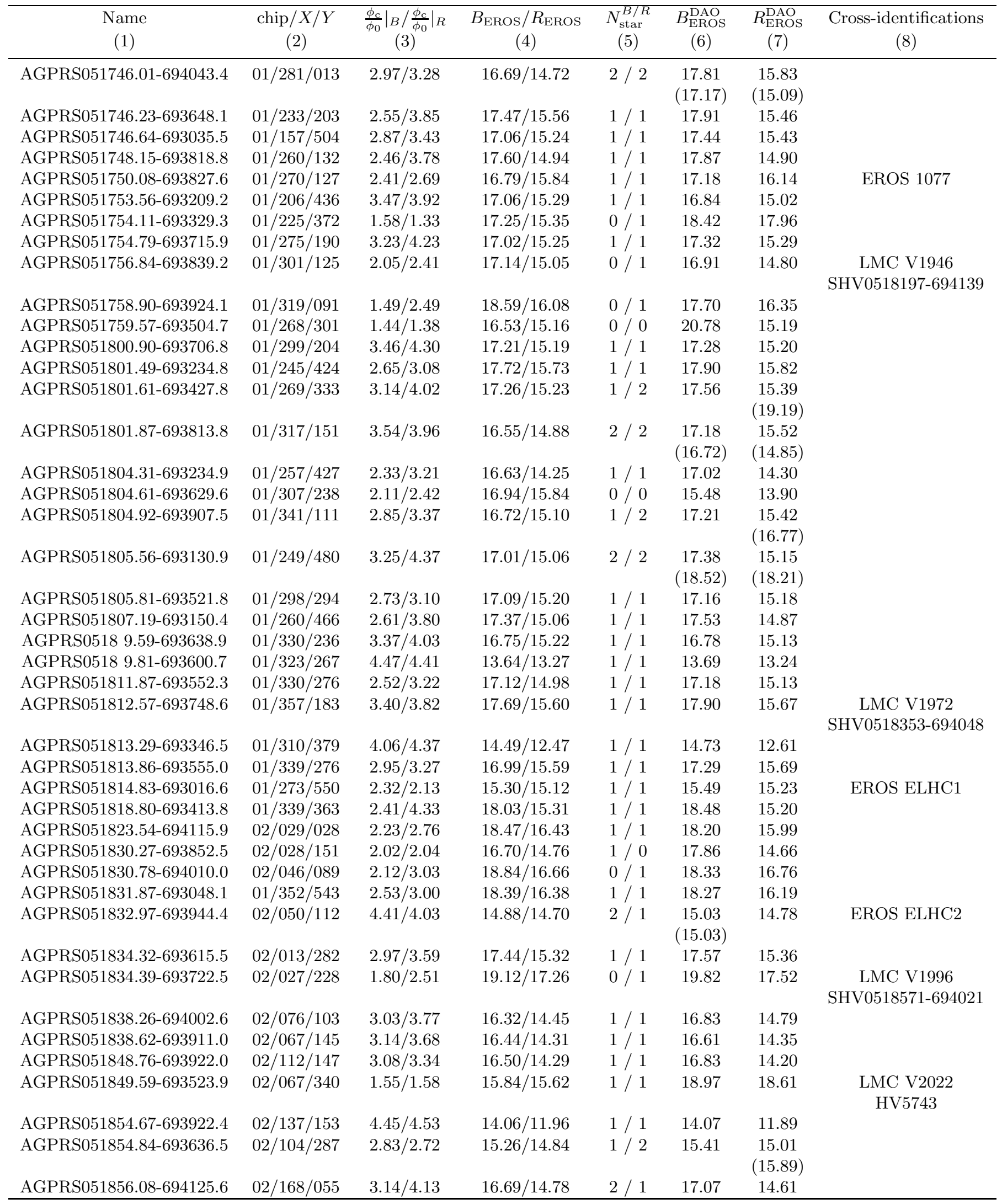




\begin{tabular}{|c|c|c|c|c|c|c|c|}
\hline $\begin{array}{c}\text { Name } \\
(1)\end{array}$ & $\begin{array}{c}\operatorname{chip} / X / Y \\
(2)\end{array}$ & $\begin{array}{c}\left.\frac{\phi_{\mathrm{c}}}{\phi_{0}}\right|_{B} /\left.\frac{\phi_{\mathrm{c}}}{\phi_{0}}\right|_{R} \\
(3)\end{array}$ & $\begin{array}{c}B_{\text {EROS }} / R_{\text {EROS }} \\
\text { (4) }\end{array}$ & $\begin{array}{c}N_{\mathrm{star}}^{B / R} \\
(5)\end{array}$ & $\begin{array}{c}B_{\mathrm{EROS}}^{\mathrm{DAO}} \\
(6)\end{array}$ & $\begin{array}{c}R_{\mathrm{EROS}}^{\mathrm{DAO}} \\
\quad(7)\end{array}$ & $\begin{array}{c}\text { Cross-identifications } \\
(8)\end{array}$ \\
\hline & & & & & $(18.00)$ & & \\
\hline AGPRS051856.52-693843.9 & $02 / 137 / 186$ & $2.46 / 3.38$ & $17.68 / 15.02$ & $1 / 1$ & 17.93 & 14.91 & \\
\hline AGPRS051900.02-69399.6 & $02 / 157 / 169$ & $2.41 / 2.42$ & $17.28 / 15.39$ & $2 / 1$ & $\begin{array}{l}17.79 \\
(18.21)\end{array}$ & 15.48 & \\
\hline AGPRS051900.42-692929.7 & $10 / 042 / 047$ & $3.27 / 4.13$ & $16.95 / 14.98$ & $1 / 1$ & 17.09 & 14.96 & \\
\hline AGPRS051901.46-693651.5 & $02 / 135 / 282$ & $3.09 / 3.94$ & $17.27 / 15.47$ & $2 / 2$ & $\begin{array}{l}17.86 \\
(18.78)\end{array}$ & $\begin{array}{l}15.58 \\
(17.24)\end{array}$ & \\
\hline AGPRS051902.35-692948.4 & $10 / 054 / 034$ & $2.18 / 3.23$ & $17.73 / 15.45$ & $1 / 1$ & 18.22 & 15.53 & \\
\hline AGPRS051902.71-693506.6 & $02 / 119 / 368$ & $2.83 / 3.62$ & $17.70 / 16.01$ & $1 / 1$ & 17.88 & 16.06 & \\
\hline AGPRS051903.30-693632.8 & 02/139/299 & $2.60 / 3.12$ & $17.69 / 16.01$ & $1 / 2$ & 17.28 & $\begin{array}{c}15.20 \\
(17.83)\end{array}$ & \\
\hline AGPRS051903.69-693614.8 & $02 / 137 / 314$ & $1.92 / 2.01$ & $17.69 / 16.19$ & $1 / 1$ & 18.27 & 17.75 & \\
\hline AGPRS051903.95-692831.1 & $10 / 045 / 098$ & $2.11 / 3.10$ & $17.01 / 15.57$ & $0 / 1$ & 16.85 & 15.92 & \\
\hline AGPRS051904.02-692933.2 & $10 / 058 / 048$ & $3.02 / 3.81$ & $17.58 / 15.68$ & $1 / 1$ & 17.57 & 15.49 & \\
\hline AGPRS051905.29-692625.3 & $10 / 025 / 201$ & $2.22 / 2.88$ & $17.50 / 14.93$ & $2 / 1$ & $\begin{array}{c}19.37 \\
(17.92)\end{array}$ & 15.05 & \\
\hline AGPRS051905.31-692733.4 & $10 / 039 / 146$ & $1.76 / 1.53$ & $17.86 / 15.90$ & $0 / 0$ & 18.09 & 15.93 & \\
\hline AGPRS051906.03-693318.1 & $02 / 111 / 459$ & $2.96 / 3.53$ & $17.30 / 15.12$ & $1 / 1$ & 17.31 & 15.09 & \\
\hline AGPRS051906.68-693413.5 & $02 / 125 / 415$ & $2.48 / 3.47$ & $18.37 / 15.06$ & $1 / 1$ & 18.64 & 15.14 & \\
\hline AGPRS051908.48-693623.6 & $02 / 159 / 312$ & $3.12 / 4.10$ & $17.16 / 15.13$ & $1 / 1$ & 17.35 & 15.18 & \\
\hline AGPRS051908.77-693216.1 & $02 / 110 / 512$ & $2.45 / 2.50$ & $16.42 / 14.95$ & $2 / 2$ & $\begin{array}{c}16.74 \\
(17.36)\end{array}$ & $\begin{array}{c}16.93 \\
(15.01)\end{array}$ & \\
\hline AGPRS051909.41-692400.8 & $10 / 013 / 322$ & $2.30 / 2.64$ & $17.35 / 15.25$ & $1 / 1$ & 17.55 & 15.38 & \\
\hline AGPRS051910.00-692605.5 & $10 / 041 / 222$ & $2.91 / 3.29$ & $16.88 / 15.35$ & $1 / 1$ & 16.85 & 15.19 & \\
\hline AGPRS051910.63-693345.3 & $02 / 136 / 442$ & $2.35 / 3.89$ & $17.85 / 14.84$ & $1 / 1$ & 18.27 & 14.95 & \\
\hline AGPRS051911.93-692604.3 & $10 / 049 / 225$ & $2.10 / 2.55$ & $18.45 / 15.65$ & $1 / 1$ & 18.72 & 15.72 & \\
\hline AGPRS051911.98-692430.2 & $10 / 030 / 301$ & $2.43 / 2.58$ & $16.81 / 14.90$ & $2 / 2$ & $\begin{array}{c}18.83 \\
(16.96)\end{array}$ & $\begin{array}{c}18.06 \\
(14.91)\end{array}$ & \\
\hline AGPRS051912.05-693201.8 & $02 / 121 / 527$ & $2.43 / 2.86$ & $17.70 / 15.70$ & $2 / 1$ & $\begin{array}{c}18.44 \\
(18.33)\end{array}$ & 15.84 & \\
\hline AGPRS051913.00-692354.4 & $10 / 027 / 331$ & $4.24 / 5.23$ & $16.57 / 14.61$ & $1 / 1$ & 16.22 & 14.20 & \\
\hline AGPRS051913.22-693539.0 & $02 / 170 / 353$ & $2.82 / 3.50$ & $17.23 / 15.35$ & $1 / 1$ & 17.63 & 15.43 & \\
\hline AGPRS051914.66-693618.1 & $02 / 184 / 323$ & $5.14 / 5.23$ & $15.39 / 14.38$ & $1 / 1$ & 14.97 & 13.88 & $\begin{array}{l}\text { LMC V2047 } \\
\text { EROS } 2093\end{array}$ \\
\hline AGPRS051915.26-693203.5 & $02 / 135 / 529$ & $2.26 / 2.20$ & $17.62 / 16.10$ & $1 / 1$ & 17.92 & 16.08 & \\
\hline AGPRS051915.43-693716.1 & $02 / 199 / 277$ & $2.20 / 2.76$ & $17.90 / 15.86$ & $1 / 1$ & 18.14 & 16.07 & \\
\hline AGPRS051915.69-694013.6 & $02 / 236 / 134$ & $2.29 / 2.57$ & $17.35 / 15.39$ & $1 / 1$ & 17.46 & 15.30 & \\
\hline AGPRS051916.62-692831.8 & $10 / 099 / 111$ & $2.42 / 3.85$ & $17.50 / 15.40$ & $0 / 1$ & 19.23 & 15.45 & \\
\hline AGPRS051917.00-692107.5 & $10 / 010 / 470$ & $1.97 / 2.56$ & $18.46 / 15.03$ & $2 / 2$ & $\begin{array}{c}19.14 \\
(19.55)\end{array}$ & $\begin{array}{c}15.23 \\
(15.23)\end{array}$ & \\
\hline AGPRS051919.26-694112.8 & 02/263/090 & $3.96 / 4.75$ & $16.39 / 14.72$ & $1 / 1$ & 16.14 & 14.35 & $\begin{array}{c}\text { LMC V2059 } \\
\text { SHV0519429-694409 }\end{array}$ \\
\hline AGPRS051919.29-693013.2 & $10 / 131 / 032$ & $2.48 / 3.43$ & $17.88 / 14.73$ & $1 / 1$ & 18.26 & 14.86 & \\
\hline AGPRS051919.33-693728.6 & $02 / 218 / 271$ & $2.35 / 3.21$ & $18.68 / 16.30$ & $1 / 1$ & 18.59 & 16.29 & \\
\hline AGPRS051919.39-692818.1 & $10 / 108 / 125$ & $3.32 / 4.24$ & $17.22 / 15.16$ & $1 / 2$ & 17.36 & $\begin{array}{c}15.25 \\
(18.28)\end{array}$ & \\
\hline AGPRS051919.94-692213.3 & $10 / 036 / 420$ & $2.43 / 3.19$ & $17.84 / 14.91$ & $1 / 1$ & 17.95 & 14.90 & \\
\hline AGPRS051919.99-694102.6 & $02 / 264 / 099$ & $2.29 / 2.75$ & $18.17 / 16.42$ & $2 / 0$ & $\begin{array}{c}18.63 \\
(19.62)\end{array}$ & 17.82 & \\
\hline AGPRS051919.99-694132.3 & $02 / 270 / 075$ & $2.69 / 3.68$ & $17.50 / 15.09$ & $1 / 1$ & 17.83 & 15.20 & \\
\hline AGPRS051920.12-693443.6 & $02 / 188 / 405$ & $2.44 / 3.45$ & $17.74 / 15.42$ & $1 / 1$ & 18.32 & 15.56 & $\begin{array}{c}\text { LMC V2057 } \\
\text { SHV0519425-693739 }\end{array}$ \\
\hline AGPRS051921.56-693622.2 & $02 / 214 / 327$ & $2.70 / 3.04$ & $16.80 / 14.46$ & $1 / 1$ & 16.80 & 14.30 & \\
\hline AGPRS051921.68-692250.3 & $10 / 051 / 392$ & $2.11 / 3.36$ & $18.11 / 15.91$ & $2 / 1$ & 19.33 & 16.17 & \\
\hline
\end{tabular}




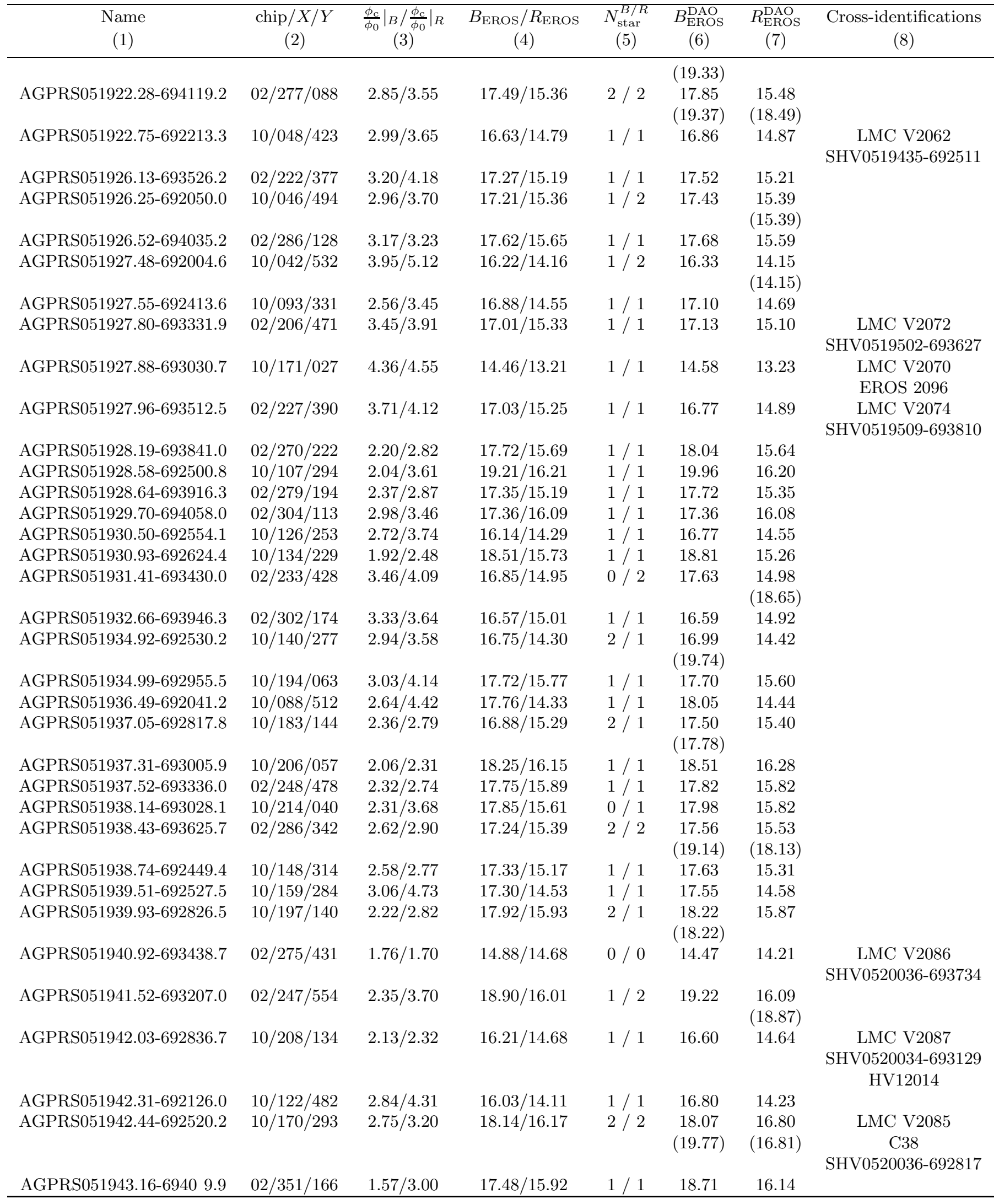




\begin{tabular}{|c|c|c|c|c|c|c|c|}
\hline $\begin{array}{l}\text { Name } \\
(1)\end{array}$ & $\begin{array}{c}\operatorname{chip} / X / Y \\
(2)\end{array}$ & $\begin{array}{c}\left.\frac{\phi_{\mathrm{c}}}{\phi_{0}}\right|_{B} /\left.\frac{\phi_{\mathrm{c}}}{\phi_{0}}\right|_{R} \\
(3)\end{array}$ & $\begin{array}{c}B_{\text {EROS }} / R_{\text {EROS }} \\
(4)\end{array}$ & $\begin{array}{c}N_{\text {star }}^{B / R} \\
\quad(5)\end{array}$ & $\begin{array}{c}B_{\mathrm{EROS}}^{\mathrm{DAO}} \\
(6)\end{array}$ & $\begin{array}{c}R_{\mathrm{EROS}}^{\mathrm{DAO}} \\
\quad(7)\end{array}$ & $\begin{array}{c}\text { Cross-identifications } \\
\text { (8) }\end{array}$ \\
\hline AGPRS051943.74-693004.5 & $10 / 233 / 065$ & $2.56 / 3.15$ & $17.36 / 15.54$ & $1 / 1$ & 17.62 & 15.67 & \\
\hline AGPRS051944.09-692009.1 & $10 / 114 / 546$ & $3.02 / 4.18$ & $17.13 / 15.05$ & $1 / 1$ & 17.37 & 15.14 & \\
\hline AGPRS051944.24-693053.5 & $10 / 245 / 026$ & $2.13 / 2.66$ & $17.75 / 14.80$ & $1 / 1$ & 18.03 & 14.87 & \\
\hline AGPRS051944.31-692614.7 & $10 / 189 / 251$ & $3.91 / 3.81$ & $15.24 / 14.89$ & $1 / 1$ & 15.39 & 14.98 & \\
\hline AGPRS051944.66-692339.1 & $10 / 159 / 377$ & $3.28 / 4.06$ & $16.89 / 15.30$ & $1 / 1$ & 17.08 & 15.36 & \\
\hline AGPRS051944.91-692959.8 & $10 / 237 / 070$ & $2.79 / 3.96$ & $17.26 / 15.28$ & $1 / 1$ & 17.78 & 15.38 & \\
\hline AGPRS051944.99-693926.5 & $02 / 350 / 203$ & $2.74 / 4.04$ & $16.60 / 14.11$ & $2 / 1$ & $\begin{array}{c}17.56 \\
(17.95)\end{array}$ & 14.18 & \\
\hline AGPRS051945.63-692825.3 & $10 / 221 / 147$ & $2.27 / 2.32$ & $17.50 / 15.15$ & $2 / 1$ & $\begin{array}{c}19.72 \\
(17.63)\end{array}$ & 14.97 & \\
\hline AGPRS051946.85-694046.9 & $02 / 374 / 140$ & $2.71 / 3.40$ & $17.67 / 15.62$ & $2 / 1$ & $\begin{array}{c}18.21 \\
(19.30)\end{array}$ & 15.72 & \\
\hline AGPRS051948.88-693455.3 & $02 / 312 / 426$ & $2.78 / 3.22$ & $17.26 / 14.93$ & $1 / 1$ & 18.02 & 14.98 & \\
\hline AGPRS051949.57-693630.3 & $02 / 334 / 350$ & $2.50 / 2.93$ & $16.99 / 15.07$ & $1 / 1$ & 17.40 & 15.16 & \\
\hline AGPRS051950.06-692925.6 & $10 / 252 / 103$ & $2.99 / 4.21$ & $17.19 / 15.03$ & $1 / 1$ & 17.36 & 15.03 & \\
\hline AGPRS051951.31-693334.2 & $02 / 306 / 494$ & $2.81 / 3.13$ & $17.18 / 15.35$ & $1 / 1$ & 17.28 & 15.28 & \\
\hline AGPRS051951.60-692519.9 & $10 / 209 / 303$ & $2.72 / 3.80$ & $16.93 / 14.95$ & $1 / 1$ & 17.32 & 15.08 & \\
\hline AGPRS051952.11-692802.8 & $10 / 244 / 172$ & $2.37 / 3.33$ & $17.74 / 15.96$ & $1 / 1$ & 19.26 & 15.92 & \\
\hline AGPRS051952.11-692902.3 & $10 / 256 / 124$ & $3.47 / 4.45$ & $16.99 / 15.00$ & $1 / 1$ & 17.11 & 15.03 & \\
\hline AGPRS051952.27-692441.1 & $10 / 204 / 335$ & $2.77 / 2.63$ & $16.98 / 15.64$ & $1 / 2$ & 17.12 & $\begin{array}{l}18.20 \\
(15.72)\end{array}$ & \\
\hline AGPRS051952.82-692240.5 & $10 / 182 / 433$ & $2.89 / 3.93$ & $16.97 / 15.19$ & $2 / 3$ & $\begin{array}{c}17.51 \\
(18.11)\end{array}$ & $\begin{array}{l}15.46 \\
(15.46)\end{array}$ & \\
\hline AGPRS051953.29-693841.5 & $02 / 376 / 248$ & $3.04 / 4.06$ & $17.45 / 15.19$ & $1 / 1$ & 16.73 & 15.08 & \\
\hline AGPRS051953.49-692713.8 & $10 / 240 / 213$ & $2.88 / 4.39$ & $16.60 / 14.85$ & $1 / 1$ & 17.05 & 14.89 & \\
\hline AGPRS051953.82-692254.1 & $10 / 189 / 423$ & $2.63 / 3.60$ & $16.13 / 14.95$ & $1 / 1$ & 16.34 & 15.07 & $\begin{array}{c}\text { LMC V2101 } \\
\text { SHV0520148-692549 }\end{array}$ \\
\hline AGPRS051953.93-692804.0 & $10 / 252 / 173$ & $2.12 / 2.74$ & $21.18 / 16.55$ & $0 / 1$ & 18.93 & 16.28 & $\begin{array}{c}\text { LMC V2103 } \\
\text { SHV0520158-693059 }\end{array}$ \\
\hline AGPRS051954.31-692218.9 & $10 / 184 / 452$ & $2.84 / 4.34$ & $17.45 / 14.25$ & $2 / 1$ & $\begin{array}{c}17.65 \\
(19.86)\end{array}$ & 14.31 & \\
\hline AGPRS051954.58-693250.1 & $02 / 311 / 533$ & $2.88 / 3.27$ & $17.39 / 15.27$ & $1 / 1$ & 17.45 & 15.27 & \\
\hline AGPRS051954.78-693525.3 & $02 / 343 / 408$ & $2.70 / 3.56$ & $17.40 / 15.24$ & $1 / 1$ & 17.65 & 15.31 & \\
\hline AGPRS051955.69-692333.7 & $10 / 205 / 393$ & $2.48 / 2.83$ & $16.83 / 14.45$ & $1 / 1$ & 17.07 & 14.54 & \\
\hline AGPRS051956.01-693539.3 & $02 / 351 / 398$ & $3.48 / 5.01$ & $17.22 / 14.50$ & $2 / 1$ & $\begin{array}{c}17.28 \\
(19.72)\end{array}$ & 14.35 & $\begin{array}{c}\text { LMC V2109 } \\
\text { SHV0520188-693833 }\end{array}$ \\
\hline AGPRS051956.30-692455.0 & $10 / 224 / 328$ & $2.34 / 2.23$ & $17.26 / 14.89$ & $1 / 1$ & 17.30 & 14.75 & \\
\hline AGPRS051956.34-693507.5 & $02 / 346 / 424$ & $1.90 / 2.58$ & $16.57 / 14.97$ & $1 / 1$ & 16.66 & 14.84 & \\
\hline AGPRS051956.39-694207.6 & $03 / 013 / 085$ & $3.40 / 4.37$ & $16.65 / 15.01$ & $1 / 1$ & 16.74 & 14.99 & \\
\hline AGPRS051956.61-693446.8 & $02 / 343 / 441$ & $3.40 / 4.11$ & $16.83 / 14.83$ & $1 / 1$ & 17.03 & 14.89 & \\
\hline AGPRS051957.12-692303.4 & $10 / 205 / 419$ & $3.06 / 4.20$ & $17.46 / 15.75$ & $1 / 1$ & 17.65 & 15.60 & \\
\hline AGPRS051957.18-692351.8 & $10 / 215 / 380$ & $1.96 / 2.94$ & $17.48 / 16.16$ & $1 / 0$ & 18.62 & 19.04 & \\
\hline AGPRS051957.24-692514.8 & $10 / 232 / 313$ & $1.97 / 2.17$ & $17.76 / 16.78$ & $1 / 1$ & 18.04 & 16.78 & EROS 1079 \\
\hline AGPRS051957.31-693337.0 & $02 / 332 / 498$ & $2.62 / 3.46$ & $17.00 / 14.39$ & $1 / 1$ & 17.27 & 14.46 & \\
\hline AGPRS051958.64-693318.9 & $02 / 334 / 514$ & $2.61 / 2.82$ & $16.90 / 15.05$ & $1 / 1$ & 16.86 & 14.77 & \\
\hline AGPRS052000.34-694054.7 & $03 / 015 / 148$ & $2.57 / 3.79$ & $18.20 / 15.54$ & $1 / 1$ & 18.34 & 15.37 & \\
\hline AGPRS052001.27-692424.4 & $10 / 239 / 358$ & $2.54 / 3.02$ & $17.71 / 15.84$ & $1 / 2$ & 18.05 & $\begin{array}{l}15.94 \\
(19.09)\end{array}$ & \\
\hline AGPRS052001.49-693413.5 & $02 / 357 / 473$ & $1.74 / 1.76$ & $18.89 / 18.11$ & $1 / 1$ & 20.02 & 19.48 & \\
\hline AGPRS052001.86-692237.4 & $10 / 220 / 445$ & $2.51 / 2.82$ & $17.14 / 15.09$ & $1 / 1$ & 17.33 & 15.15 & \\
\hline AGPRS052001.91-694321.6 & $03 / 051 / 031$ & $2.06 / 3.00$ & $17.15 / 15.26$ & $2 / 2$ & $\begin{array}{c}17.83 \\
(18.97)\end{array}$ & $\begin{array}{l}15.28 \\
(19.27)\end{array}$ & \\
\hline AGPRS052001.93-693404.1 & $02 / 357 / 481$ & $1.25 / 1.50$ & $17.60 / 17.49$ & $0 / 0$ & 17.60 & 17.34 & \\
\hline AGPRS052002.46-692045.5 & $10 / 200 / 536$ & $3.40 / 4.42$ & $17.08 / 14.78$ & $1 / 1$ & 17.20 & 14.84 & \\
\hline
\end{tabular}




\begin{tabular}{|c|c|c|c|c|c|c|c|}
\hline $\begin{array}{l}\text { Name } \\
(1)\end{array}$ & $\begin{array}{c}\operatorname{chip} / X / Y \\
(2)\end{array}$ & $\begin{array}{c}\left.\frac{\phi_{\mathrm{c}}}{\phi_{0}}\right|_{B} /\left.\frac{\phi_{\mathrm{c}}}{\phi_{0}}\right|_{R} \\
(3)\end{array}$ & $\begin{array}{c}B_{\text {EROS }} / R_{\text {EROS }} \\
(4)\end{array}$ & $\begin{array}{c}N_{\mathrm{star}}^{B / R} \\
(5)\end{array}$ & $\begin{array}{c}B_{\mathrm{EROS}}^{\mathrm{DAO}} \\
(6)\end{array}$ & $\begin{array}{c}R_{\mathrm{EROS}}^{\mathrm{DAO}} \\
\quad(7)\end{array}$ & $\begin{array}{c}\text { Cross-identifications } \\
\text { (8) }\end{array}$ \\
\hline AGPRS052003.13-692101.3 & $10 / 206 / 524$ & $2.49 / 2.52$ & $17.04 / 15.16$ & $2 / 1$ & $\begin{array}{l}18.17 \\
(17.54)\end{array}$ & 15.13 & \\
\hline AGPRS052003.83-693916.4 & $03 / 010 / 231$ & $2.13 / 2.08$ & $17.33 / 15.20$ & $1 / 1$ & 17.19 & 14.99 & \\
\hline AGPRS052003.86-692917.6 & $10 / 309 / 124$ & $2.20 / 2.60$ & $17.06 / 14.29$ & $1 / 1$ & 17.28 & 14.35 & $\begin{array}{c}\text { LMC V2117 } \\
\text { SHV0520254-693210 }\end{array}$ \\
\hline AGPRS052004.07-692205.6 & $10 / 223 / 473$ & $2.87 / 3.20$ & $16.79 / 15.04$ & $1 / 2$ & 16.99 & $\begin{array}{c}17.87 \\
(15.22)\end{array}$ & \\
\hline AGPRS052005.91-694342.9 & 03/072/018 & $1.85 / 1.52$ & $17.34 / 15.20$ & $1 / 1$ & 17.44 & 15.19 & \\
\hline AGPRS052006.71-694235.8 & $03 / 062 / 073$ & $3.35 / 4.12$ & $17.11 / 15.34$ & $1 / 1$ & 17.27 & 15.35 & \\
\hline AGPRS052007.68-694110.4 & $03 / 049 / 143$ & $2.96 / 3.48$ & $16.84 / 14.81$ & $1 / 1$ & 17.12 & 14.96 & \\
\hline AGPRS052009.17-692515.5 & $10 / 283 / 325$ & $2.28 / 2.73$ & $17.29 / 14.99$ & $1 / 1$ & 17.16 & 14.82 & \\
\hline AGPRS0520 9.99-694132.0 & $03 / 063 / 128$ & $1.77 / 2.56$ & $17.84 / 15.79$ & $1 / 1$ & 18.61 & 15.68 & \\
\hline AGPRS052011.04-694250.1 & 03/083/066 & $2.78 / 3.67$ & $16.61 / 15.61$ & $1 / 1$ & 16.60 & 15.26 & \\
\hline AGPRS052011.97-694030.1 & $03 / 059 / 180$ & $2.00 / 3.63$ & $18.73 / 15.70$ & $1 / 1$ & 19.85 & 15.58 & $\begin{array}{c}\text { LMC V2129 } \\
\text { SHV0520355-694322 }\end{array}$ \\
\hline AGPRS052013.14-694346.0 & 03/103/023 & $3.60 / 4.45$ & $16.95 / 14.91$ & $1 / 1$ & 16.93 & 14.78 & \\
\hline AGPRS052015.12-692024.9 & $10 / 250 / 566$ & $3.58 / 4.67$ & $16.63 / 14.23$ & $1 / 2$ & 16.50 & $\begin{array}{l}14.06 \\
(14.06)\end{array}$ & \\
\hline AGPRS052015.91-693611.4 & $03 / 024 / 393$ & $2.44 / 3.11$ & $16.89 / 15.32$ & $1 / 1$ & 17.06 & 15.39 & \\
\hline AGPRS052016.95-692919.8 & $10 / 365 / 136$ & $2.28 / 2.37$ & $17.57 / 15.80$ & $1 / 1$ & 17.78 & 15.78 & \\
\hline AGPRS052017.83-694137.1 & 03/097/132 & $3.60 / 3.72$ & $16.29 / 15.10$ & $2 / 1$ & $\begin{array}{l}16.50 \\
(16.50)\end{array}$ & 15.21 & \\
\hline AGPRS052018.35-693850.6 & $03 / 066 / 267$ & $3.07 / 3.28$ & $16.79 / 15.04$ & $2 / 1$ & $\begin{array}{l}17.16 \\
(17.17)\end{array}$ & 15.08 & \\
\hline AGPRS052019.13-692253.7 & $10 / 297 / 450$ & $1.84 / 2.26$ & $18.36 / 15.78$ & $0 / 1$ & 18.54 & 16.03 & \\
\hline AGPRS052019.49-692655.7 & $10 / 347 / 255$ & $2.58 / 2.94$ & $17.28 / 15.48$ & $1 / 1$ & 17.43 & 15.46 & \\
\hline AGPRS052019.51-693530.2 & $03 / 031 / 430$ & $2.19 / 2.40$ & $18.90 / 16.54$ & $1 / 1$ & 19.65 & 16.56 & $\begin{array}{c}\text { LMC V2140 } \\
\text { SHV0520422-693821 }\end{array}$ \\
\hline AGPRS052019.73-694257.5 & 03/121/069 & $2.62 / 3.15$ & $17.99 / 15.22$ & $1 / 1$ & 17.95 & 14.87 & $\begin{array}{c}\text { LMC V2144 } \\
\text { SHV0520437-694548 }\end{array}$ \\
\hline AGPRS052020.18-693345.7 & $03 / 013 / 515$ & $2.78 / 3.51$ & $17.34 / 14.81$ & $1 / 1$ & 17.47 & 14.67 & $\begin{array}{c}\text { LMC V2142 } \\
\text { SHV0520427-693637 }\end{array}$ \\
\hline AGPRS052021.01-694406.0 & $03 / 140 / 015$ & $1.92 / 1.64$ & $17.86 / 15.87$ & $0 / 0$ & 17.09 & 14.92 & \\
\hline AGPRS052021.21-69369.5 & $03 / 046 / 400$ & $2.76 / 3.53$ & $17.69 / 15.18$ & $1 / 1$ & 17.95 & 15.28 & \\
\hline AGPRS052021.64-694011.6 & $03 / 096 / 205$ & $3.00 / 3.52$ & $16.98 / 14.66$ & $1 / 1$ & 17.17 & 14.65 & \\
\hline AGPRS052023.41-693517.9 & $03 / 045 / 444$ & $2.31 / 2.69$ & $16.98 / 15.24$ & $1 / 1$ & 17.29 & 15.39 & \\
\hline AGPRS052024.38-693728.0 & $03 / 075 / 340$ & $2.14 / 2.81$ & $16.96 / 15.03$ & $1 / 1$ & 17.48 & 15.17 & \\
\hline AGPRS052025.63-693505.9 & $03 / 052 / 456$ & $1.84 / 2.48$ & $16.82 / 15.09$ & $1 / 1$ & 17.88 & 15.48 & \\
\hline AGPRS052026.04-693828.3 & $03 / 094 / 293$ & $2.76 / 3.40$ & $16.94 / 14.34$ & $1 / 1$ & 17.19 & 14.45 & \\
\hline AGPRS052027.37-693805.2 & $03 / 095 / 313$ & $2.50 / 3.28$ & $17.56 / 15.66$ & $1 / 1$ & 17.68 & 15.52 & \\
\hline AGPRS052027.53-692524.5 & $10 / 363 / 337$ & $1.96 / 2.08$ & $18.65 / 17.56$ & $1 / 1$ & 19.64 & 18.20 & \\
\hline AGPRS052027.83-693539.7 & $03 / 068 / 431$ & $2.25 / 2.04$ & $15.22 / 15.13$ & $2 / 2$ & $\begin{array}{c}15.40 \\
(19.23)\end{array}$ & $\begin{array}{c}18.06 \\
(15.22)\end{array}$ & \\
\hline AGPRS052028.15-693643.3 & $03 / 082 / 380$ & $3.05 / 4.13$ & $17.49 / 15.12$ & $1 / 1$ & 17.64 & 15.18 & \\
\hline AGPRS052028.27-692423.6 & $10 / 354 / 387$ & $2.28 / 3.15$ & $18.41 / 15.68$ & $1 / 1$ & 18.71 & 15.77 & $\begin{array}{c}\text { LMC V2154 } \\
\text { SHV0520498-692715 }\end{array}$ \\
\hline AGPRS052029.16-693531.5 & $03 / 072 / 439$ & $2.57 / 3.13$ & $17.75 / 15.70$ & $1 / 1$ & 17.92 & 15.60 & \\
\hline AGPRS052030.16-694253.6 & $03 / 164 / 083$ & $3.18 / 3.62$ & $16.92 / 14.80$ & $1 / 1$ & 17.02 & 14.83 & \\
\hline AGPRS052030.93-693905.5 & $03 / 122 / 268$ & $1.94 / 2.42$ & $17.48 / 15.60$ & $1 / 1$ & 18.01 & 15.95 & \\
\hline AGPRS052031.19-694322.1 & $03 / 174 / 061$ & $2.16 / 2.16$ & $17.33 / 15.48$ & $1 / 1$ & 17.49 & 15.47 & \\
\hline AGPRS052031.56-694148.5 & $03 / 157 / 137$ & $3.65 / 5.09$ & $16.86 / 14.66$ & $1 / 1$ & 16.61 & 14.36 & \\
\hline AGPRS052032.21-694225.3 & $03 / 167 / 108$ & $2.62 / 2.52$ & $15.25 / 14.53$ & $1 / 1$ & 15.21 & 14.35 & \\
\hline AGPRS052033.20-692448.5 & $10 / 380 / 372$ & $1.94 / 1.58$ & $17.89 / 14.74$ & $0 / 0$ & 18.06 & 16.82 & \\
\hline AGPRS052033.35-693302.0 & $03 / 060 / 564$ & $3.15 / 3.76$ & $16.82 / 15.16$ & $1 / 1$ & 17.00 & 15.15 & \\
\hline
\end{tabular}




\begin{tabular}{|c|c|c|c|c|c|c|c|}
\hline $\begin{array}{c}\text { Name } \\
(1)\end{array}$ & $\begin{array}{c}\operatorname{chip} / X / Y \\
(2)\end{array}$ & $\begin{array}{c}\left.\frac{\phi_{\mathrm{c}}}{\phi_{0}}\right|_{B} /\left.\frac{\phi_{\mathrm{c}}}{\phi_{0}}\right|_{R} \\
(3)\end{array}$ & $\begin{array}{c}B_{\text {EROS }} / R_{\text {EROS }} \\
(4)\end{array}$ & $\begin{array}{c}N_{\text {star }}^{B / R} \\
\quad(5)\end{array}$ & $\begin{array}{c}B_{\mathrm{EROS}}^{\mathrm{DAO}} \\
(6)\end{array}$ & $\begin{array}{c}R_{\text {EROS }}^{\mathrm{DAO}} \\
\quad(7)\end{array}$ & $\begin{array}{c}\text { Cross-identifications } \\
\text { (8) }\end{array}$ \\
\hline AGPRS052033.48-693605.5 & 03/097/416 & $3.20 / 4.39$ & $17.55 / 15.30$ & $1 / 1$ & 17.71 & 15.31 & \\
\hline AGPRS052035.38-692911.8 & $11 / 025 / 162$ & $2.44 / 2.76$ & $16.48 / 14.40$ & $1 / 1$ & 16.77 & 14.49 & \\
\hline AGPRS052035.76-692858.7 & $11 / 024 / 173$ & $2.98 / 4.07$ & $17.38 / 15.04$ & $1 / 1$ & 17.82 & 15.12 & \\
\hline AGPRS052036.53-692337.3 & $10 / 380 / 433$ & $2.04 / 1.84$ & $16.66 / 15.00$ & $2 / 1$ & $\begin{array}{c}18.73 \\
(16.90)\end{array}$ & 14.98 & \\
\hline AGPRS052036.83-693343.6 & $03 / 083 / 534$ & $4.96 / 5.31$ & $14.85 / 12.93$ & $1 / 1$ & 14.40 & 12.42 & \\
\hline AGPRS052037.50-693057.4 & $11 / 055 / 079$ & $3.57 / 3.62$ & $14.83 / 13.93$ & $1 / 1$ & 14.92 & 13.95 & $\begin{array}{l}\text { LMC V2171 } \\
\text { HV } 2466\end{array}$ \\
\hline AGPRS052037.60-693040.1 & $11 / 052 / 093$ & $2.22 / 3.46$ & $16.70 / 14.20$ & $1 / 1$ & 16.89 & 14.30 & \\
\hline AGPRS052037.79-692320.4 & $10 / 382 / 448$ & $2.46 / 2.76$ & $17.92 / 15.91$ & $1 / 1$ & 18.90 & 15.44 & \\
\hline AGPRS052038.73-694344.2 & $03 / 210 / 051$ & $2.64 / 3.22$ & $17.38 / 15.38$ & $1 / 1$ & 17.80 & 15.56 & \\
\hline AGPRS052040.46-693718.9 & $03 / 141 / 364$ & $2.13 / 2.48$ & $19.29 / 15.93$ & $1 / 1$ & 18.75 & 15.65 & \\
\hline AGPRS052041.05-693646.2 & $03 / 137 / 391$ & $2.07 / 2.37$ & $16.94 / 14.93$ & $0 / 1$ & 17.44 & 14.97 & \\
\hline AGPRS052041.52-692105.3 & $10 / 371 / 561$ & $2.40 / 3.58$ & $17.81 / 15.48$ & $1 / 2$ & 18.15 & $\begin{array}{c}15.39 \\
(17.33)\end{array}$ & \\
\hline AGPRS052042.54-693634.5 & $03 / 141 / 402$ & $2.58 / 3.56$ & $16.85 / 14.96$ & $1 / 1$ & 17.38 & 15.13 & \\
\hline AGPRS052045.04-694316.3 & $03 / 231 / 080$ & $2.41 / 2.22$ & $16.52 / 16.34$ & $1 / 1$ & 16.82 & 16.74 & \\
\hline AGPRS052046.19-693446.4 & $03 / 135 / 493$ & $4.54 / 5.12$ & $15.48 / 13.51$ & $1 / 1$ & 15.54 & 13.44 & $\begin{array}{c}\text { LMC V2182 } \\
\text { SHV0521087-693737 }\end{array}$ \\
\hline AGPRS052046.85-692732.6 & $11 / 054 / 254$ & $2.24 / 2.15$ & $16.79 / 15.08$ & $2 / 2$ & $\begin{array}{c}17.92 \\
(17.52)\end{array}$ & $\begin{array}{l}17.93 \\
(15.31)\end{array}$ & \\
\hline AGPRS052046.89-692937.8 & $11 / 079 / 153$ & $2.14 / 2.21$ & $17.19 / 15.22$ & $1 / 1$ & 17.09 & 14.96 & \\
\hline AGPRS052048.40-693323.8 & $03 / 128 / 562$ & $2.52 / 2.89$ & $16.28 / 14.30$ & $1 / 1$ & 16.65 & 14.42 & \\
\hline AGPRS052048.41-693333.7 & $03 / 130 / 554$ & $2.09 / 2.36$ & $17.74 / 15.65$ & $0 / 1$ & 17.56 & 15.44 & \\
\hline AGPRS052048.52-692857.8 & $11 / 078 / 187$ & $1.64 / 1.65$ & $15.85 / 15.40$ & $1 / 0$ & 19.53 & 15.52 & \\
\hline AGPRS052048.92-694320.0 & $03 / 248 / 081$ & $2.87 / 3.42$ & $17.08 / 15.30$ & $1 / 2$ & 17.55 & $\begin{array}{c}15.51 \\
(17.75)\end{array}$ & \\
\hline AGPRS052050.54-69289.6 & $11 / 077 / 228$ & $2.48 / 3.01$ & $16.76 / 14.54$ & $1 / 1$ & 17.02 & 14.69 & \\
\hline AGPRS052052.43-692824.4 & $11 / 088 / 218$ & $2.41 / 3.00$ & $17.00 / 14.50$ & $1 / 1$ & 17.14 & 14.46 & \\
\hline AGPRS052052.91-692547.8 & $11 / 059 / 345$ & $2.33 / 2.66$ & $17.65 / 15.29$ & $1 / 1$ & 17.62 & 15.17 & \\
\hline AGPRS052054.04-692503.4 & $11 / 055 / 382$ & $2.68 / 3.87$ & $17.24 / 14.59$ & $1 / 1$ & 17.45 & 14.69 & \\
\hline AGPRS052054.57-692220.8 & $11 / 025 / 514$ & $3.35 / 4.13$ & $16.59 / 15.05$ & $1 / 1$ & 16.81 & 15.14 & \\
\hline AGPRS052055.91-694116.5 & $03 / 253 / 188$ & $3.29 / 4.81$ & $17.15 / 14.46$ & $1 / 1$ & 17.19 & 14.44 & \\
\hline AGPRS052056.58-693512.1 & $03 / 184 / 483$ & $3.27 / 3.69$ & $16.39 / 14.63$ & $1 / 1$ & 16.55 & 14.71 & \\
\hline AGPRS052056.64-694307.6 & 03/278/099 & $2.32 / 2.67$ & $16.80 / 14.83$ & $1 / 1$ & 17.04 & 14.76 & \\
\hline AGPRS052056.77-694138.6 & $03 / 261 / 171$ & $2.01 / 1.81$ & $16.72 / 14.95$ & $1 / 2$ & 16.82 & $\begin{array}{c}19.03 \\
(15.09)\end{array}$ & \\
\hline AGPRS052057.04-693431.8 & $03 / 178 / 516$ & $2.32 / 2.54$ & $17.35 / 15.57$ & $1 / 1$ & 17.50 & 15.48 & \\
\hline AGPRS052057.84-693445.2 & $03 / 184 / 506$ & $2.31 / 2.50$ & $18.12 / 16.40$ & $1 / 1$ & 18.31 & 16.50 & \\
\hline AGPRS052058.10-692829.2 & $11 / 113 / 220$ & $2.65 / 3.08$ & $16.59 / 15.25$ & $1 / 1$ & 16.83 & 15.37 & \\
\hline AGPRS052058.24-692147.2 & $11 / 034 / 545$ & $3.22 / 4.72$ & $16.36 / 14.12$ & $1 / 1$ & 16.67 & 14.12 & \\
\hline AGPRS052059.11-692943.6 & $11 / 132 / 161$ & $2.25 / 3.27$ & $17.97 / 15.62$ & $1 / 2$ & 18.09 & $\begin{array}{c}18.03 \\
(15.60)\end{array}$ & \\
\hline AGPRS052100.25-692320.1 & $11 / 061 / 472$ & $2.83 / 3.49$ & $16.68 / 14.75$ & $1 / 1$ & 16.95 & 14.80 & \\
\hline AGPRS052100.26-694104.7 & $03 / 269 / 202$ & $2.87 / 3.42$ & $16.78 / 14.90$ & $1 / 1$ & 17.08 & 14.97 & \\
\hline AGPRS052100.80-693815.8 & $03 / 238 / 339$ & $3.14 / 4.12$ & $17.16 / 15.14$ & $1 / 1$ & 17.38 & 15.15 & \\
\hline AGPRS052101.18-692904.1 & $11 / 133 / 195$ & $2.26 / 2.53$ & $17.13 / 15.13$ & $1 / 1$ & 17.26 & 15.15 & \\
\hline AGPRS052102.59-692929.5 & $11 / 144 / 176$ & $2.17 / 2.80$ & $17.75 / 15.19$ & $1 / 1$ & 18.40 & 15.55 & \\
\hline AGPRS052102.80-693440.4 & $03 / 204 / 515$ & $3.20 / 3.74$ & $16.60 / 14.57$ & $1 / 1$ & 16.92 & 14.69 & \\
\hline AGPRS052102.84-693843.2 & $03 / 252 / 319$ & $2.44 / 3.20$ & $17.14 / 14.96$ & $1 / 1$ & 17.10 & 14.63 & \\
\hline AGPRS052102.90-693523.9 & $03 / 213 / 480$ & $1.82 / 1.98$ & $19.89 / 17.95$ & $0 / 1$ & 19.14 & 18.48 & \\
\hline AGPRS052102.93-693735.2 & $03 / 239 / 374$ & $1.49 / 1.64$ & $16.51 / 15.30$ & $0 / 0$ & 16.41 & 15.20 & \\
\hline AGPRS052103.90-693052.9 & $11 / 166 / 110$ & $2.78 / 3.08$ & $17.40 / 15.40$ & $1 / 1$ & 17.40 & 15.32 & \\
\hline AGPRS052104.78-694306.8 & $03 / 312 / 108$ & $2.66 / 3.97$ & $17.16 / 15.23$ & $1 / 1$ & 17.50 & 15.32 & \\
\hline
\end{tabular}




\begin{tabular}{|c|c|c|c|c|c|c|c|}
\hline $\begin{array}{l}\text { Name } \\
(1)\end{array}$ & $\begin{array}{c}\operatorname{chip} / X / Y \\
(2)\end{array}$ & $\begin{array}{c}\left.\frac{\phi_{\mathrm{c}}}{\phi_{0}}\right|_{B} /\left.\frac{\phi_{\mathrm{c}}}{\phi_{0}}\right|_{R} \\
(3)\end{array}$ & $\begin{array}{c}B_{\text {EROS }} / R_{\text {EROS }} \\
(4)\end{array}$ & $\begin{array}{c}N_{\text {star }}^{B / R} \\
(5)\end{array}$ & $\begin{array}{c}B_{\mathrm{EROS}}^{\mathrm{DAO}} \\
(6)\end{array}$ & $\begin{array}{l}R_{\mathrm{EROS}}^{\mathrm{DAO}} \\
\quad(7)\end{array}$ & $\begin{array}{c}\text { Cross-identifications } \\
\text { (8) }\end{array}$ \\
\hline AGPRS052105.46-692429.9 & $11 / 097 / 421$ & $2.01 / 2.12$ & $18.12 / 17.25$ & $1 / 1$ & 19.15 & 18.26 & \\
\hline AGPRS052105.93-694201.4 & $03 / 304 / 162$ & $3.49 / 4.38$ & $17.06 / 15.18$ & $1 / 1$ & 17.15 & 15.17 & \\
\hline AGPRS052106.51-693952.2 & $03 / 281 / 267$ & $2.18 / 2.68$ & $18.19 / 15.08$ & $1 / 1$ & 18.45 & 15.23 & \\
\hline AGPRS052106.87-693711.8 & $03 / 251 / 397$ & $2.10 / 2.78$ & $17.63 / 16.58$ & $1 / 1$ & 18.47 & 16.44 & \\
\hline AGPRS052108.60-692704.9 & $11 / 141 / 299$ & $2.41 / 2.61$ & $17.11 / 15.43$ & $1 / 1$ & 17.34 & 15.36 & \\
\hline AGPRS052108.92-692930.1 & $11 / 171 / 182$ & $2.76 / 4.57$ & $17.46 / 14.46$ & $1 / 1$ & 17.76 & 14.46 & \\
\hline AGPRS0521 9.52-693418.0 & $03 / 228 / 540$ & $3.35 / 4.26$ & $16.70 / 14.55$ & $2 / 1$ & $\begin{array}{c}16.77 \\
(19.50)\end{array}$ & 14.43 & \\
\hline AGPRS0521 9.88-693920.6 & $03 / 289 / 296$ & $2.53 / 3.91$ & $17.68 / 15.17$ & $2 / 1$ & $\begin{array}{c}18.24 \\
(19.91)\end{array}$ & 15.20 & \\
\hline AGPRS052110.31-693243.9 & $11 / 215 / 027$ & $2.54 / 3.07$ & $17.18 / 15.71$ & $1 / 1$ & 17.58 & 15.86 & \\
\hline AGPRS052111.83-693353.7 & $03 / 233 / 562$ & $2.97 / 3.72$ & $17.14 / 14.79$ & $2 / 1$ & $\begin{array}{c}17.32 \\
(19.84)\end{array}$ & 14.84 & \\
\hline AGPRS052112.95-693131.7 & $11 / 212 / 088$ & $2.15 / 3.73$ & $17.49 / 14.85$ & $1 / 1$ & 18.35 & 14.99 & \\
\hline AGPRS052113.16-694159.5 & $03 / 334 / 171$ & $2.60 / 3.03$ & $17.23 / 15.47$ & $1 / 1$ & 17.56 & 15.49 & \\
\hline AGPRS052114.98-693235.0 & $11 / 233 / 039$ & $2.62 / 3.81$ & $16.21 / 14.85$ & $1 / 1$ & 16.76 & 15.03 & \\
\hline AGPRS052116.31-693834.3 & $03 / 307 / 340$ & $2.86 / 2.77$ & $16.40 / 15.77$ & $1 / 1$ & 16.61 & 15.91 & EROS 2095 \\
\hline AGPRS052116.63-693903.2 & $03 / 314 / 317$ & $2.06 / 2.36$ & $17.18 / 14.52$ & $1 / 1$ & 17.43 & 14.61 & \\
\hline AGPRS052118.95-693428.8 & $03 / 270 / 541$ & $2.90 / 3.39$ & $17.51 / 15.54$ & $1 / 1$ & 17.63 & 15.46 & \\
\hline AGPRS052119.35-692959.5 & $11 / 221 / 169$ & $2.68 / 4.16$ & $17.86 / 15.51$ & $1 / 1$ & 17.99 & 15.39 & \\
\hline AGPRS052119.62-694042.2 & $03 / 346 / 240$ & $2.32 / 3.03$ & $17.75 / 15.43$ & $1 / 1$ & 18.00 & 15.48 & $\begin{array}{c}\text { LMC V2209 } \\
\text { SHV0521431-694328 }\end{array}$ \\
\hline AGPRS052119.82-693450.9 & $03 / 278 / 524$ & $0.73 / 1.06$ & $16.09 / 16.18$ & $0 / 0$ & 15.69 & 18.32 & \\
\hline AGPRS052119.93-693022.6 & $11 / 228 / 151$ & $2.46 / 3.96$ & $17.96 / 15.38$ & $1 / 1$ & 17.97 & 15.36 & \\
\hline AGPRS052120.46-693132.6 & $11 / 244 / 095$ & $2.26 / 2.56$ & $16.93 / 14.96$ & $1 / 1$ & 17.04 & 14.90 & \\
\hline AGPRS052120.84-693119.4 & $11 / 243 / 106$ & $3.46 / 4.47$ & $16.55 / 14.56$ & $1 / 1$ & 16.71 & 14.60 & \\
\hline AGPRS052120.92-692415.0 & $11 / 160 / 449$ & $2.32 / 2.74$ & $17.67 / 15.47$ & $2 / 1$ & $\begin{array}{c}17.14 \\
(17.14)\end{array}$ & 15.11 & \\
\hline AGPRS052121.49-693819.8 & $03 / 326 / 357$ & $2.29 / 4.04$ & $18.21 / 15.66$ & $1 / 1$ & 19.13 & 15.48 & $\begin{array}{c}\text { LMC V2212 } \\
\text { SHV0521450-694107 }\end{array}$ \\
\hline AGPRS052123.94-692441.2 & $11 / 178 / 431$ & $3.09 / 3.79$ & $16.63 / 14.18$ & $3 / 1$ & 18.61 & 14.29 & \\
\hline AGPRS052123.96-694025.5 & $03 / 361 / 258$ & $2.26 / 2.84$ & $18.42 / 16.58$ & $1 / 1$ & 19.36 & 16.80 & $\begin{array}{c}\text { LMC V2213 } \\
\text { SHV0521476-694312 }\end{array}$ \\
\hline AGPRS052124.02-693213.0 & $11 / 267 / 066$ & $2.67 / 3.02$ & $16.34 / 14.03$ & $1 / 1$ & 16.44 & 14.04 & \\
\hline AGPRS052124.22-693650.4 & $03 / 320 / 432$ & $3.54 / 4.23$ & $16.47 / 14.69$ & $1 / 1$ & 16.60 & 14.72 & \\
\hline AGPRS052124.58-692922.9 & $11 / 236 / 204$ & $2.48 / 3.63$ & $17.41 / 15.09$ & $1 / 1$ & 17.93 & 14.97 & \\
\hline AGPRS052127.55-693715.7 & $03 / 339 / 415$ & $2.14 / 3.11$ & $18.08 / 15.50$ & $1 / 1$ & 18.11 & 14.73 & \\
\hline AGPRS052128.89-692541.9 & $11 / 211 / 387$ & $2.50 / 3.42$ & $17.05 / 15.10$ & $1 / 1$ & 17.49 & 15.20 & \\
\hline AGPRS052129.70-693051.1 & $11 / 275 / 138$ & $2.20 / 1.90$ & $16.76 / 14.58$ & $1 / 1$ & 17.58 & 14.82 & \\
\hline AGPRS052130.29-693155.0 & $11 / 290 / 087$ & $3.10 / 3.92$ & $17.07 / 15.30$ & $1 / 1$ & 17.65 & 15.42 & \\
\hline AGPRS052131.18-693435.6 & $03 / 323 / 548$ & $2.42 / 3.06$ & $17.38 / 15.21$ & $1 / 1$ & 17.89 & 15.42 & \\
\hline AGPRS052131.59-692620.0 & $11 / 230 / 359$ & $3.01 / 4.37$ & $17.31 / 15.34$ & $1 / 1$ & 17.50 & 15.31 & \\
\hline AGPRS052131.61-693816.5 & $03 / 368 / 370$ & $3.23 / 4.30$ & $16.71 / 14.66$ & $1 / 1$ & 16.86 & 14.69 & \\
\hline AGPRS052132.90-693743.5 & $03 / 367 / 398$ & $2.66 / 2.72$ & $16.60 / 14.80$ & $2 / 2$ & $\begin{array}{c}19.09 \\
(16.89)\end{array}$ & $\begin{array}{c}18.49 \\
(14.88)\end{array}$ & \\
\hline AGPRS052135.45-69319.5 & $11 / 303 / 129$ & $2.89 / 3.57$ & $16.79 / 14.60$ & $1 / 1$ & 16.99 & 14.73 & \\
\hline AGPRS052135.57-693615.3 & $03 / 361 / 472$ & $1.58 / 1.97$ & $16.67 / 16.19$ & $1 / 1$ & 18.71 & 17.20 & \\
\hline AGPRS052136.10-692902.9 & $11 / 281 / 232$ & $2.56 / 3.49$ & $18.07 / 15.93$ & $1 / 1$ & 18.17 & 15.85 & \\
\hline AGPRS052136.79-693502.5 & $03 / 352 / 532$ & $3.66 / 4.69$ & $16.87 / 14.86$ & $1 / 1$ & 16.99 & 14.80 & \\
\hline AGPRS052137.04-694353.4 & 04/040/103 & $2.36 / 2.75$ & $17.00 / 15.13$ & $2 / 1$ & $\begin{array}{c}17.69 \\
(18.13)\end{array}$ & 15.26 & \\
\hline AGPRS052139.15-692715.4 & $11 / 273 / 322$ & $2.31 / 3.11$ & $18.49 / 15.03$ & $1 / 1$ & 18.38 & 14.93 & \\
\hline AGPRS052139.57-692230.2 & $11 / 219 / 553$ & $2.33 / 3.12$ & $17.76 / 15.78$ & $1 / 1$ & 18.36 & 15.98 & \\
\hline AGPRS052141.09-693308.1 & $11 / 350 / 039$ & $2.40 / 2.66$ & $17.58 / 15.22$ & $1 / 2$ & 17.81 & 15.45 & \\
\hline
\end{tabular}




\begin{tabular}{|c|c|c|c|c|c|c|c|}
\hline $\begin{array}{c}\text { Name } \\
(1)\end{array}$ & $\begin{array}{c}\operatorname{chip} / X / Y \\
(2)\end{array}$ & $\begin{array}{c}\left.\frac{\phi_{\mathrm{c}}}{\phi_{0}}\right|_{B} /\left.\frac{\phi_{\mathrm{c}}}{\phi_{0}}\right|_{R} \\
(3)\end{array}$ & $\begin{array}{c}B_{\text {EROS }} / R_{\text {EROS }} \\
(4)\end{array}$ & $\begin{array}{c}N_{\text {star }}^{B / R} \\
\quad(5)\end{array}$ & $\begin{array}{c}B_{\mathrm{EROS}}^{\mathrm{DAO}} \\
(6)\end{array}$ & $\begin{array}{c}R_{\mathrm{EROS}}^{\mathrm{DAO}} \\
\quad(7)\end{array}$ & $\begin{array}{c}\text { Cross-identifications } \\
\text { (8) }\end{array}$ \\
\hline & & & & & & $(18.15)$ & \\
\hline AGPRS052142.55-692759.3 & $11 / 296 / 290$ & $3.36 / 4.14$ & $16.63 / 14.96$ & $1 / 1$ & 16.78 & 14.97 & \\
\hline AGPRS052142.86-692854.1 & $11 / 308 / 246$ & $2.73 / 3.68$ & $16.95 / 15.07$ & $3 / 1$ & 17.50 & 15.16 & \\
\hline AGPRS052143.06-692509.2 & $11 / 265 / 428$ & $2.37 / 2.63$ & $17.07 / 15.22$ & $1 / 1$ & 17.55 & 15.42 & \\
\hline AGPRS052143.12-693213.7 & $11 / 348 / 085$ & $2.96 / 3.84$ & $17.04 / 14.93$ & $2 / 1$ & $\begin{array}{l}17.15 \\
(17.15)\end{array}$ & 14.92 & \\
\hline AGPRS052143.55-693859.7 & $04 / 010 / 347$ & $2.01 / 3.13$ & $18.11 / 15.50$ & $1 / 2$ & 18.56 & $\begin{array}{c}15.54 \\
(15.54)\end{array}$ & \\
\hline AGPRS052144.48-694331.8 & $04 / 067 / 128$ & $2.82 / 3.35$ & $16.86 / 14.66$ & $1 / 1$ & 16.91 & 14.77 & \\
\hline AGPRS052144.58-692223.0 & $11 / 239 / 564$ & $2.44 / 2.87$ & $16.70 / 14.63$ & $1 / 1$ & 16.89 & 14.63 & \\
\hline AGPRS052145.50-693025.3 & $11 / 337 / 175$ & $2.94 / 3.13$ & $16.79 / 15.29$ & $1 / 1$ & 16.95 & 15.30 & \\
\hline AGPRS052145.91-693250.7 & $11 / 367 / 058$ & $2.75 / 4.16$ & $16.73 / 14.97$ & $1 / 1$ & 17.16 & 15.07 & \\
\hline AGPRS052147.34-694255.8 & $04 / 072 / 160$ & $1.96 / 2.54$ & $99.90 / 16.92$ & $0 / 1$ & 19.33 & 17.10 & \\
\hline AGPRS052148.02-694520.1 & $04 / 103 / 044$ & $2.69 / 3.75$ & $17.49 / 15.28$ & $3 / 1$ & 17.86 & 15.28 & \\
\hline AGPRS052148.21-694201.2 & $04 / 065 / 205$ & $1.79 / 1.76$ & $19.99 / 16.52$ & $0 / 0$ & 19.51 & 16.07 & \\
\hline AGPRS052148.86-694116.3 & $04 / 059 / 242$ & $2.67 / 3.49$ & $18.37 / 16.02$ & $1 / 1$ & 18.44 & 16.06 & \\
\hline AGPRS052149.14-693821.0 & $04 / 026 / 384$ & $2.38 / 2.83$ & $17.17 / 15.17$ & $1 / 1$ & 17.87 & 15.44 & \\
\hline AGPRS052149.98-693254.6 & $11 / 385 / 059$ & $2.51 / 3.00$ & $17.14 / 15.23$ & $1 / 1$ & 16.94 & 14.94 & \\
\hline AGPRS052151.05-694521.4 & $04 / 116 / 046$ & $3.55 / 4.40$ & $17.07 / 14.97$ & $1 / 1$ & 17.07 & 14.90 & \\
\hline AGPRS052152.27-693052.5 & $11 / 371 / 160$ & $2.56 / 2.79$ & $16.02 / 14.12$ & $2 / 2$ & $\begin{array}{c}19.15 \\
(16.03)\end{array}$ & $\begin{array}{l}18.17 \\
(13.86)\end{array}$ & \\
\hline AGPRS052152.38-694107.1 & $04 / 072 / 253$ & $2.67 / 3.30$ & $17.10 / 15.08$ & $1 / 1$ & 17.48 & 15.19 & \\
\hline AGPRS052152.50-692310.2 & $11 / 282 / 534$ & $2.85 / 3.23$ & $16.86 / 15.08$ & $1 / 1$ & 17.05 & 15.20 & \\
\hline AGPRS052152.68-693104.1 & $11 / 375 / 151$ & $2.43 / 2.58$ & $17.37 / 15.21$ & $1 / 2$ & 17.21 & $\begin{array}{c}14.84 \\
(18.73)\end{array}$ & $\begin{array}{c}\text { LMC V2238 } \\
\text { SHV0522149-693347 }\end{array}$ \\
\hline AGPRS052155.98-692626.2 & $11 / 335 / 379$ & $3.40 / 4.48$ & $17.04 / 14.80$ & $1 / 1$ & 17.09 & 14.78 & \\
\hline AGPRS052156.21-693521.7 & $04 / 021 / 536$ & $2.95 / 3.48$ & $17.13 / 15.07$ & $1 / 1$ & 17.22 & 15.13 & \\
\hline AGPRS052156.63-693614.3 & $04 / 033 / 494$ & $2.74 / 3.89$ & $17.41 / 15.15$ & $1 / 1$ & 17.83 & 15.16 & \\
\hline AGPRS052200.43-693924.6 & $04 / 086 / 344$ & $2.43 / 2.90$ & $17.49 / 15.85$ & $2 / 1$ & $\begin{array}{c}18.37 \\
(19.66)\end{array}$ & 16.11 & \\
\hline AGPRS052200.44-694519.5 & $04 / 155 / 057$ & $3.44 / 4.52$ & $17.40 / 15.28$ & $1 / 1$ & 17.13 & 14.98 & $\begin{array}{c}\text { LMC V2252 } \\
\text { SHV0522250-694803 }\end{array}$ \\
\hline AGPRS052200.69-692829.7 & $11 / 379 / 284$ & $2.40 / 3.11$ & $18.85 / 15.76$ & $1 / 2$ & 18.57 & $\begin{array}{l}15.48 \\
(18.80)\end{array}$ & \\
\hline AGPRS052202.24-692322.5 & $11 / 326 / 534$ & $2.28 / 2.82$ & $18.41 / 16.17$ & $1 / 1$ & 18.63 & 16.25 & \\
\hline AGPRS052202.47-693733.4 & $04 / 073 / 436$ & $1.72 / 2.85$ & $17.64 / 15.71$ & $1 / 1$ & 18.66 & 15.51 & \\
\hline AGPRS052202.96-692627.6 & $11 / 365 / 385$ & $2.48 / 3.31$ & $17.60 / 15.07$ & $1 / 1$ & 17.89 & 15.19 & \\
\hline AGPRS052204.08-694619.6 & $04 / 182 / 012$ & $2.47 / 2.99$ & $17.90 / 15.21$ & $1 / 2$ & 18.14 & $\begin{array}{l}15.33 \\
(17.37)\end{array}$ & \\
\hline AGPRS052204.15-692439.1 & $11 / 349 / 474$ & $2.30 / 2.87$ & $17.43 / 14.93$ & $1 / 1$ & 17.72 & 15.06 & \\
\hline AGPRS052204.29-693954.2 & $04 / 108 / 324$ & $2.11 / 2.11$ & $17.04 / 14.96$ & $1 / 1$ & 17.28 & 15.09 & \\
\hline AGPRS052204.80-693331.6 & $12 / 038 / 044$ & $2.36 / 2.82$ & $17.51 / 15.51$ & $1 / 1$ & 17.63 & 15.55 & \\
\hline AGPRS052205.85-693614.7 & $04 / 072 / 503$ & $3.69 / 4.67$ & $17.20 / 15.30$ & $0 / 1$ & 18.65 & 15.20 & \\
\hline AGPRS052207.10-694229.8 & $04 / 150 / 201$ & $2.59 / 3.52$ & $17.72 / 15.69$ & $1 / 1$ & 17.75 & 15.35 & \\
\hline AGPRS052207.23-692433.1 & $11 / 361 / 482$ & $2.39 / 2.79$ & $17.18 / 14.96$ & $1 / 1$ & 17.39 & 15.09 & \\
\hline AGPRS052209.39-693058.9 & $12 / 028 / 172$ & $2.42 / 3.29$ & $16.77 / 14.95$ & $2 / 1$ & $\begin{array}{c}17.35 \\
(19.80)\end{array}$ & 15.12 & \\
\hline AGPRS052210.50-692932.5 & $12 / 016 / 243$ & $2.48 / 3.28$ & $16.22 / 14.32$ & $1 / 1$ & 16.56 & 14.42 & \\
\hline AGPRS052211.14-692419.5 & $11 / 375 / 497$ & $2.86 / 3.26$ & $17.47 / 15.36$ & $2 / 1$ & $\begin{array}{c}17.42 \\
(21.48)\end{array}$ & 15.21 & \\
\hline AGPRS052213.07-693724.4 & $04 / 116 / 454$ & $2.20 / 2.52$ & $18.80 / 16.01$ & $0 / 2$ & 18.06 & $\begin{array}{l}16.08 \\
(18.93)\end{array}$ & \\
\hline AGPRS052213.89-692344.6 & $11 / 380 / 528$ & $1.86 / 1.37$ & $17.35 / 14.88$ & $0 / 0$ & 17.42 & 14.88 & \\
\hline AGPRS052214.22-693148.3 & $12 / 058 / 137$ & $2.35 / 2.33$ & $17.90 / 17.18$ & $1 / 1$ & 18.45 & 17.68 & \\
\hline
\end{tabular}




\begin{tabular}{|c|c|c|c|c|c|c|c|}
\hline $\begin{array}{l}\text { Name } \\
(1)\end{array}$ & $\begin{array}{c}\operatorname{chip} / X / Y \\
(2)\end{array}$ & $\begin{array}{c}\left.\frac{\phi_{\mathrm{c}}}{\phi_{0}}\right|_{B} /\left.\frac{\phi_{\mathrm{c}}}{\phi_{0}}\right|_{R} \\
(3)\end{array}$ & $\begin{array}{c}B_{\text {EROS }} / R_{\text {EROS }} \\
(4)\end{array}$ & $\begin{array}{c}N_{\text {star }}^{B / R} \\
(5)\end{array}$ & $\begin{array}{c}B_{\mathrm{EROS}}^{\mathrm{DAO}} \\
(6)\end{array}$ & $\begin{array}{l}R_{\mathrm{EROS}}^{\mathrm{DAO}} \\
\quad(7)\end{array}$ & $\begin{array}{c}\text { Cross-identifications } \\
\text { (8) }\end{array}$ \\
\hline AGPRS052214.48-693800.8 & $04 / 129 / 426$ & $2.40 / 2.47$ & $17.29 / 15.39$ & $1 / 1$ & 17.33 & 15.34 & \\
\hline AGPRS052215.87-694413.4 & $04 / 207 / 126$ & $3.86 / 3.58$ & $16.36 / 15.91$ & $1 / 2$ & 16.35 & $\begin{array}{l}16.15 \\
(16.74)\end{array}$ & \\
\hline AGPRS052218.06-693637.4 & $04 / 128 / 497$ & $2.19 / 3.13$ & $19.13 / 16.78$ & $0 / 1$ & 19.18 & 16.81 & $\begin{array}{c}\text { LMC V2272 } \\
\text { SHV0522418-693921 }\end{array}$ \\
\hline AGPRS052220.64-693341.5 & $12 / 107 / 052$ & $2.51 / 3.90$ & $18.10 / 15.64$ & $0 / 1$ & 19.69 & 15.65 & \\
\hline AGPRS052220.84-692615.3 & $12 / 022 / 413$ & $3.48 / 4.38$ & $17.15 / 15.35$ & $1 / 1$ & 17.22 & 15.32 & \\
\hline AGPRS052221.29-693634.0 & $04 / 141 / 503$ & $2.17 / 3.44$ & $18.18 / 14.98$ & $1 / 1$ & 18.72 & 15.08 & \\
\hline AGPRS052222.96-694200.1 & $04 / 211 / 241$ & $2.88 / 3.97$ & $17.83 / 15.61$ & $1 / 1$ & 17.82 & 15.39 & \\
\hline AGPRS052224.18-693305.1 & $12 / 115 / 085$ & $3.14 / 3.75$ & $16.85 / 15.07$ & $1 / 1$ & 17.05 & 15.14 & $\begin{array}{c}\text { LMC V2278 } \\
\text { SHV0522474-693548 }\end{array}$ \\
\hline AGPRS052224.88-693202.8 & $12 / 106 / 136$ & $2.76 / 3.72$ & $18.19 / 15.68$ & $1 / 1$ & 17.61 & 15.67 & \\
\hline AGPRS052224.90-693837.2 & $04 / 180 / 407$ & $3.21 / 4.16$ & $17.04 / 14.93$ & $1 / 1$ & 17.35 & 15.00 & \\
\hline AGPRS052225.05-694452.0 & $04 / 253 / 104$ & $2.49 / 3.39$ & $17.57 / 15.55$ & $1 / 1$ & 17.93 & 15.55 & \\
\hline AGPRS052225.50-694400.6 & $04 / 245 / 146$ & $2.72 / 3.70$ & $17.86 / 15.87$ & $1 / 1$ & 18.06 & 15.84 & \\
\hline AGPRS052225.67-692351.8 & $12 / 015 / 534$ & $3.47 / 4.30$ & $16.74 / 14.94$ & $1 / 1$ & 16.92 & 15.00 & \\
\hline AGPRS052226.79-693740.2 & $04 / 177 / 455$ & $2.25 / 2.99$ & $17.53 / 15.94$ & $2 / 1$ & $\begin{array}{c}18.66 \\
(18.31)\end{array}$ & 16.11 & \\
\hline AGPRS052229.50-692513.2 & $12 / 047 / 472$ & $2.67 / 3.04$ & $16.69 / 14.14$ & $1 / 1$ & 16.90 & 14.25 & \\
\hline AGPRS052231.32-694230.2 & $04 / 252 / 225$ & $3.29 / 4.64$ & $17.12 / 14.50$ & $1 / 1$ & 17.18 & 14.47 & \\
\hline AGPRS052233.78-693808.7 & $04 / 212 / 439$ & $3.31 / 3.69$ & $17.25 / 15.77$ & $1 / 1$ & 17.47 & 15.85 & \\
\hline AGPRS052233.92-694332.7 & $04 / 275 / 177$ & $2.26 / 2.25$ & $17.05 / 14.65$ & $1 / 1$ & 17.27 & 14.75 & \\
\hline AGPRS052234.58-694630.2 & $04 / 312 / 034$ & $3.02 / 3.95$ & $17.19 / 14.87$ & $1 / 1$ & 17.40 & 14.92 & \\
\hline AGPRS052236.48-693438.3 & $12 / 185 / 022$ & $2.28 / 2.88$ & $17.19 / 15.14$ & $1 / 1$ & 17.51 & 15.27 & \\
\hline AGPRS052237.26-693107.8 & $12 / 148 / 193$ & $1.66 / 1.76$ & $17.06 / 15.00$ & $0 / 1$ & 17.10 & 15.47 & \\
\hline AGPRS052238.97-693040.2 & $12 / 150 / 217$ & $2.59 / 4.02$ & $18.09 / 15.68$ & $2 / 2$ & $\begin{array}{c}18.64 \\
(19.38)\end{array}$ & $\begin{array}{l}15.63 \\
(17.65)\end{array}$ & \\
\hline AGPRS052240.72-693027.6 & $12 / 155 / 229$ & $1.68 / 1.92$ & $18.34 / 15.89$ & $0 / 1$ & 20.03 & 15.81 & \\
\hline AGPRS052241.07-694046.1 & $04 / 273 / 319$ & $2.20 / 2.57$ & $17.71 / 15.72$ & $1 / 1$ & 17.63 & 15.36 & \\
\hline AGPRS052242.38-694237.7 & $04 / 300 / 230$ & $2.34 / 2.67$ & $17.61 / 15.80$ & $1 / 1$ & 17.63 & 15.50 & \\
\hline AGPRS052242.77-692428.0 & $12 / 095 / 522$ & $2.23 / 2.33$ & $18.60 / 16.17$ & $1 / 2$ & 18.81 & $\begin{array}{c}16.27 \\
(19.53)\end{array}$ & \\
\hline AGPRS052242.95-693923.1 & $04 / 265 / 388$ & $2.71 / 3.15$ & $16.89 / 15.05$ & $1 / 1$ & 17.16 & 15.15 & \\
\hline AGPRS052243.20-693127.5 & $12 / 177 / 183$ & $3.17 / 4.38$ & $17.52 / 15.33$ & $1 / 1$ & 17.65 & 15.32 & \\
\hline AGPRS052244.00-693828.8 & $04 / 259 / 433$ & $3.92 / 4.09$ & $15.81 / 14.38$ & $1 / 1$ & 15.81 & 14.30 & \\
\hline AGPRS052244.12-69309.5 & $12 / 166 / 247$ & $3.38 / 4.05$ & $16.54 / 14.58$ & $2 / 1$ & $\begin{array}{c}16.59 \\
(19.68)\end{array}$ & 14.48 & \\
\hline AGPRS052244.54-693345.2 & $12 / 209 / 073$ & $2.06 / 2.55$ & $17.82 / 15.12$ & $1 / 1$ & 18.20 & 15.15 & $\begin{array}{c}\text { LMC V2299 } \\
\text { SHV0523078-693626 }\end{array}$ \\
\hline AGPRS052247.19-692449.6 & $12 / 118 / 509$ & $1.74 / 2.46$ & $15.87 / 13.59$ & $0 / 1$ & 15.98 & 13.67 & \\
\hline AGPRS052248.39-692736.6 & $12 / 155 / 375$ & $1.94 / 2.24$ & $17.65 / 15.75$ & $1 / 1$ & 17.85 & 15.88 & \\
\hline AGPRS052249.26-694658.1 & $04 / 379 / 026$ & $2.85 / 3.91$ & $16.97 / 14.92$ & $1 / 1$ & 17.21 & 14.93 & \\
\hline AGPRS052250.30-693100.5 & $12 / 202 / 212$ & $2.40 / 2.89$ & $17.43 / 14.67$ & $2 / 2$ & $\begin{array}{c}19.95 \\
(17.71)\end{array}$ & $\begin{array}{l}14.78 \\
(14.78)\end{array}$ & $\begin{array}{c}\text { LMC V2305 } \\
\text { SHV0523125-693341 }\end{array}$ \\
\hline AGPRS052250.31-693604.5 & $04 / 258 / 556$ & $2.70 / 4.12$ & $17.99 / 15.38$ & $1 / 1$ & 18.47 & 15.40 & $\begin{array}{c}\text { LMC V2310 } \\
\text { SHV0523136-693845 }\end{array}$ \\
\hline AGPRS052250.54-694138.5 & $04 / 323 / 286$ & $2.78 / 3.15$ & $17.14 / 15.36$ & $2 / 1$ & $\begin{array}{c}17.90 \\
(17.93)\end{array}$ & 15.55 & \\
\hline AGPRS052252.30-692830.9 & $12 / 182 / 335$ & $2.37 / 2.84$ & $17.22 / 15.39$ & $1 / 1$ & 17.67 & 15.55 & \\
\hline AGPRS052252.66-694620.2 & $04 / 386 / 060$ & $2.45 / 3.38$ & $17.59 / 15.45$ & $2 / 1$ & $\begin{array}{c}18.04 \\
(18.04)\end{array}$ & 15.57 & \\
\hline AGPRS052253.39-693403.6 & $12 / 250 / 067$ & $2.19 / 2.13$ & $17.33 / 15.31$ & $1 / 1$ & 17.78 & 15.36 & \\
\hline AGPRS052254.31-693353.6 & $12 / 252 / 076$ & $2.88 / 3.63$ & $17.10 / 15.14$ & $1 / 1$ & 17.27 & 15.17 & \\
\hline AGPRS052255.00-693652.3 & $04 / 287 / 522$ & $2.46 / 3.41$ & $17.80 / 16.04$ & $1 / 1$ & 18.71 & 15.90 & LMC V2322 \\
\hline
\end{tabular}




\begin{tabular}{|c|c|c|c|c|c|c|c|}
\hline $\begin{array}{c}\text { Name } \\
(1)\end{array}$ & $\begin{array}{c}\operatorname{chip} / X / Y \\
(2)\end{array}$ & $\begin{array}{c}\left.\frac{\phi_{\mathrm{c}}}{\phi_{0}}\right|_{B} /\left.\frac{\phi_{\mathrm{c}}}{\phi_{0}}\right|_{R} \\
(3)\end{array}$ & $\begin{array}{c}B_{\text {EROS }} / R_{\text {EROS }} \\
(4)\end{array}$ & $\begin{array}{c}N_{\text {star }}^{B / R} \\
\quad(5)\end{array}$ & $\begin{array}{c}B_{\mathrm{EROS}}^{\mathrm{DAO}} \\
(6)\end{array}$ & $\begin{array}{c}R_{\mathrm{EROS}}^{\mathrm{DAO}} \\
\quad(7)\end{array}$ & $\begin{array}{c}\text { Cross-identifications } \\
\text { (8) }\end{array}$ \\
\hline & & & & & & & SHV0523185-693932 \\
\hline AGPRS052255.09-692712.8 & $12 / 179 / 401$ & $2.17 / 2.16$ & $17.54 / 15.50$ & $1 / 1$ & 17.65 & 15.44 & \\
\hline AGPRS052255.76-694117.7 & $04 / 341 / 308$ & $2.92 / 4.43$ & $17.37 / 14.67$ & $1 / 1$ & 17.54 & 14.74 & \\
\hline AGPRS052256.69-693938.8 & $04 / 326 / 389$ & $3.00 / 3.61$ & $16.77 / 15.05$ & $0 / 1$ & 17.51 & 15.11 & \\
\hline AGPRS052258.55-692621.5 & $12 / 184 / 446$ & $2.72 / 2.77$ & $14.92 / 14.09$ & $1 / 1$ & 15.11 & 14.19 & $\begin{array}{c}\text { LMC V } 2326 \\
\text { HV } 2479\end{array}$ \\
\hline AGPRS052258.74-694017.2 & $04 / 342 / 360$ & $2.73 / 3.57$ & $17.16 / 15.21$ & $1 / 1$ & 17.54 & 15.34 & \\
\hline AGPRS052300.72-692625.5 & $12 / 194 / 445$ & $2.07 / 2.30$ & $17.16 / 15.33$ & $1 / 1$ & 17.42 & 15.43 & \\
\hline AGPRS052301.77-693633.4 & $04 / 312 / 544$ & $2.58 / 3.45$ & $18.79 / 16.66$ & $1 / 1$ & 18.78 & 16.60 & $\begin{array}{c}\text { LMC V2337 } \\
\text { SHV0523257-693914 }\end{array}$ \\
\hline AGPRS052305.20-693918.3 & $04 / 358 / 414$ & $3.26 / 4.17$ & $17.40 / 15.10$ & $1 / 1$ & 17.46 & 15.04 & \\
\hline AGPRS052305.77-693427.6 & $12 / 307 / 060$ & $1.72 / 1.50$ & $17.08 / 15.02$ & $0 / 0$ & 17.04 & 14.85 & \\
\hline AGPRS052306.63-692857.3 & $12 / 248 / 328$ & $1.87 / 1.71$ & $17.14 / 14.94$ & $0 / 0$ & 18.76 & 15.03 & \\
\hline AGPRS052308.85-693432.6 & $12 / 321 / 059$ & $2.72 / 4.37$ & $17.14 / 14.82$ & $1 / 1$ & 17.47 & 14.86 & \\
\hline AGPRS052313.61-693720.1 & $04 / 371 / 518$ & $2.50 / 3.17$ & $17.43 / 15.51$ & $2 / 1$ & $\begin{array}{c}18.77 \\
(17.72)\end{array}$ & 15.30 & \\
\hline AGPRS052315.05-692951.0 & $12 / 294 / 293$ & $2.84 / 3.95$ & $18.05 / 15.58$ & $1 / 1$ & 18.22 & 15.54 & \\
\hline AGPRS052315.36-693156.2 & $12 / 319 / 192$ & $3.72 / 4.72$ & $16.33 / 14.30$ & $1 / 1$ & 16.47 & 14.36 & \\
\hline AGPRS052316.08-692808.5 & $12 / 279 / 377$ & $3.11 / 4.05$ & $17.29 / 15.42$ & $1 / 1$ & 17.44 & 15.42 & \\
\hline AGPRS052317.73-692649.0 & $12 / 271 / 443$ & $2.87 / 3.21$ & $17.67 / 15.30$ & $1 / 1$ & 17.80 & 15.46 & \\
\hline AGPRS052317.76-692927.2 & $12 / 301 / 315$ & $1.74 / 1.81$ & $17.12 / 14.87$ & $0 / 1$ & 17.28 & 14.95 & \\
\hline AGPRS052318.13-693001.0 & $12 / 309 / 288$ & $2.60 / 4.09$ & $18.18 / 15.41$ & $1 / 1$ & 18.26 & 15.41 & \\
\hline AGPRS052318.92-692601.1 & $12 / 267 / 483$ & $3.07 / 3.64$ & $16.72 / 14.73$ & $1 / 1$ & 16.83 & 14.86 & \\
\hline AGPRS052319.99-693028.0 & $12 / 322 / 268$ & $2.15 / 2.47$ & $18.15 / 15.64$ & $1 / 1$ & 18.07 & 15.59 & \\
\hline AGPRS052322.73-692559.6 & $12 / 283 / 488$ & $2.69 / 3.32$ & $16.12 / 13.95$ & $1 / 1$ & 16.32 & 14.08 & $\begin{array}{c}\text { LMC V2362 } \\
\text { SHV0523449-692840 }\end{array}$ \\
\hline AGPRS052323.13-693134.9 & $12 / 348 / 217$ & $2.77 / 4.27$ & $18.12 / 15.60$ & $1 / 1$ & 18.20 & 15.53 & \\
\hline AGPRS052323.45-693111.8 & $12 / 345 / 236$ & $3.28 / 4.46$ & $17.69 / 15.42$ & $1 / 1$ & 17.72 & 15.35 & $\begin{array}{c}\text { LMC V2365 } \\
\text { SHV0523459-693349 }\end{array}$ \\
\hline AGPRS052326.04-693138.5 & $12 / 361 / 217$ & $2.59 / 3.28$ & $17.76 / 15.74$ & $1 / 1$ & 17.80 & 15.73 & \\
\hline AGPRS052328.62-692848.7 & $12 / 340 / 357$ & $2.90 / 3.67$ & $16.93 / 15.09$ & $1 / 1$ & 17.17 & 15.18 & \\
\hline AGPRS052329.13-693209.5 & $12 / 380 / 195$ & $2.51 / 3.30$ & $17.63 / 14.69$ & $1 / 1$ & 17.85 & 14.79 & \\
\hline AGPRS052329.80-693133.2 & $12 / 376 / 225$ & $2.82 / 3.80$ & $17.11 / 15.27$ & $1 / 1$ & 17.16 & 15.24 & $\begin{array}{c}\text { LMC V2373 } \\
\text { SHV0523529-693412 }\end{array}$ \\
\hline AGPRS052344.56-692500.1 & $12 / 365 / 558$ & $2.43 / 2.61$ & $17.40 / 15.36$ & $1 / 1$ & 17.55 & 15.41 & \\
\hline AGPRS052612.31-694940.7 & $07 / 014 / 088$ & $3.69 / 4.68$ & $17.23 / 15.27$ & $1 / 1$ & 17.28 & 15.18 & \\
\hline AGPRS052621.04-695001.6 & $07 / 055 / 079$ & $2.21 / 2.66$ & $17.43 / 14.88$ & $1 / 1$ & 17.91 & 14.99 & \\
\hline AGPRS052624.63-694943.5 & $07 / 067 / 097$ & $2.79 / 3.42$ & $16.34 / 14.64$ & $1 / 1$ & 16.56 & 14.71 & \\
\hline AGPRS052625.96-694840.0 & $07 / 061 / 150$ & $3.10 / 3.98$ & $18.06 / 15.64$ & $1 / 1$ & 17.53 & 15.22 & \\
\hline AGPRS052629.78-694326.6 & $07 / 020 / 409$ & $4.03 / 4.87$ & $16.41 / 14.51$ & $1 / 1$ & 16.42 & 14.48 & \\
\hline AGPRS052630.69-694354.6 & $07 / 029 / 387$ & $2.85 / 3.54$ & $17.88 / 15.73$ & $1 / 1$ & 18.01 & 15.76 & \\
\hline AGPRS052631.92-694542.8 & $07 / 054 / 300$ & $2.08 / 2.11$ & $17.61 / 16.33$ & $1 / 2$ & 18.72 & $\begin{array}{c}17.57 \\
(18.15)\end{array}$ & \\
\hline AGPRS052631.98-694457.5 & $07 / 046 / 337$ & $2.48 / 3.47$ & $17.23 / 15.49$ & $2 / 1$ & $\begin{array}{c}17.83 \\
(17.86)\end{array}$ & 15.44 & \\
\hline AGPRS052632.50-694512.8 & $07 / 051 / 325$ & $3.57 / 3.10$ & $16.67 / 16.48$ & $1 / 0$ & 16.88 & 16.88 & EROS 1037 \\
\hline AGPRS052633.41-694703.0 & $07 / 075 / 236$ & $2.53 / 2.40$ & $17.08 / 16.62$ & $1 / 2$ & 17.35 & $\begin{array}{l}16.87 \\
(19.08)\end{array}$ & \\
\hline AGPRS052636.04-694829.3 & $07 / 102 / 168$ & $2.88 / 4.02$ & $17.48 / 15.30$ & $1 / 1$ & 17.94 & 15.38 & \\
\hline AGPRS052638.23-694537.7 & $07 / 080 / 310$ & $2.94 / 3.44$ & $17.33 / 15.33$ & $1 / 1$ & 17.55 & 15.37 & \\
\hline AGPRS052638.88-694242.9 & $07 / 051 / 453$ & $2.14 / 2.87$ & $18.08 / 15.59$ & $2 / 1$ & $\begin{array}{c}20.26 \\
(18.42)\end{array}$ & 15.58 & \\
\hline AGPRS052640.44-694708.5 & $07 / 106 / 238$ & $3.14 / 3.98$ & $17.15 / 15.27$ & $1 / 1$ & 17.39 & 15.28 & \\
\hline AGPRS052641.03-694716.5 & $07 / 110 / 232$ & $2.80 / 3.31$ & $17.14 / 15.10$ & $1 / 1$ & 17.58 & 15.23 & \\
\hline
\end{tabular}




\begin{tabular}{|c|c|c|c|c|c|c|c|}
\hline $\begin{array}{l}\text { Name } \\
(1)\end{array}$ & $\begin{array}{c}\operatorname{chip} / X / Y \\
(2)\end{array}$ & $\begin{array}{c}\left.\frac{\phi_{\mathrm{c}}}{\phi_{0}}\right|_{B} /\left.\frac{\phi_{\mathrm{c}}}{\phi_{0}}\right|_{R} \\
(3)\end{array}$ & $\begin{array}{c}B_{\text {EROS }} / R_{\text {EROS }} \\
(4)\end{array}$ & $\begin{array}{c}N_{\text {star }}^{B / R} \\
(5)\end{array}$ & $\begin{array}{c}B_{\mathrm{EROS}}^{\mathrm{DAO}} \\
(6)\end{array}$ & $\begin{array}{c}R_{\mathrm{EROS}}^{\mathrm{DAO}} \\
\quad(7)\end{array}$ & $\begin{array}{c}\text { Cross-identifications } \\
\text { (8) }\end{array}$ \\
\hline AGPRS052642.30-694060.0 & $07 / 047 / 540$ & $2.84 / 3.39$ & $16.52 / 14.84$ & $1 / 1$ & 16.86 & 14.99 & \\
\hline AGPRS052642.62-694550.0 & $07 / 101 / 304$ & $3.08 / 3.72$ & $16.68 / 14.72$ & $1 / 1$ & 16.49 & 14.73 & \\
\hline AGPRS052643.62-694515.5 & $07 / 099 / 333$ & $3.24 / 4.62$ & $17.39 / 14.54$ & $1 / 1$ & 17.54 & 14.60 & \\
\hline AGPRS052644.85-694625.6 & $07 / 117 / 277$ & $2.58 / 3.63$ & $17.30 / 15.40$ & $1 / 1$ & 17.84 & 15.55 & \\
\hline AGPRS052647.42-694457.8 & $07 / 112 / 351$ & $2.77 / 3.41$ & $16.71 / 14.94$ & $1 / 1$ & 16.96 & 15.14 & \\
\hline AGPRS052647.62-695005.6 & $07 / 169 / 100$ & $2.71 / 3.14$ & $17.18 / 15.68$ & $1 / 1$ & 17.34 & 15.56 & \\
\hline AGPRS052649.68-694711.5 & $07 / 146 / 244$ & $2.54 / 3.59$ & $17.33 / 15.36$ & $2 / 1$ & $\begin{array}{c}18.16 \\
(17.54)\end{array}$ & 15.37 & \\
\hline AGPRS052651.19-694328.8 & $07 / 112 / 427$ & $3.19 / 3.65$ & $16.25 / 14.62$ & $1 / 1$ & 16.50 & 14.69 & \\
\hline AGPRS052652.35-694402.0 & $07 / 123 / 401$ & $3.41 / 4.58$ & $16.73 / 14.28$ & $1 / 1$ & 16.81 & 14.26 & $\begin{array}{l}\text { LMC V2666 } \\
\text { WBP } 35\end{array}$ \\
\hline AGPRS052653.58-694651.4 & $07 / 159 / 264$ & $3.05 / 3.98$ & $17.11 / 15.11$ & $2 / 1$ & $\begin{array}{c}17.58 \\
(18.42)\end{array}$ & 15.17 & \\
\hline AGPRS052654.70-694931.9 & 07/193/134 & $2.09 / 2.92$ & $18.34 / 15.55$ & $2 / 1$ & $\begin{array}{c}19.87 \\
(19.32)\end{array}$ & 15.76 & \\
\hline AGPRS052659.79-694509.3 & $07 / 167 / 353$ & $3.24 / 4.09$ & $17.47 / 15.27$ & $1 / 1$ & 17.67 & 15.34 & \\
\hline AGPRS052700.05-694233.8 & $07 / 140 / 480$ & $3.20 / 4.09$ & $16.13 / 14.13$ & $1 / 1$ & 16.36 & 14.17 & \\
\hline AGPRS052702.99-694600.7 & $07 / 190 / 314$ & $3.12 / 3.92$ & $17.07 / 14.98$ & $1 / 1$ & 17.41 & 15.07 & \\
\hline AGPRS052704.90-695045.7 & $07 / 250 / 083$ & $3.03 / 2.94$ & $15.62 / 14.67$ & $1 / 1$ & 15.31 & 14.26 & $\begin{array}{l}\text { EROS } 2089 \\
\text { HV968 }\end{array}$ \\
\hline AGPRS052706.38-694910.7 & $07 / 239 / 162$ & $2.62 / 3.52$ & $18.27 / 15.81$ & $1 / 1$ & 18.33 & 15.59 & \\
\hline AGPRS052706.91-694108.4 & $07 / 154 / 556$ & $2.59 / 2.86$ & $16.94 / 15.09$ & $1 / 1$ & 17.19 & 15.17 & \\
\hline AGPRS052707.61-694719.4 & $07 / 224 / 254$ & $2.28 / 3.24$ & $17.89 / 15.77$ & $0 / 0$ & 16.81 & 14.22 & \\
\hline AGPRS052707.65-694740.2 & $07 / 228 / 237$ & $2.43 / 2.44$ & $16.54 / 14.92$ & $1 / 2$ & 16.94 & $\begin{array}{c}15.23 \\
(17.35)\end{array}$ & \\
\hline AGPRS052708.90-694335.3 & $07 / 189 / 438$ & $2.58 / 3.28$ & $17.96 / 15.83$ & $1 / 1$ & 18.22 & 15.85 & \\
\hline AGPRS0527 9.77-694157.0 & $07 / 175 / 519$ & $3.07 / 4.69$ & $17.65 / 14.95$ & $1 / 1$ & 17.75 & 14.87 & $\begin{array}{l}\text { LMC V2697 } \\
\text { WBP } 46\end{array}$ \\
\hline AGPRS052710.74-694358.2 & $07 / 201 / 421$ & $3.16 / 4.05$ & $16.85 / 14.80$ & $1 / 1$ & 17.11 & 14.84 & $\begin{array}{c}\text { LMC V2698 } \\
\text { SHV0527357-694620 }\end{array}$ \\
\hline AGPRS052711.75-694832.6 & $07 / 255 / 198$ & $3.26 / 4.16$ & $16.66 / 14.89$ & $1 / 1$ & 16.82 & 14.97 & \\
\hline AGPRS052715.89-694357.9 & $07 / 223 / 426$ & $2.89 / 3.35$ & $16.51 / 14.63$ & $1 / 1$ & 16.74 & 14.70 & \\
\hline AGPRS052715.91-694206.4 & $07 / 203 / 517$ & $3.71 / 4.56$ & $16.47 / 14.29$ & $1 / 1$ & 16.58 & 14.22 & \\
\hline AGPRS052716.84-694923.5 & $07 / 286 / 161$ & $2.60 / 3.00$ & $17.17 / 15.25$ & $1 / 2$ & 17.43 & $\begin{array}{c}15.33 \\
(15.33)\end{array}$ & \\
\hline AGPRS052717.59-695001.0 & $07 / 296 / 131$ & $3.06 / 3.89$ & $17.28 / 15.20$ & $2 / 1$ & $\begin{array}{c}17.16 \\
(20.03)\end{array}$ & 14.93 & \\
\hline AGPRS052718.53-694916.8 & $07 / 292 / 168$ & $2.86 / 3.86$ & $17.65 / 14.70$ & $1 / 1$ & 17.70 & 14.54 & \\
\hline AGPRS052720.11-694441.9 & $07 / 249 / 394$ & $2.78 / 3.25$ & $17.34 / 15.16$ & $1 / 1$ & 17.54 & 15.16 & $\begin{array}{l}\text { LMC V2716 } \\
\text { WBP } 53\end{array}$ \\
\hline AGPRS052720.72-694607.1 & $07 / 267 / 325$ & $2.53 / 3.13$ & $17.50 / 15.39$ & $1 / 1$ & 17.96 & 15.56 & \\
\hline AGPRS052721.73-694138.6 & $07 / 223 / 545$ & $3.25 / 4.06$ & $16.94 / 14.88$ & $0 / 1$ & 17.34 & 14.96 & \\
\hline AGPRS052728.50-695003.3 & $07 / 343 / 139$ & $2.45 / 2.69$ & $17.29 / 15.32$ & $1 / 1$ & 17.36 & 15.20 & \\
\hline AGPRS052729.39-694942.3 & $07 / 343 / 157$ & $2.74 / 2.83$ & $16.21 / 14.49$ & $1 / 1$ & 16.52 & 14.48 & $\begin{array}{c}\text { LMC V2733 } \\
\text { SHV0527552-695202 }\end{array}$ \\
\hline AGPRS052731.27-695200.1 & $07 / 376 / 046$ & $3.43 / 3.94$ & $16.91 / 15.06$ & $2 / 2$ & $\begin{array}{c}17.29 \\
(18.11)\end{array}$ & $\begin{array}{l}15.29 \\
(16.32)\end{array}$ & \\
\hline AGPRS052739.07-694204.3 & $07 / 302 / 540$ & $2.45 / 2.60$ & $16.52 / 14.97$ & $1 / 1$ & 16.68 & 15.01 & \\
\hline AGPRS052744.69-694338.7 & $07 / 343 / 468$ & $2.97 / 3.86$ & $17.67 / 15.04$ & $1 / 1$ & 17.77 & 15.02 & \\
\hline
\end{tabular}



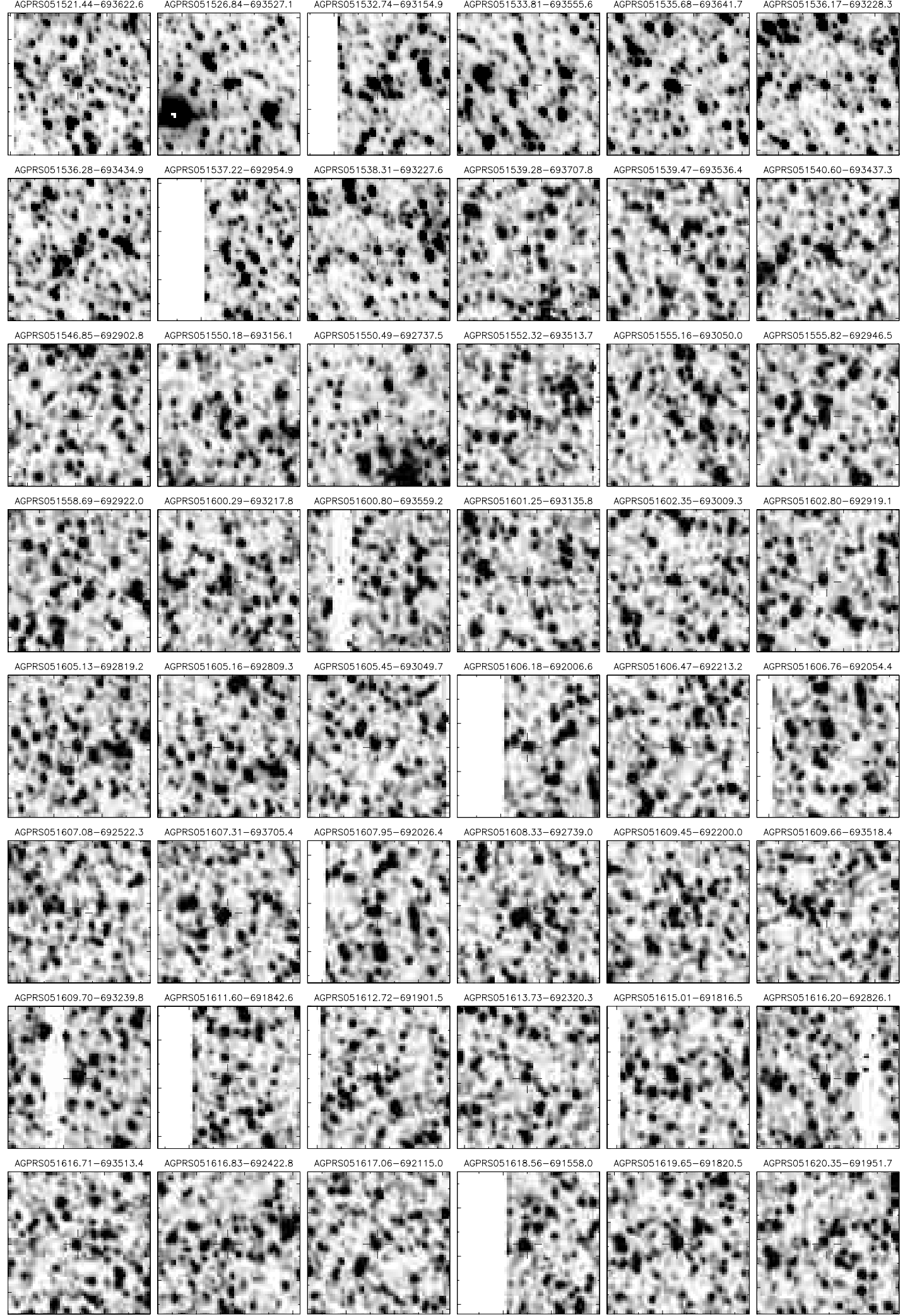

Fig. 8. $1.2^{\prime} \times 1.2^{\prime}$ finding charts for each variable in the $R_{\mathrm{EROS}}$ filter 
AGPRO51621.48-691726.1 AGCPSO51622.42-692019.3

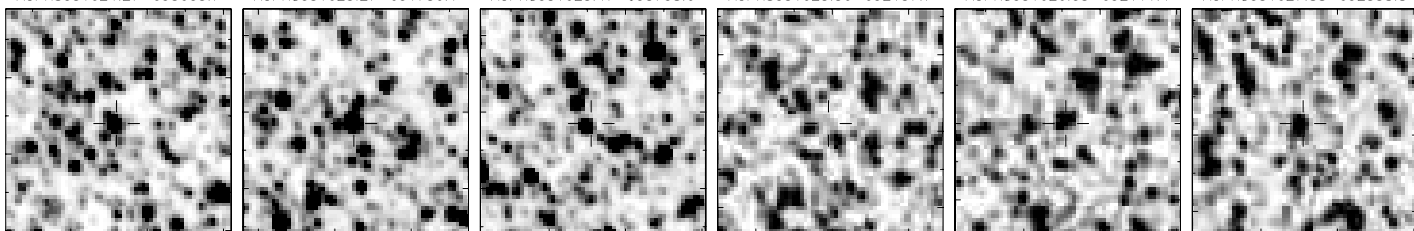

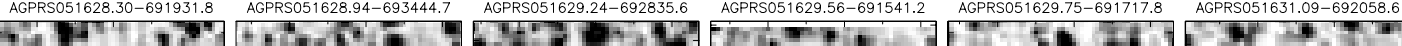

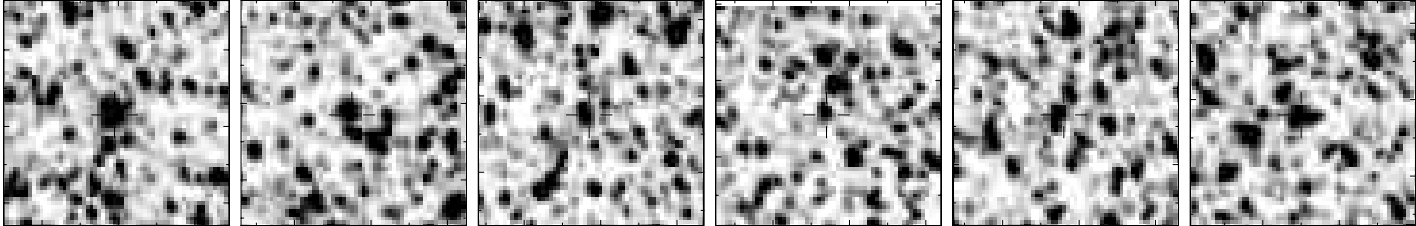

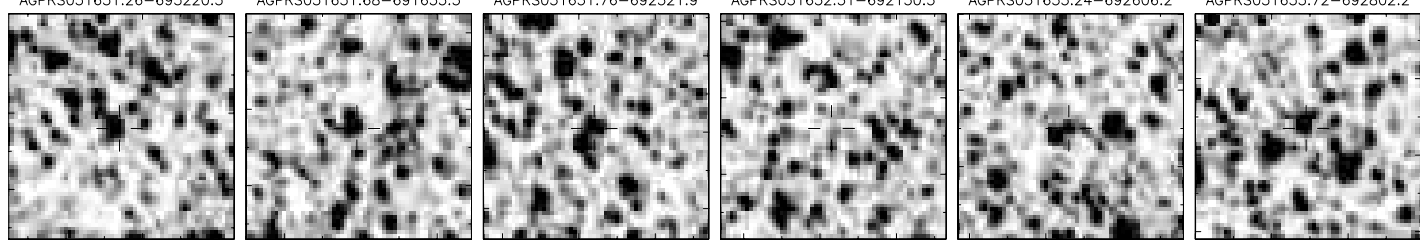
W.

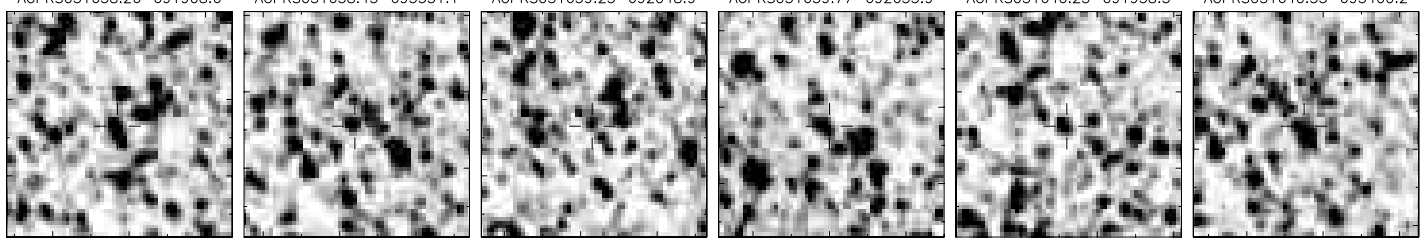

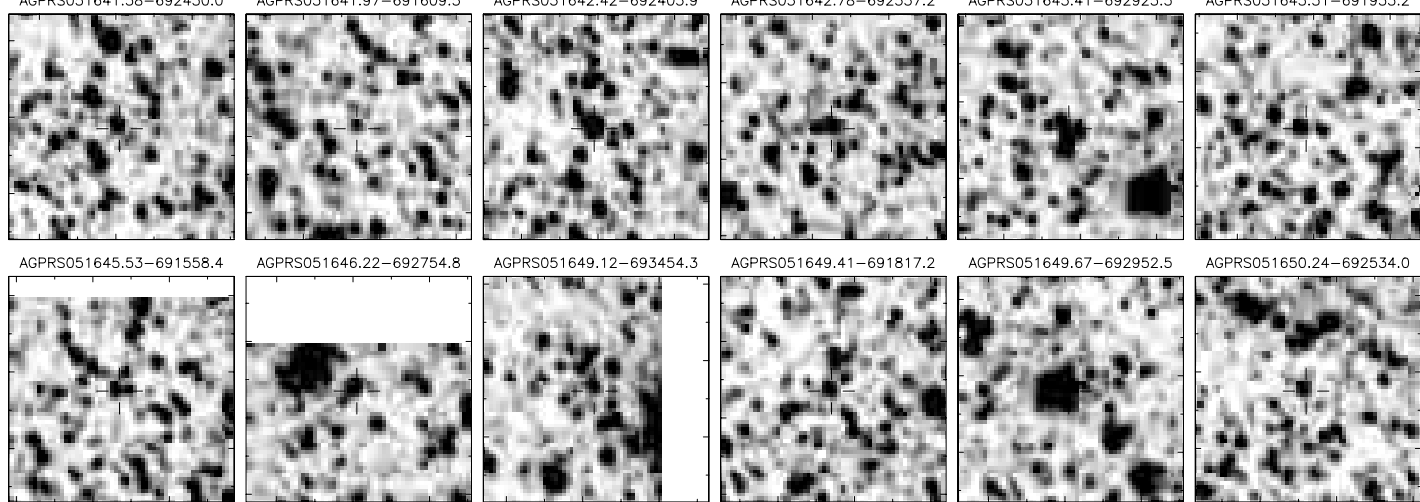

Fig. 8. continued 


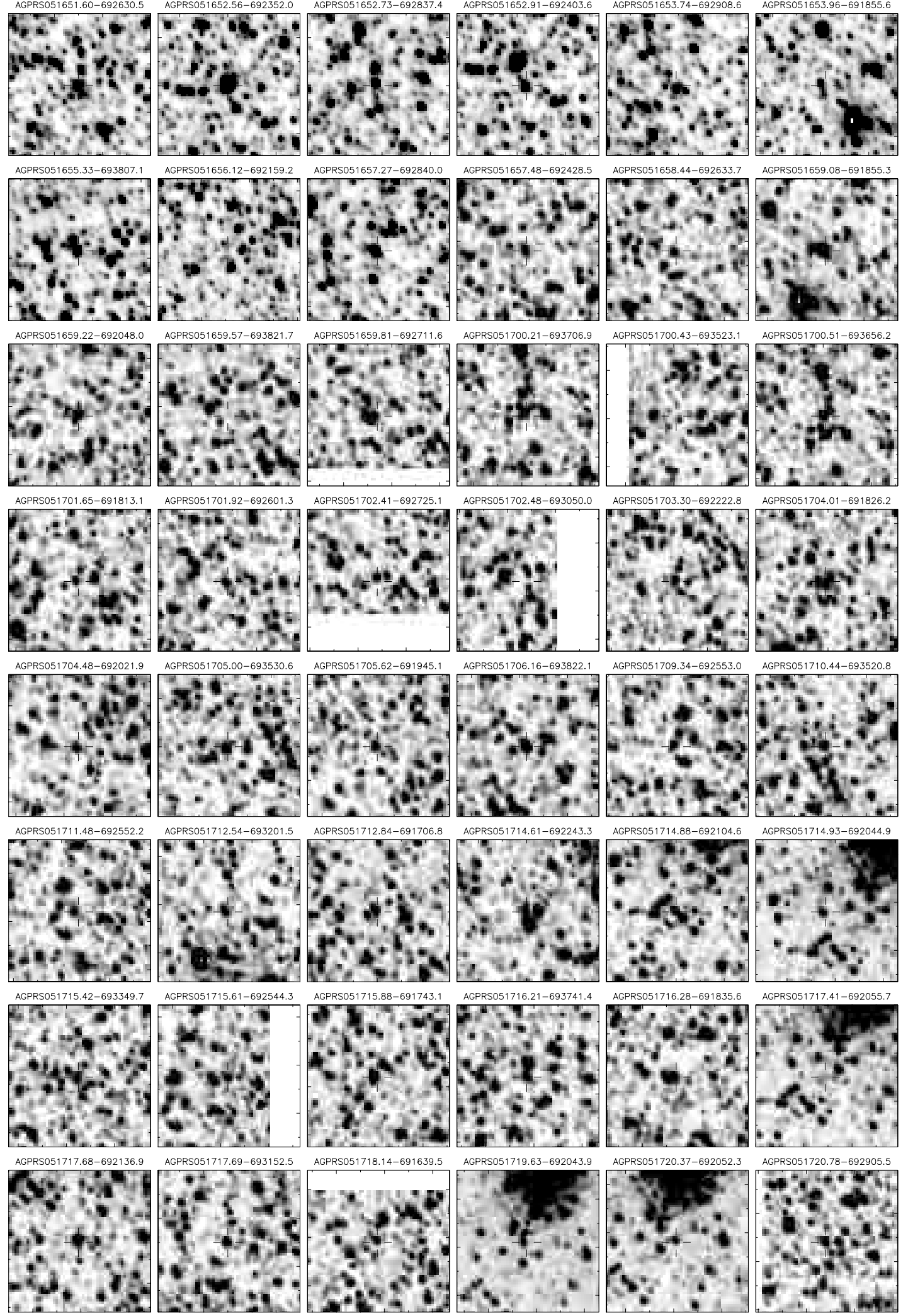

Fig. 8. continued 

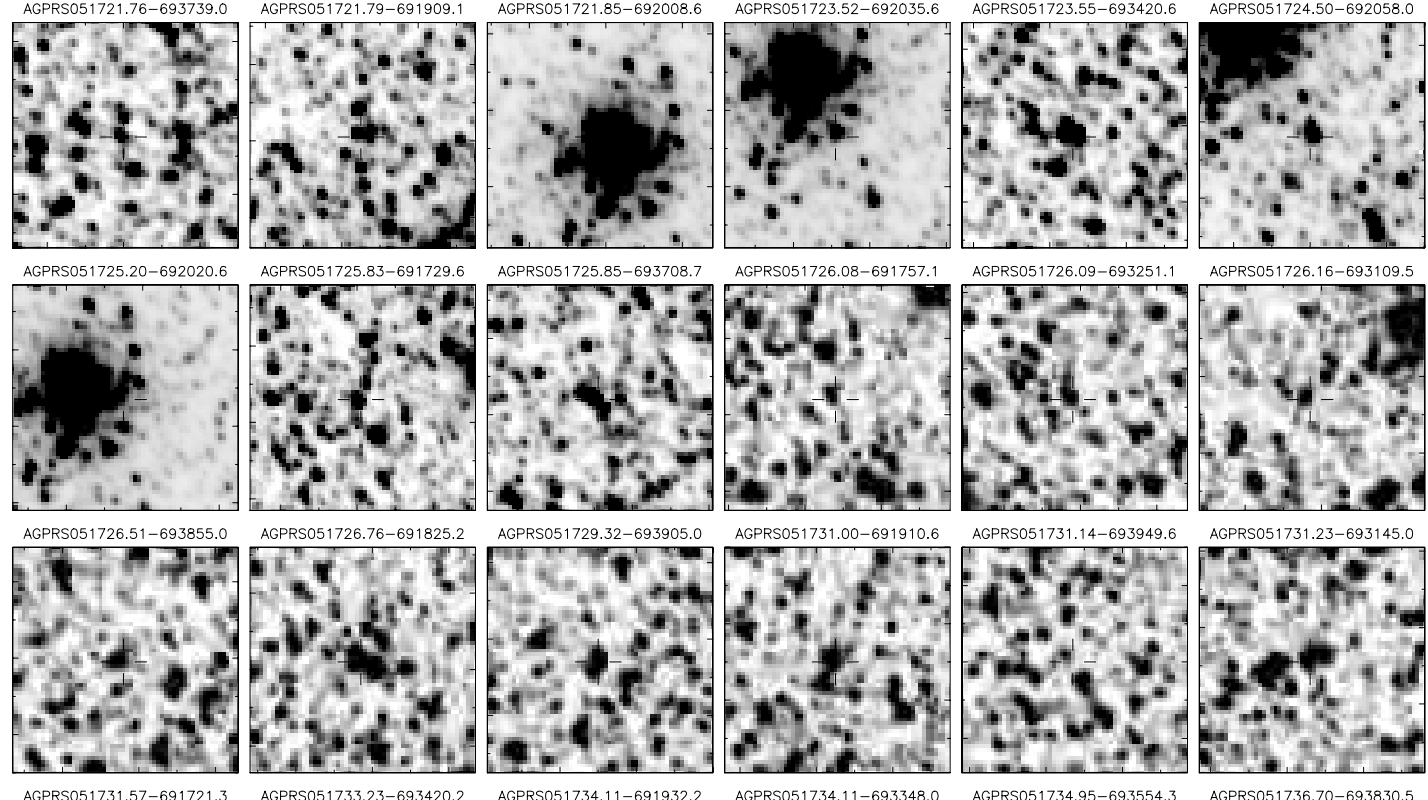

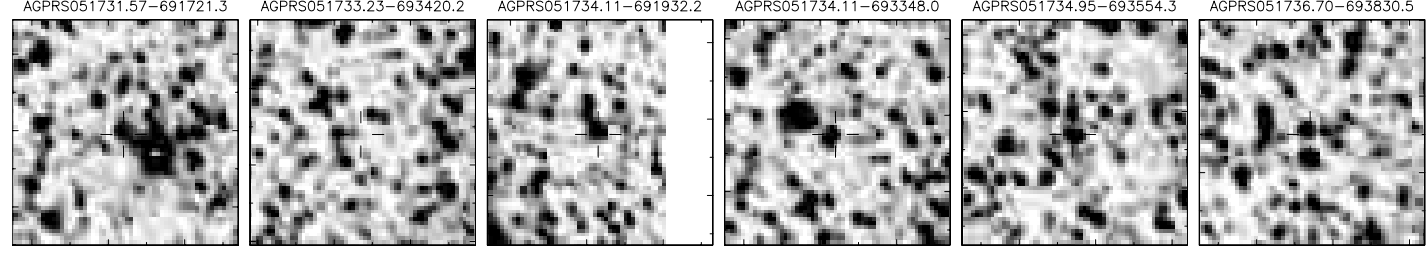

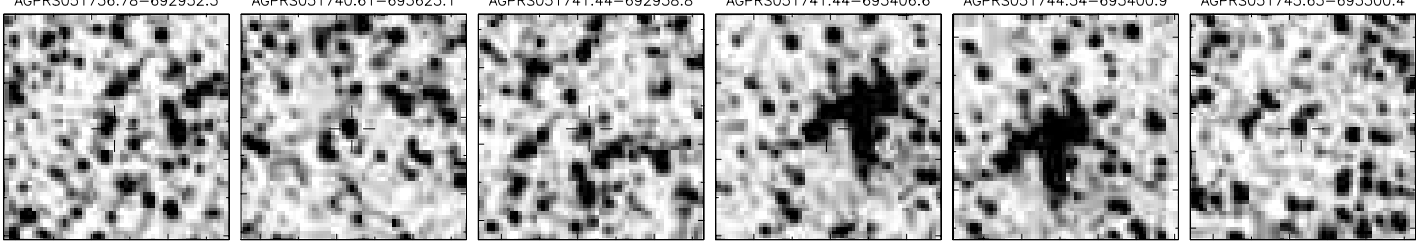
35 210 .

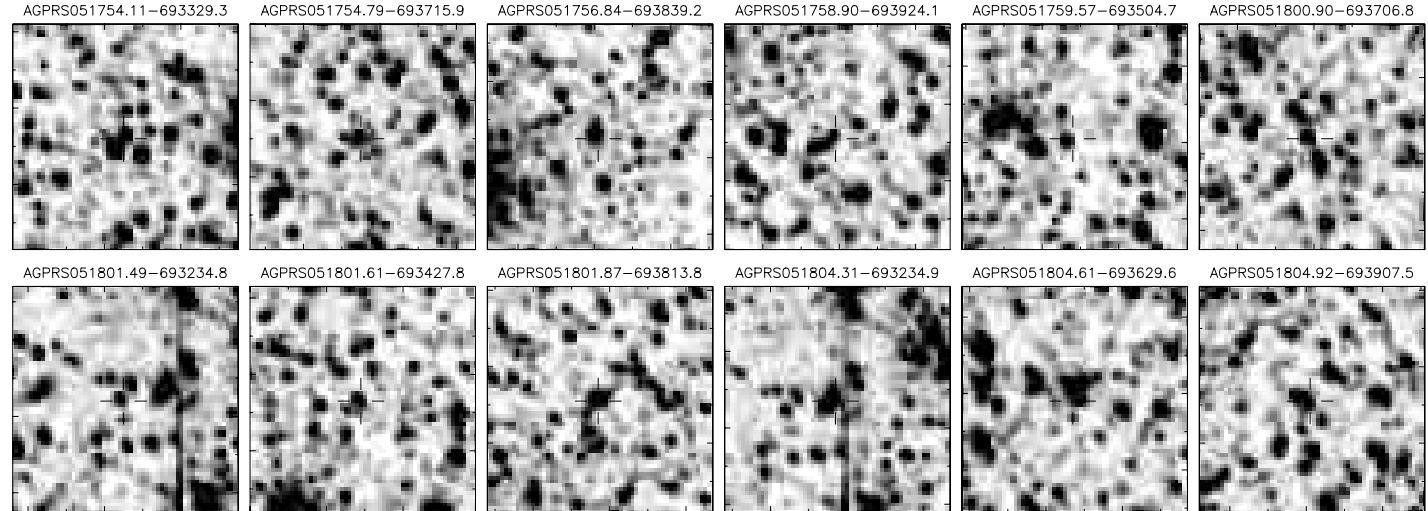

Fig. 8. continued 


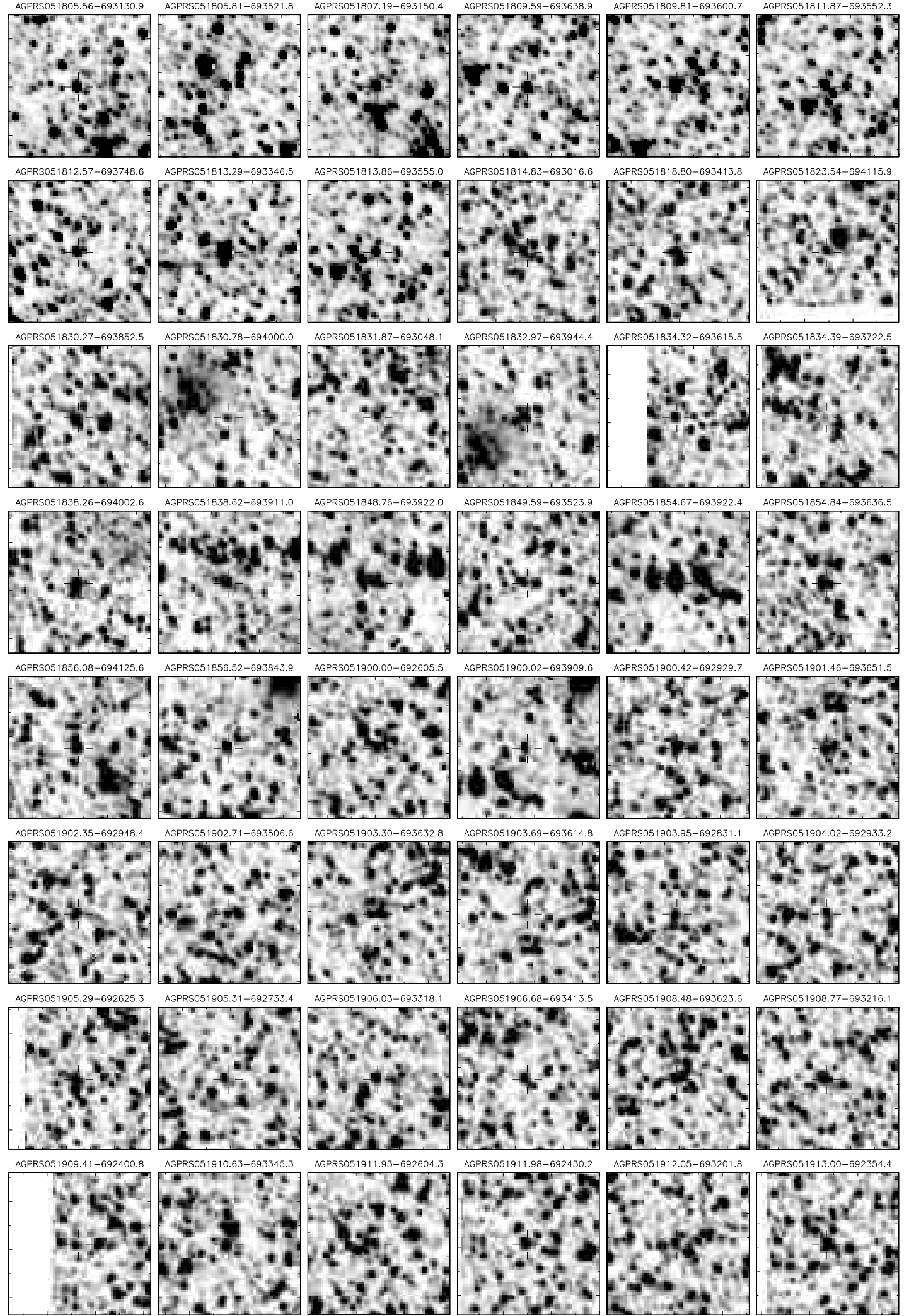

Fig. 8. continued 


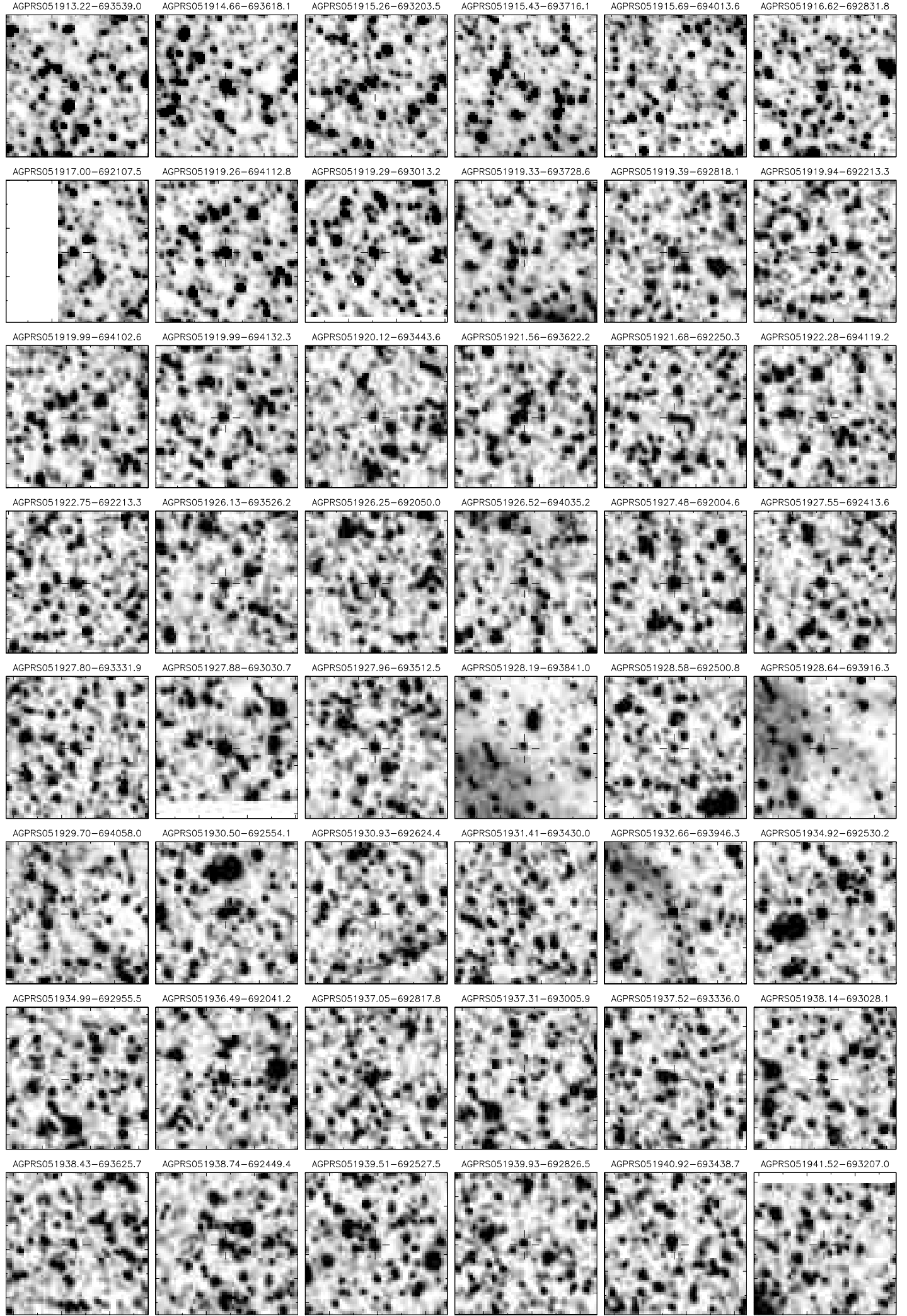

Fig. 8. continued 

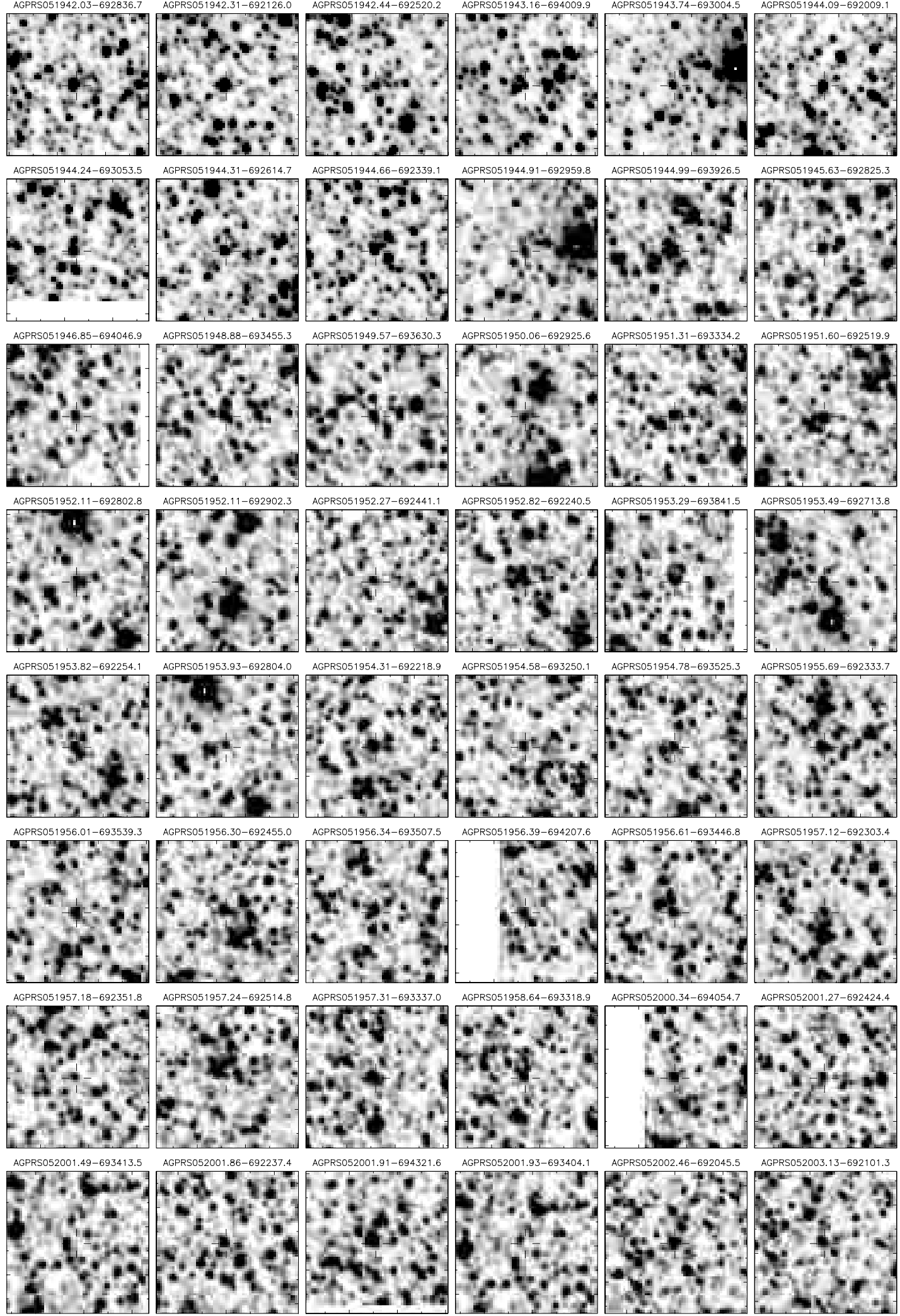

Fig. 8. continued 


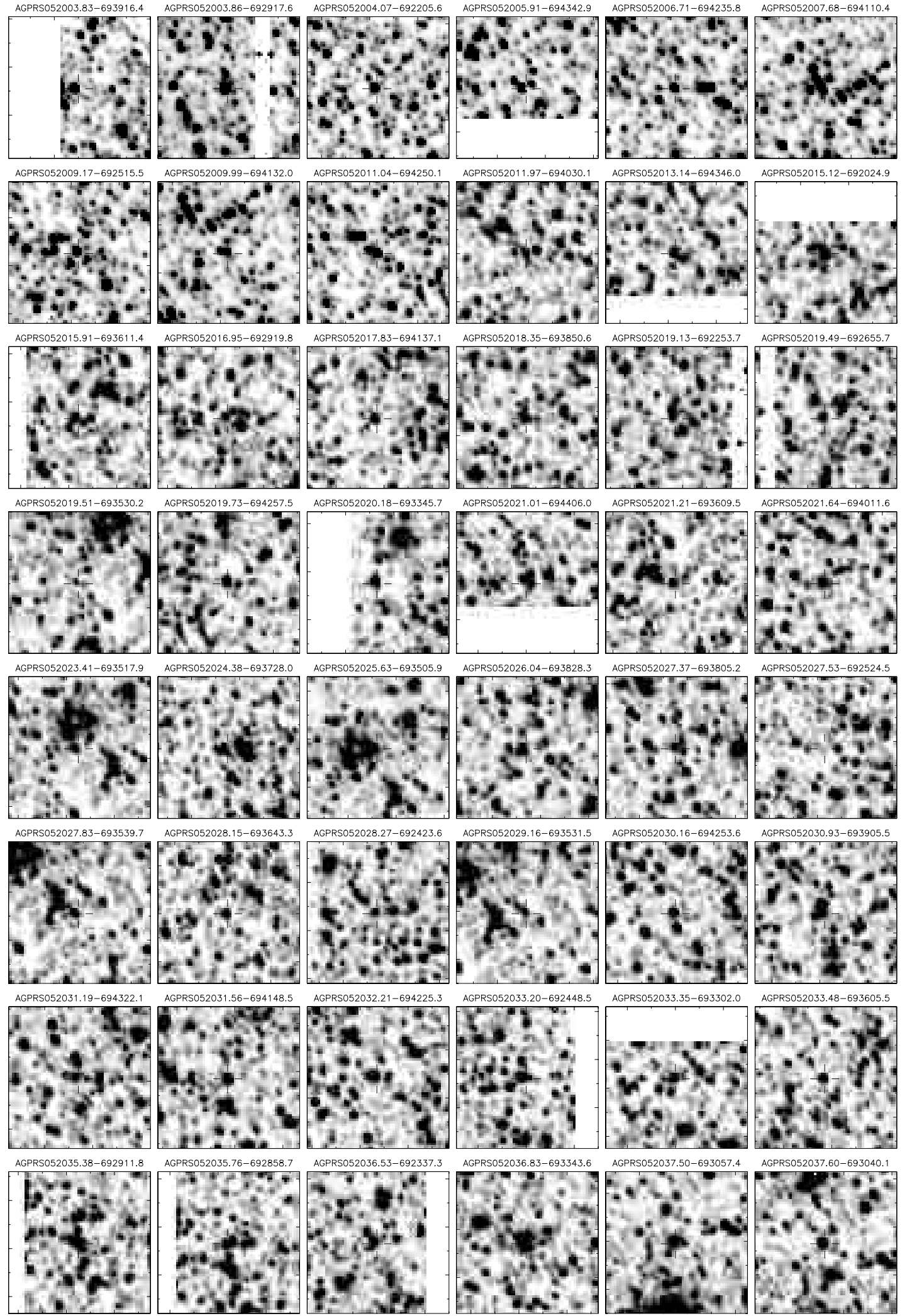

Fig. 8. continued 


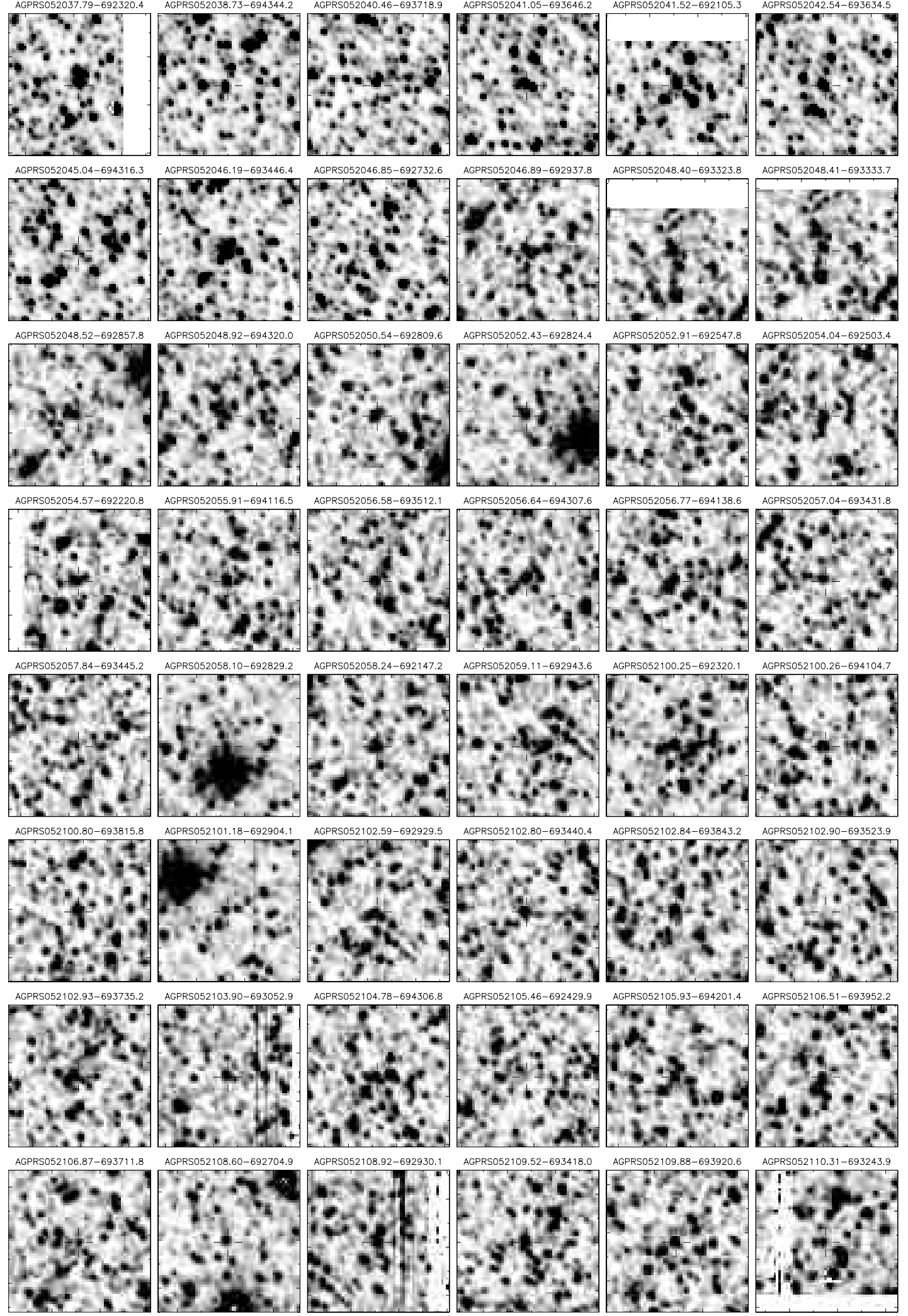

Fig. 8. continued 


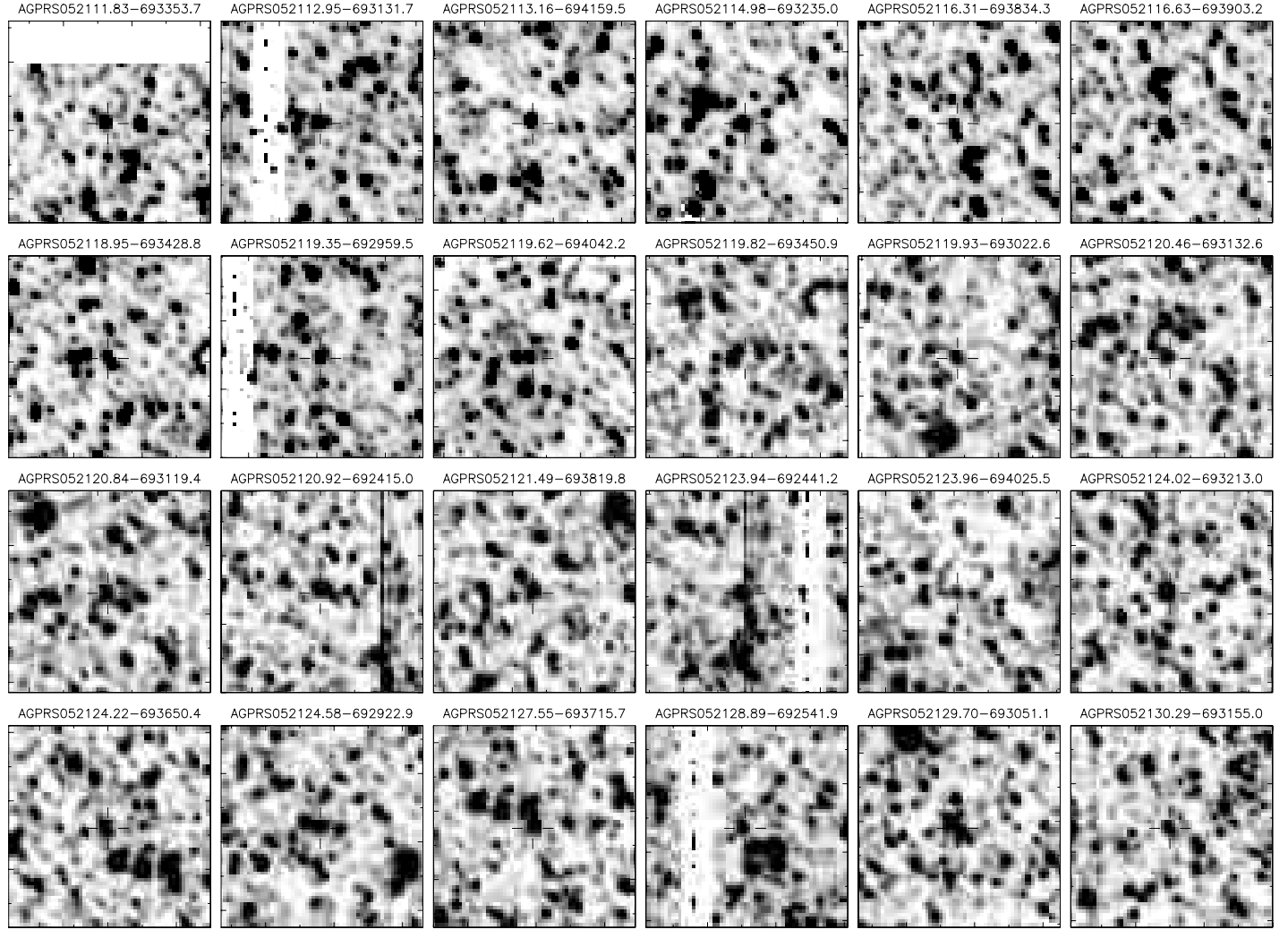

(3)
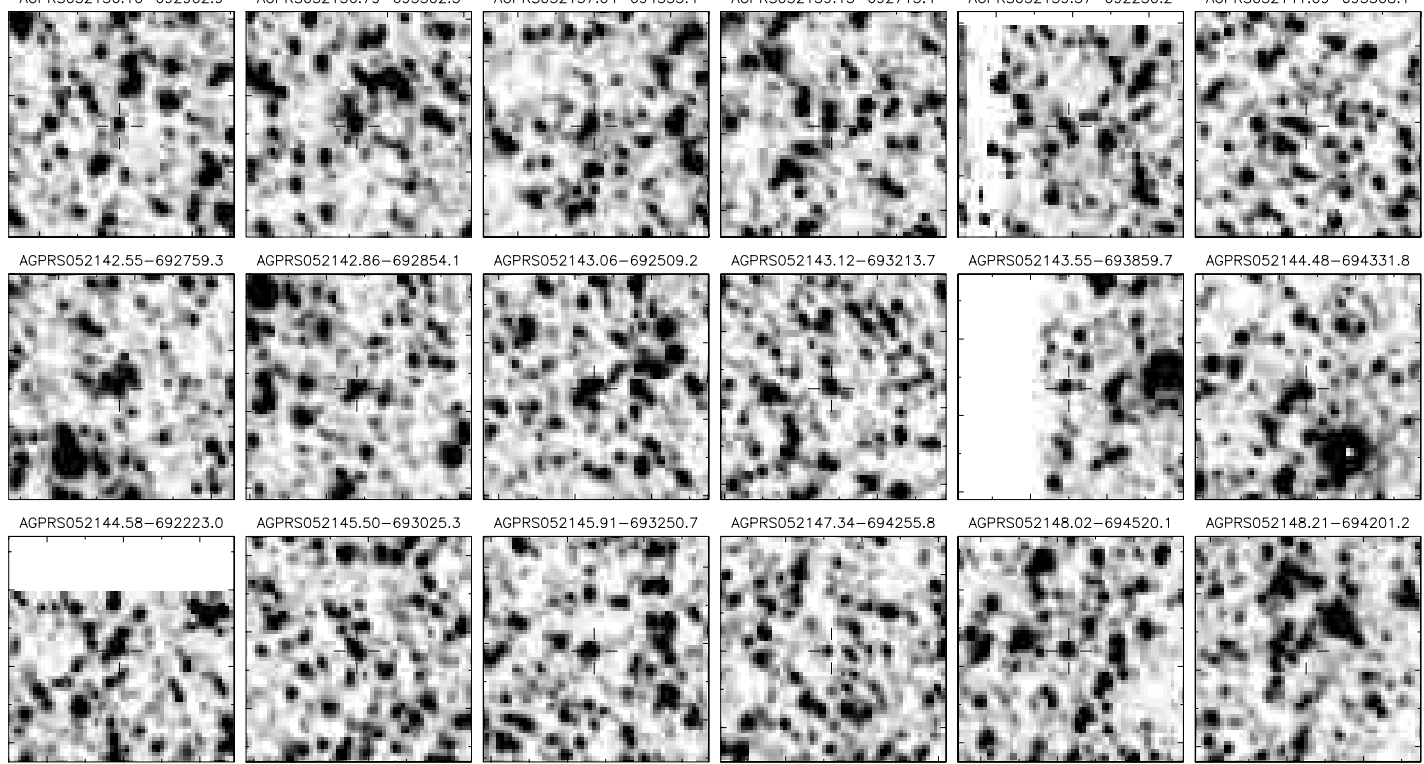

Fig. 8. continued 


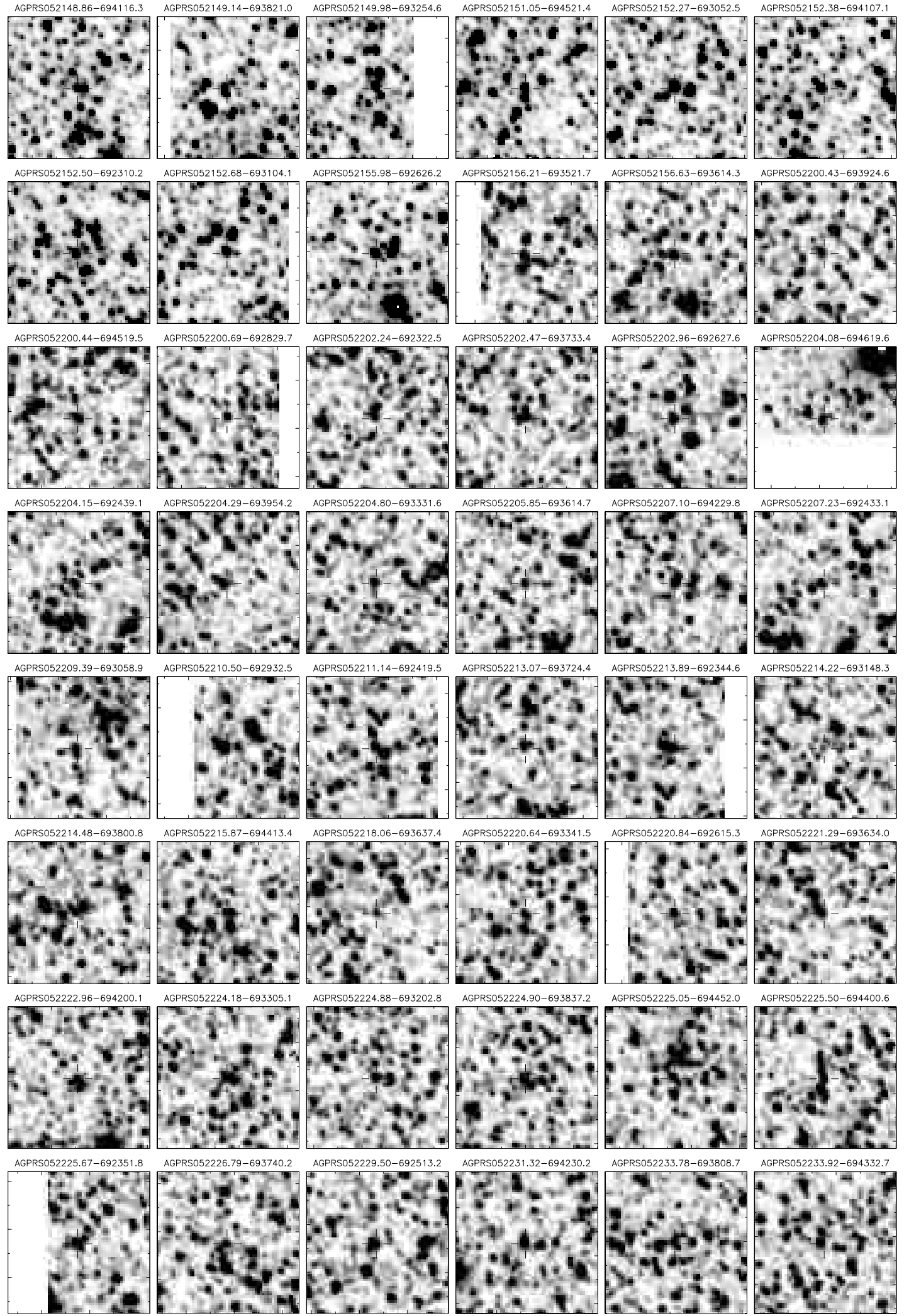

Fig. 8. continued 


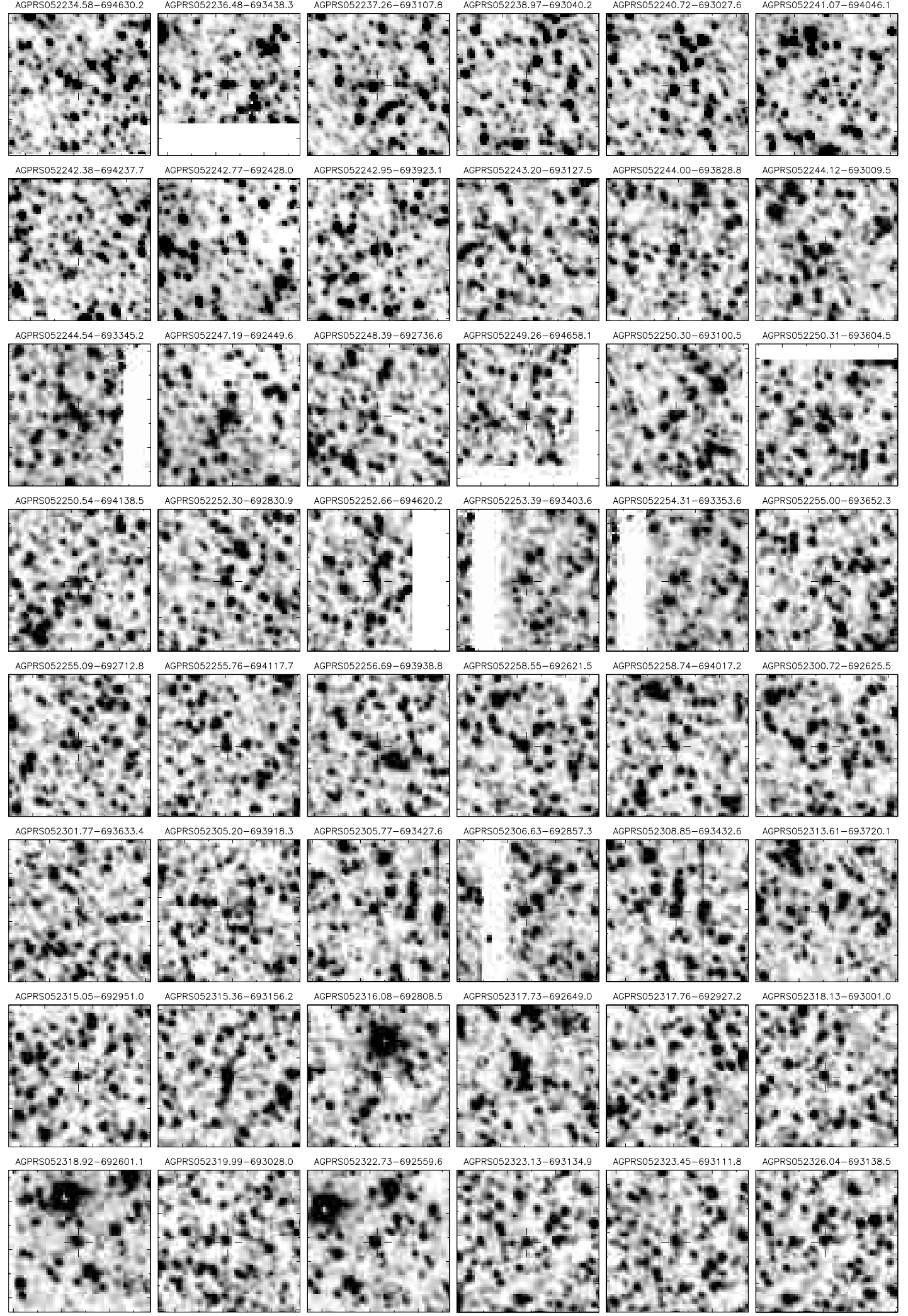

Fig. 8. continued 

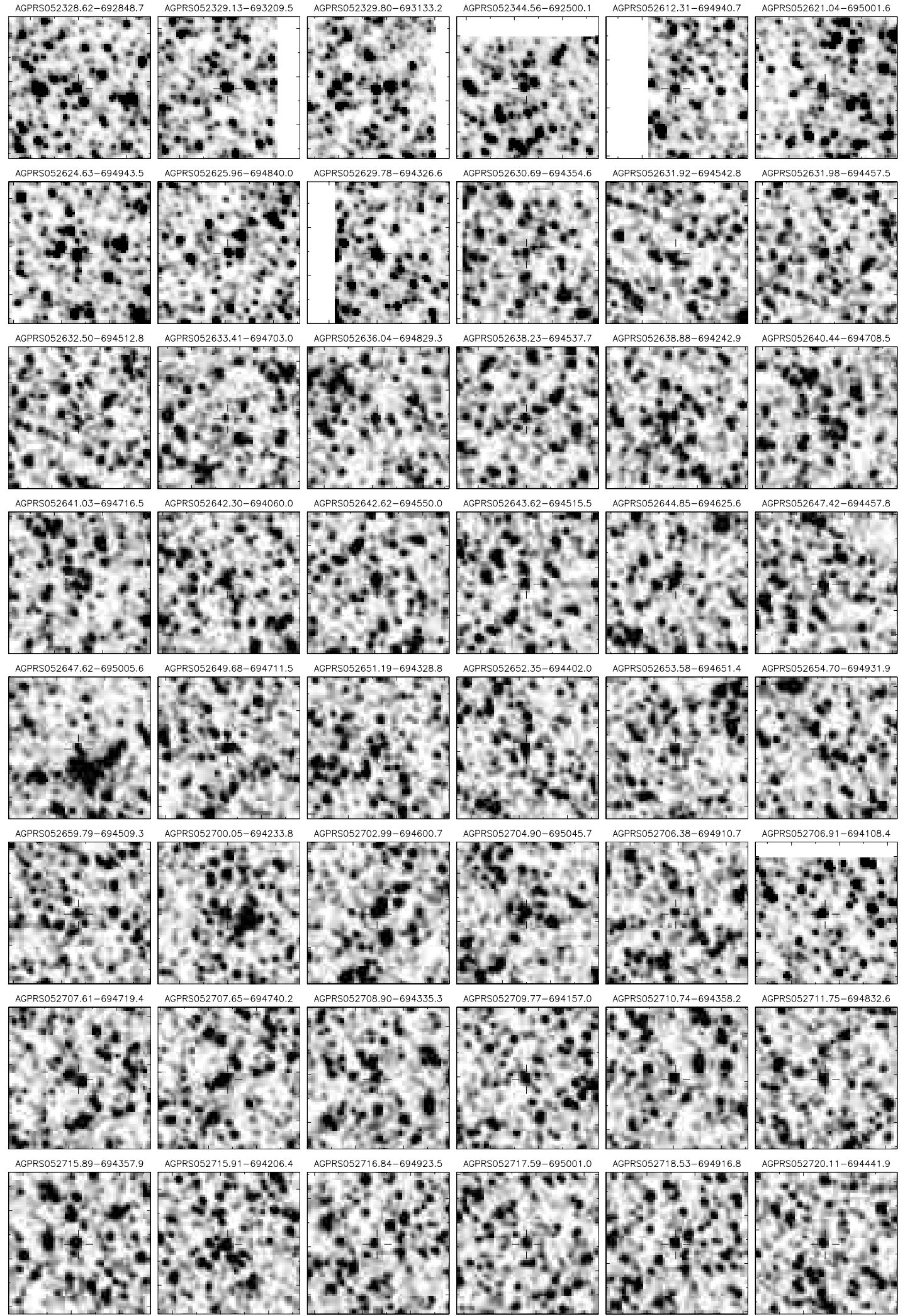

Fig. 8. continued 


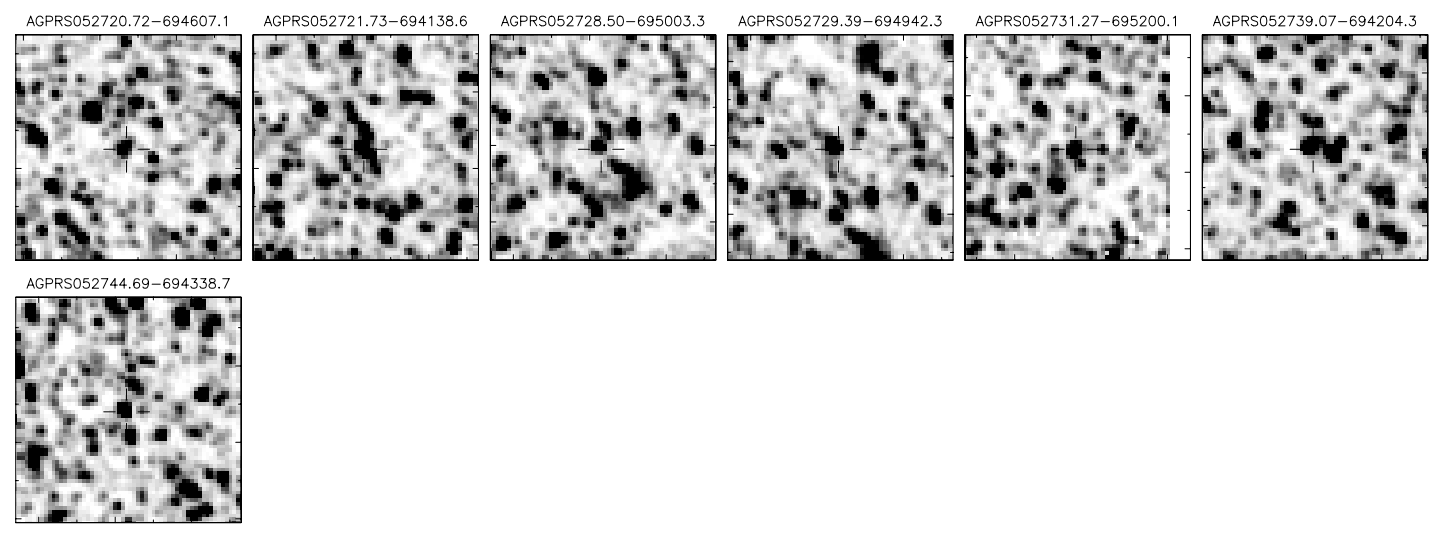

Fig. 8. continued 